\title{
aprendizaje servicio: diálogo universidad y sociedad
}

Publicación derivada de las II Jornadas Aps y responsabilidad social; Facultad de Ciencias Humanas y de la Educación de la Universidad de Zaragoza celebrado el 7 de noviembre de 2017 en el Casino de ${ }_{\text {Huesca }}$

\section{Coordinación}



Copyright $\odot$ los autores.

( $)$ Fotografía y diseño de portada: Alfonso Revilla Carrasco.

aprendizaje servicio: diálogo universidad y sociedad

Publicación derivada de las II Jornadas ApS y responsabilidad social; Facultad de Ciencias

Humanas y de la Educación de la Universidad de Zaragoza que tuvo lugar el 7denoviembre de 2017 en el Casino de Huesca.

Para citar la obra:

Lira, E. M., Revilla, A., y Lozano, A. (2018). Aprendizaje de servicio: diálogo universidad y sociedad.

España, Zaragoza: Prensas Universitarias de Zaragoza

Coordinadores: Eva Lira, Azucena Lozano y Alfonso Revilla Carrasco.

Edita: Prensas Universitarias de la Universidad de Zaragoza

Universidad de Zaragoza.

Ayuntamiento de Huesca

Huesca, 2018.

ISBN: 978-84-09-01440-8

Depósito Legal:

Reservados todos los derechos. Cualquier forma de reproducción, distribución, comunicación pública o trasformación de esta obra solo puede ser realizada con la autorización de sus titulares, salvo excepción prevista por la ley. Dirijase a CEDRO (Centro Español de Derechos Reprográficos, www.cedro.org) si necesita fotocopiar o escanear algún fragmento de esta obra. 

Las prácticas de ApS en las que se dan cita diferentes métodos de aprendizaje activo, como el aprendizaje experiencial, el cooperativo o el constructivismo, se ajustan a los fundamentos pedagógicos demandados en el Espacio Europeo de Educación Superior (EEES).

Los proyectos de aprendizaje-servicio permiten desarrollar los contenidos curriculares, es decir, aprendizajes académicos, facilitando la práctica de la planificación, el esfuerzo, la responsabilidad y el compromiso solidario. La metodología práctica de "Aprendizaje-Servicio", además de lograr mayor formación profesional y personal por parte de nuestros estudiantes, contribuye, a devolver a la sociedad la confianza que ha depositado en nosotros como organización promotora de conocimiento y de compromiso social. 



\section{Prologo Marta Liesa \\ Universidad ApS y responsabilidad social. Pilar Arranz. \\ Apoyo escolar a centros educativos con orientación intercultural. Ester Ayllón, Lidia Bañares y María Jesús Vicén.}

Estudiantes de magisterio trabajando en la ciudad de las niñas y los niños. Ester Ayllón, Lidia Bañares, M. Ángeles Eito, Azucena Lozano, Silvia Martínez, M. Pilar Moreno, M. Jesús Vicén y Nieves Moyano.

Atención a la Diversidad: desarrollo de competencias del profesorado inclusivo desde la metodología de ApS. Sandra Vázquez, Cecilia Latorre y Marta Liesa.

Recreos cooperativos e inclusivos: Una oportunidad de aprender contribuyendo. Alberto Aibar, Azucena Lozano, Marta Liesa, Eduardo Ibor, Nieves Moyano y Sandra Vázquez.

Capítulo 6. Down Universidad. Elías Vived, Jorge Arbués y Ana GarcíaCarpintero.

Experiencia de aprendizaje de servicio fuera del aula: apoyo y refuerzo escolar en la comunidad con alumnos de primaria. Rafa Díaz, María Sierra y Sergio Gallego.

Propuesta futura de ApS: Cyberbullying e inteligencia emocional. Eva M. Lira, Mara Socolovski y Ana Moreno.

Propuesta futura de ApS: El rol de la inteligencia emocional (IE) y la autoeficacia (AF) en la relación entre el ciberbullying "victimización" y el estrés, la ansiedad y la depresión: Loreto Tomey, Eva M. Lira, Mara Socolovski y Ana Moreno.

Propuesta futura de ApS: La relación entre el ciberbullying y las quejas somáticas en función del sexo. Cristina Artal, Eva M. Lira, Ana Moreno y Mara Socolovski.

Propuesta futura de ApS: Música, inteligencia emocional y angustia psicológica (depresión y ansiedad). Eva M. Lira y Sara Escuer.

Propuesta futura de ApS: El videoartivismo como contexto para el desarrollo de actividades del ApS. Miguel Ángel Alvira Juan.

Capítulo 13. Fotografía y conocimiento; aprender a ver, aprender a comprometerse. Alfonso Revilla Carrasco y Fernando J. Sadio-Ramos.

Capítulo 14. Exposición MIRADAS. Alfonso Revilla Carrasco.

Caprtulo 15. Música y diversidad: la música coral al servicio de la sociedad. Sara Escuer. 



\section{Prólogo}

Como Decana de la Facultad de Ciencias Humanas y de la Educación es un motivo de satisfacción publicar este libro que recoge todas las experiencias de AprendizajeServicio que llevamos a cabo en nuestro centro.

Partimos de la premisa de que en una Facultad de Educación uno de nuestros objetivos prioritarios es formar a buenos ciudadanos, hombres y mujeres que sean capaces de mejorar la sociedad y no sólo su currículum personal.

Además los universitarios y en nuestro caso los futuros maestros son elementos muy importantes en la provocación de cambios en su entorno, y en la contribución a un mundo mejor. A través de nuestros proyectos de Aprendizaje-Servicio los futuros egresados en el Grado de Magisterio tienen la oportunidad de contribuir a la mejora de las relaciones sociales que se dan en los recreos de los Centros de Educación Infantil y Primaria, de proporcionar apoyo escolar a los niños sin recursos, de construir una ciudad más accesible desde los ojos de un niño, de aliviar la soledad de las personas mayores, de compartir espacios y actividades con personas con discapacidad, entre otras muchas propuestas de aprendizaje en servicio.

No podemos olvidar que nuestra institución tiene como una de sus finalidades principales el proporcionar conocimientos, y para ello hemos elegido la metodología de Aprendizaje-Servicio, ya que hacer un servicio a la comunidad y ayudar a los otros, es uno de los métodos de aprendizaje más eficaces, porque los alumnos y alumnas encuentran sentido a lo que estudian cuando aplican sus conocimientos y habilidades en una práctica solidaria. 
El Aprendizaje-Servicio constituye hoy en día una de las principales vías metodológicas para fomentar el aprendizaje global y significativo en los alumnos, desarrollando todas las competencias transversales, en definitiva, una metodología por y para la formación integral de los alumnos. La Facultad de Ciencias Humanas y de la Educación es pionera en llevar a cabo experiencias de este tipo.

La metodología práctica de Aprendizaje-Servicio, además de lograr mayor formación profesional y personal por parte de nuestros estudiantes contribuye, aunque sea modestamente, a devolver a la sociedad la confianza que ha depositado en nosotros como organización promotora de conocimiento y de compromiso social. El Aprendizaje-Servicio representa un aprendizaje significativo y bidireccional entre quien realiza el servicio y quien se beneficia de su ayuda.

Partiendo de esta realidad, nuestro compromiso con este texto se centra en el desarrollo y divulgación de prácticas de Aprendizaje-Servicio en y desde nuestra institución, que puedan extrapolarse y/o replicarse en otros centros. Por ello cada capítulo recoge uno de estos proyectos: el proyecto de apoyo escolar a centros educativos con orientación intercultural, la ciudad de las niñas y los niños, el proyecto de atención a la diversidad, el proyecto de recreos cooperativos, el proyecto campus oportunidades para la inclusión con la asociación Down, el proyecto de apoyo y refuerzo escolar en la comunidad con alumnos de primaria, entre otros que van a ser explicados en este texto.

Para realizar las actividades de Aprendizaje-Servicio hemos contado con el inestimable apoyo y la coordinación directa de la profesora Pilar Arranz, quien también escribe uno de los capítulos del libro.

Marta Liesa Orús 


\title{
1 \\ Universidad, $A p S y$ responsabilidad social.
}

\author{
Pilar Arranz \\ Universidad de Zaragoza \\ parranz@unizar.es
}

De acuerdo con el ya numeroso elenco de estudios, nacionales e internacionales, dedicados al valor e impacto de la metodología aprendizaje-servicio (en adelante ApS) en la formación de los estudiantes universitarios, considero no existe ninguna duda acerca de la idoneidad de su empleo en la educación superior. No obstante, deseo subrayar que la referencia a "impacto en la formación de los estudiantes" incluye, además de la consecución de los consabidos aprendizajes académicos y las competencias genéricas comunes a todas las titulaciones, los relacionados con la formación en valores, en responsabilidad personal, social y ciudadana, en sentido de la justicia, etc. Tales aprendizajes no son en absoluto una desiderata de un grupo de profesores e investigadores con inquietudes ajenas a lo que en general pueda entenderse como obligación de la enseñanza universitaria, sino que están explicitados en normativas y documentos oficiales, tales como el Estatuto del Estudiante Universitario (MEC, 2010), los Estatutos generales de las diferentes universidades españolas o la propuesta de la Comisión de Sostenibilidad de la CRUE (2015).

Es por ello que analizando las competencias que puede dinamizar la metodología ApS y asumiendo también la propia responsabilidad universitaria de vincular su labor al entorno social, especialmente al de la comunidad próxima, estimo como innegable la valiosa aportación que su puesta en práctica proporciona a la universidad como institución y a sus principales agentes, a los estudiantes y también al profesorado que la implementa, puesto que, además de optimizar la propia labor docente, puede dar lugar al desarrollo de investigaciones de notable interés. 
Sin embargo y a pesar de los argumentos expuestos, el ApS no acaba de formar parte de las metodologías más empleadas en el contexto universitario, ni tampoco se institucionaliza al ritmo deseable en el mismo. Desde mi punto de vista, entre los motivos de lo que podría denominarse escasa consolidación del ApS en el entorno universitario, algunos de ellos ya se mencionaban en el análisis DAFO (Debilidades-Amenazas- Fortalezas-Oportunidades) realizado en 2013 tras la puesta en práctica de proyectos de ApS en la Universidad de Zaragoza durante varios cursos consecutivos (el DAFO completo puedes consultarse en Arranz, Vázquez y Abán, 2013: 302-303).

Así, entre las debilidades que se percibían internamente desde el grupo de profesorado que formábamos parte activa del proyecto de innovación ApS en la Universidad de Zaragoza destacaba (y así sigue siendo) la escasa disposición de tiempos comunes para la planificación de experiencias y para la coordinación con otros profesores. A ello cabe añadir que el mayor inconveniente sigue encontrándose actualmente en hallar tiempos comunes con los representantes de los centros o entidades sociales "partenaires", lo cual es muy necesario para una óptima planificación y coordinación. Aunque puedan resultar ya manidas expresiones como "sociedad convulsa" o "coyuntura compleja", lo cierto es que la cotidianeidad de la labor docente e investigadora del profesorado universitario se torna cada vez más complicada, dispersa e incluso apresurada. Ello es especialmente manifiesto en el profesorado no permanente que desea promocionar y/o estabilizarse.

Relacionada con la promoción docente y como otra debilidad reseñada en el citado DAFO de 2013 y que puede afirmarse persiste, es la referida al escaso interés (constatado) de una parte del profesorado universitario por implantar la metodología ApS en sus asignaturas, a pesar de presentarles exitosos proyectos desarrollados en otras instituciones de educación superior (españolas en muchos casos) relacionados con su área de conocimiento. ¿A qué se debe tal desinterés? A mi juicio y basándome en la experiencia de casi una decena de años de trabajo y estudio sobre ApS, considero que existen dos razones principales que, a su vez, se retroalimentan afectando negativamente a la decisión de implementar un proyecto de ApS en una o varias asignaturas: el Espacio Europeo de Educación Superior aboga por la excelencia y las universidades competitivas frente a las de otros continentes, principalmente Asia y América del Norte. La excelencia, como se comprueba, se mide principalmente por publicaciones de impacto y patentes tecnológicas. Priman los artículos de investigación no teniendo reconocimiento alguno la calidad de la docencia. El ApS conlleva un proceso de investigación-acción, dando prioridad a la planificación, a la acción y a la reflexión continua, lo cual supone una inversión notable de tiempo, al menos en los primeros cursos en que se implanta un proyecto de ApS. Y de ello no es sencillo que se derive 
un artículo de impacto, menos todavía si no se incluye metodología cuantitativa en el tratamiento de la información. Por consiguiente, una buena parte del profesorado debe elegir entre dedicación docente o investigación y artículo que pueda ser publicable a corto-medio plazo. En este sentido, además de ser muy legítimo que el profesorado desee promocionar y/o estabilizarse en la institución, ésta, a su vez, nos presiona para adquirir méritos de investigación y así favorecer el ascenso los rankings internacionales, lo cual también es muy legítimo, habiendo aceptado los estándares de calidad con los que nos evalúan.

Obviamente y en esta coyuntura, el apoyo institucional se otorga principalmente a la investigación, a las publicaciones de impacto y a las patentes. El reconocimiento de la buena docencia no tiene repercusión en la carrera docente, $y$, lo que es peor, parece que en la misión de las universidades la responsabilidad social que les corresponde se ciñe a cumplir con la sostenibilidad ambiental, dejando de lado el compromiso social y la necesaria formación en valores de sus estudiantes y también del resto de agentes. En este sentido y dada la estrecha relación entre el Aps y la denominada Responsabilidad Social Universitaria (RSU), me parece de interés mencionar que entre los resultados de Larran y Andrades (2013), fruto una investigación sobre los frenos y los aceleradores para la implantación de la Responsabilidad Social en las universidades españolas, los Consejos Sociales de las universidades participantes destacaban como freno a la misma la falta de formación en valores sociales y/o éticos del profesorado, así como el escaso nivel de conciencia, interés y compromiso de los grupos de interés hacia la RSU, con insuficiente, también, apoyo institucional en cada universidad. Teniendo en cuenta que en el estudio participaron 55 universidades públicas y 10 privadas, los resultados del estudio resultan poco alentadores y, ciertamente, si el profesorado no está suficientemente formado en valores sociales, no podremos pretender que adquiera el compromiso de contribuir a dicha formación entre sus estudiantes.

Sin embargo y a pesar de que, por lo expuesto hasta el momento, podría calificarse como poco amable mi visión del presente y futuro del ApS en las instituciones universitarias y en la nuestra en particular, existen también motivos para el optimismo. Tras varios años de trayectoria formal como miembro del grupo impulsor de ApS en nuestra universidad, se constata que, afortunadamente, determinados proyectos de asignaturas en diversas titulaciones se han consolidado y forman ya parte de la impronta de dichas asignaturas a lo largo de los últimos cursos. Ello es especialmente manifiesto en las titulaciones de los grados de Maestro que se imparten en el campus de Huesca, tal y como se evidencia en los capítulos de esta publicación. A ello ha contribuido, sin ninguna duda, la implicación del equipo directivo de la Facultad de 
Ciencias Humanas y de la Educación, impulsando e implicándose como centro en proyectos que han tenido una trascendencia más allá del entorno próximo y en los cuales la participación de la Administración educativa y de entidades sociales de prestigio ha contribuido también al éxito de los proyectos y a su continuidad. No obstante, hay que subrayar que el trabajo de algunos profesores y profesoras de esta facultad ha sido clave para que pueda afirmarse que el ApS es inherente a la filosofía pedagógica de este centro y muestra de una verdadera pedagogía experiencial, como apuntan Santos, Sotelino y Lorenzo (2015) cuando se refieren a esta metodología.

Siendo evidente (y lógica) la prevalencia en todas las universidades españolas del empleo del ApS en titulaciones relacionadas con la educación, hay ejemplos, también en nuestra institución, de cómo va adentrándose en las preferencias metodológicas de docentes de muy diversas titulaciones. No en vano el componente de aprendizaje experiencial, en entorno real y dando respuesta a necesidades, hace muy atractivo el empleo del ApS. Así, y tras una formación y asesoramiento a compañeros de diferentes áreas de conocimiento, se implementaron proyectos en las titulaciones de Periodismo, Ciencias de la Actividad Física y el Deporte, Terapia Ocupacional, Administración y Dirección de Empresas, Económicas, Óptica, Odontología e Ingenierías. Algunos de ellos continúan desarrollándose y parecen consolidados; otros dejaron de llevarse a la práctica por diferentes razones mencionadas ya en la primera parte de este capítulo.

En este sentido, estimo resulta de interés aludir al estudio realizado en el curso 2016/17 (Arranz, Dieste y Escolano, 2017) que analizó las características y ámbitos de conocimiento de los proyectos de ApS que, al menos de forma oficial (como PIIDUZ), se estaban desarrollando durante dicho curso en la Universidad de Zaragoza. De un total de 206 proyectos de innovación, únicamente un 8,25\% estaban relacionados con el empleo de la metodología ApS en una o varias asignaturas, observándose incluso, respecto a los realizados en el curso 2015/16, una pequeña disminución del porcentaje.

Agrupando en macroáreas los proyectos, se observó que un 5,88\% correspondía a Arte y Humanidades, un $11,75 \%$ a Ciencias, el mismo porcentaje que presentaban Ciencias de la Salud e Ingeniería y Arquitectura, mientras que más del 50\% de los proyectos (un 58,82\% exactamente) se incardinaban en Ciencias Sociales y Jurídicas. Dada la amplitud de titulaciones de esta macroárea, se analizó específicamente cada uno de los proyectos que correspondía a la misma, extrayéndose los de las diferentes titulaciones. Complementariamente y con objeto de profundizar más en el conocimiento de estos proyectos, indagamos en la adscripción del profesorado que coordinaba cada uno de ellos. Los datos evidenciaron una polarización todavía mayor hacia 
titulaciones relacionadas con el ámbito educativo que la reflejada por macroáreas, ya que el 52,94\% de los proyectos de ApS se desarrollaban en asignaturas de titulaciones relacionadas directamente con Educación (Grados de Maestro y Máster en Profesorado), mientras que los restantes se distribuían, en igual porcentaje, entre asignaturas de las titulaciones de Administración y Dirección de Empresas, Económicas, Periodismo e Ingenierías.

Nuevamente, estos resultados nos llevan a concluir que la metodología ApS no está suficientemente implementada en nuestra Universidad, poniéndose igualmente de manifiesto que, en titulaciones como Derecho, Enfermería o Trabajo Social, que tanto prestigio social tienen en otras universidades por su vinculación con el entorno vulnerable a través de consolidados proyectos de ApS, no se logra (o no se pretende) implementar proyectos similares. Por obvias cuestiones de espacio y tema, no procede ahondar en las posibles razones.

Es muy destacable, por tanto, el protagonismo del profesorado que, perteneciendo a diferentes áreas de conocimiento, tiene responsabilidad docente en las titulaciones de los Grados de Maestro y del Máster en Profesorado en sus diferentes especialidades, y que, en pro de una mayor calidad de los aprendizajes de sus estudiantes, incluye el ApS en su asignatura. Ello, desde mi punto de vista, tiene una triple valía, además de promover más y mejores aprendizajes y competencias y de aportar un servicio al entorno; me refiero a la clara repercusión que la práctica del ApS ha tenido en el conocimiento de la misma por parte de los centros educativos y del profesorado que, en diferentes etapas (Educación Infantil, Primaria, Secundaria, Bachillerato y Formación Profesional), ha sido la contraparte de los docentes universitarios, conociendo las virtudes del ApS y desarrollando posteriormente proyectos en los que su alumnado ha sido el protagonista de otros proyectos que desde el centro se han puesto en práctica en distintas entidades locales, sociales e incluso en los que la contraparte ha sido nuevamente la universidad, pero con una inversión de roles, los estudiantes de etapas inferiores a la universitaria han prestado un servicio social a aquélla. La administración educativa puede estar muy orgullosa del intercambio teórico y práctico entre profesorado de los diferentes niveles, todos ellos de igual valía, en esta ocasión gracias al empeño y dedicación en torno al ApS. 


\section{Bibliografía recomendada}

Arranz, P.; Vázquez, S. y Abán, A. (2013). El proyecto Aprendizaje-Servicio en la Universidad de Zaragoza: un análisis DAFO. En L. Rubio, E. Prats y L. Gómez (coords.). Universidad y sociedad: experiencias de aprendizaje-servicio en la universidad, 299-304. Barcelona: Universidad de Barcelona.

Arranz, P; Dieste, B. y Escolano, E. (2017). Estudio sobre la implementación de la metodología Aprendizaje-Servicio en la Universidad de Zaragoza. En Virginia Martínez, Noelia Melero, Eduardo Ibáñez y María del Carmen Sánchez (coords). Derribando muros. El compromiso de la Universidad con la justicia social y el desarrollo sostenible. Sevilla: Universidad Pablo Olavide.

Comisión de Sostenibilidad/ CRUE (2015). Institucionalización del Aprendizaje-Servicio como estrategia docente dentro del marco de la Responsabilidad Social Universitaria para la promoción de la Sostenibilidad en la Universidad. Documento Técnico aprobado por el Comité Ejecutivo y el Plenario de la Comisión de Sostenibilidad (Grupo CADEP), celebrado en León el día 29 de mayo de 2015.

Larrán, M. y Andrades, F.J. (2013). Frenos y aceleradores para la implantación de la Responsabilidad Social en las universidades españolas. Prisma Social, Revista de Ciencias Sociales, 10: 233-270.

MEC- Ministerio de Educación y Ciencia (2010). Real Decreto 1791/2010 de 30 de diciembre, por el que se aprueba el Estatuto del Estudiante Universitario. Madrid: MEC.

Santos, M.A.; Sotelino, A. y Lorenzo, M. (2015). Aprendizaje-servicio y misión cívica de la universidad. Barcelona: Octaedro. 


\title{
2 \\ Apoyo escolar a centros educativos con orientación intercultural.
}

\author{
Ester Ayllón, Lidia Bañares y M. Jesús Vicén \\ Universidad de Zaragoza \\ eayllon@unizar.es
}

\subsection{Introducción}

Este curso surge como consecuencia de una necesidad social por parte de los centros educativos de la ciudad de Huesca en los ámbitos de educación formal y no formal, y en el marco de una trayectoria investigadora sobre la escolarización de los niños/as gitanos/as. Véase la obra de María Jesús Vicén, Lidia Bañares y Reyes Lalueza, Los gitanos en la escuela: Análisis desde los sectores implicados (1995).

Nuestras escuelas, al igual que las del resto de países comunitarios, están experimentando una profunda transformación por la creciente presencia de alumnado de otras culturas y procedencias, como resultado de las nuevas tendencias migratorias de carácter internacional (Esteve, 2003). La de-manda de apoyo escolar de dichas instituciones educativas pretende compensar las carencias que ciertos colectivos de niños y niñas, sufren como consecuencia de vivir en ambientes socio-familiares empobrecidos culturalmente por diversas causas. Por ejemplo, emigrantes que desconocen la lengua, apoyos específicos para garantizar el éxito escolar en la Educación Secundaria en niños gitanos con buen rendimiento académico...

Tal y como considera Esteve (2004), los profundos cambios sociales que se han derivado de la incorporación en nuestras aulas y escuelas de un numeroso grupo de 
niños y niñas inmigrantes, exige al docente reestructurar sus estrategias educativas, volviendo a reflexionar sobre sus valores y objetivos como docentes.

La idoneidad de este curso se fundamenta en las líneas investigadoras iniciadas en el curso 1987-88 con una investigación de cuatro años sobre "Valoración de la integración escolar de minorías étnicas (sector población gitana) en la provincia de Huesca". Y la inclusión de la asignatura optativa "Educación intercultural" en la titulación en 1994, además de la impartición de cursos de doctorado de la misma temática y sobre "Educación en valores".

Esta actividad académica complementaria se inicia en 1996 y sigue vigente en la actualidad.

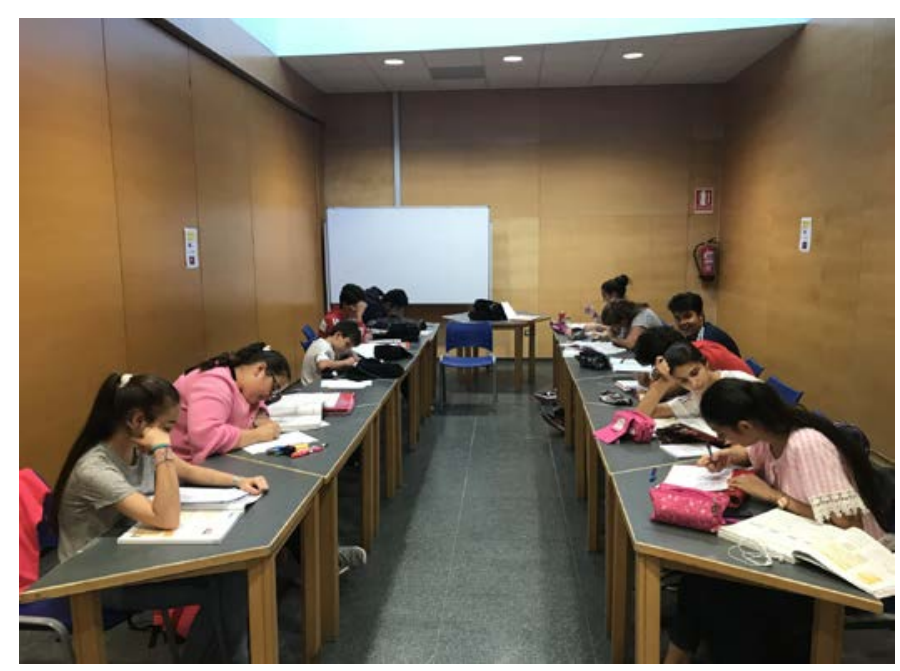

\subsection{Objetivos}

-Ofrecer a los estudiantes espacios de reflexión para una sociedad cada vez más multicultural y multiétnica.

-Promover la comunicación y potenciar el desarrollo de actitudes que estimulen una convivencia intercultural capaz de "transformar las dificultades en posibilidades" (Paulo Freire).

-Llevar a la práctica y experimentar técnicas de trabajo y estrategias metodológicas alternativas.

-Acercamiento a una realidad sociocultural diferente de la suya.

-Utilizar esta práctica como espacio de experimentación para acercarse a la realidad 
profesional desde una doble perspectiva: formativa y preventiva.

-Habituar a los estudiantes a invertir su tiempo en tareas solidarias y de compromiso con la sociedad y con los colectivos más desfavorecidos.

\subsection{Participantes}

Alumnado del Grado de Maestro de las especialidades de Educación Infantil y Primaria de la Facultad de Ciencias Humanas y de la Educación de Huesca.

Niñas y niños de los centros educativos de Educación Primaria.

Estudiantes de la E.S.O.

\subsection{Metodología}

Activa y Dinámicas de Trabajo en Grupo con el objetivo de desarrollar una dimensión personal y social. El estudiante universitario mediante el desempeño de su trabajo empatizará con estos colectivos étnico-culturales. Logrando un enriquecimiento mutuo a nivel personal y profesional.

- $\quad$ Utilización de técnicas de motivación al estudio y trabajo escolar.

- $\quad$ Atención a los niños en pequeño grupo.

\subsection{Actividades}

Estarán moduladas en función de las necesidades que presenten los niños y niñas para compensar las carencias sociofamiliares en la realización de los deberes escolares en el ámbito extraescolar.

La tipología de las actividades que realizan los estudiantes universitarios serían las siguientes:

- Jornada informativa-formativa sobre el programa específico que cada centro ha elaborado.

- $\quad$ Refuerzo en los aprendizajes básicos de los niños.

- Utilización de técnicas para compensar las dificultades en el aprendizaje (dislalias, dislexias...).

- $\quad$ Realización de material didáctico para apoyar específicamente dichos aprendizajes.

- $\quad$ Ayuda en la realización de las tareas escolares.

- $\quad$ Realizan tareas de refuerzo en las asignaturas de lenguas extranjeras y científicas (el caso de los estudiantes de la ESO).

2.6. Centros e instituciones 
Actualmente demandan dicho servicio:

- $\quad$ Secretariado Gitano de Huesca.

- $\quad$ I.E.S. Sierra de Guara.

- $\quad$ Centro de Apoyo escolar de Cáritas de Huesca.

\subsection{Resultados}

a) En relación a los centros educativos.

La satisfacción de los centros receptores se refleja en los informes fina-les que emiten en la que resaltan la tarea de calidad y entrega de los estudiantes. Valoran positivamente la implicación de la Facultad como forma de cooperación social.

b) En relación al aprendizaje del estudiante universitario.

Los estudiantes universitarios desarrollan competencias generales y transversales de la titulación del Grado de Maestro y, muchas específicas en relación a la tarea de apoyo escolar. Búsqueda de estrategias diversas para afrontar la dificultad educativa con la que se encuentran.

\subsection{Conclusiones}

Se ofrece a los estudiantes espacios de aprendizaje activo en relación con las demandas sociales y las medidas de discriminación positiva que deben intentar paliar las diferencias socioculturales de la población infantil.

Se contribuye así a la proyección de la Universidad como ejercicio de responsabilidad social.

\section{A modo de Epílogo: Nuestro sueño. Nuestra utopía}

Esta línea metodológica es coherente con las propuestas de nuestros trabajos de investigación publicados anteriormente y donde proponíamos (Bañares, L., y Vicén. M.J., 2008: 78) "aplicar un nuevo enfoque metodológico y reiterar, como ya propusimos en nuestros trabajos anteriores insertar la cultura gitana en el currículo, ya que en la propuesta actual se sigue silenciando y, como ya reconocimos (Bañares, Lalueza, y Vicén, 1994) es "una de las culturas sin voz". Pero esta propuesta es una parte únicamente del enfoque con el que nos identificamos. Paulo Freire (1997) iba mucho más lejos al defender que hay que transformar en lugar de adaptar: 
Servir al orden dominante, es lo que hacen hoy los intelectuales progresistas que negando a la práctica educativa cualquier intención desveladora, reducen la educación a pura transferencia de contenidos "suficientes" para la vida feliz de la gente. Consideran la vida que se vive adaptados al mundo, sin sueños de transformación.

Nos sentimos identificadas con su concepto de educación ya que engloba todos los aspectos, también la utopía y la ilusión:

La educación necesita tanto de formación técnica, científica y profesional como de sueños y de utopía.

Hay una frase del pedagogo brasileño que resume nuestra postura y enfoque de la interculturalidad:

\section{"La cuestión está en cómo las dificulta-des se transforman en posibilidades".}

\section{Bibliografía recomendada}

Bañares, L., Lalueza, R. y Vicén. M.J. (1994). La cultura española sin voz en Actas del Congreso Internacional Nuevas Perspectivas críticas en Educación, pp.101-105. Barcelona 6-8 de julio de 1994. Barcelona: Estudis de formació continuada. Universitat de Barcelona.

Bañares, L., Lalueza, R. y Vicén. M.J. (2005). Presentación de un plan de educación intercultural en la formación de maestros. (1991-2003). Valoración de su implantación. En Interculturalidad, Formación del Profesorado y Educación. Madrid: Pearson, educación.

Bañares, L., y Vicén. M.J. (2008). Educación intercultural y cultura gitana en Vived, E. y Vicén, M.J. (coords.), Formación y prácticas educativas en escenarios de inclusión sociaL, Zaragoza, Prensas universitarias de la Universidad de Zaragoza, pp.53-83.

Esteve, J.M. (2003). La tercera revolución educativa. La educación en la sociedad del conocimiento. Barcelona. Paidós.

Esteve, J.M. (2004). La formación del profesorado para una educación intercultural, Bordón, 56 (1), pp.95-115.

Freire, P. (1997). A la sombra de este árbol. Barcelona: El Roure Office Nacional d'Information sur les Enseignements et les Professions (1997). L'école pour savoir sa place. Pour une meilleure scolarisation des enfants des familles tsiganes et voyageurs. París: ONISEP. 
Vicén, M.J., Bañares, L., y Lalueza, R. (1995). Los gitanos en la escuela: Análisis desde los sectores implicados en Los gitanos en la historia y la cultura. Granada: Junta de Andalucía. Consejería de Trabajo y Asuntos Sociales de Granada, pp. 337-355 


\section{3 \\ Estudiantes de magisterio trabajando con las niñas y los niños de la ciudad.}

Ester Ayllón, Lidia Bañares, M. Angeles Eito; Azucena Lozano, Silvia Martínez, M. Pilar Moreno, M. Jesús Vicén y Nieves Moyano

Universidad de Zaragoza

eayllon@unizar.es

\subsection{Contexto}

El Proyecto La Ciudad de las niñas y de los Niños es un proyecto internacional de participación ciudadana que pretende tomar al niño y a la niña como parámetro de la construcción de la ciudad, persigue su participación social plena. Se trata de un proyecto para la ciudad y la ciudadanía, en definitiva, el fomento de una ciudadanía activa y solidaria, donde todas y todos nos damos la mano para una convivencia más humanizada y humanizadora.

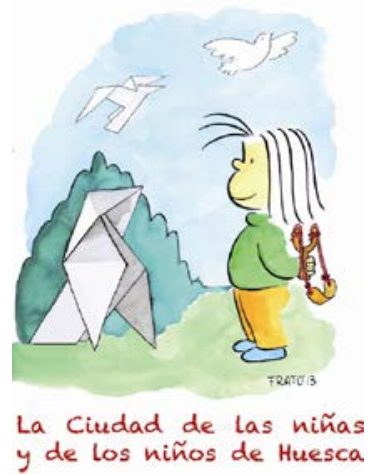


Fue impulsado por el pedagogo italiano Francesco Tonucci fundamentado en la experiencia que realizó en Fano y que dio lugar a la publicación del libro La ciudad de los niños (1996). Pretende y, pone todo su empeño, en hacer efectivo el cumplimiento del Artículo 12 de la Convención sobre los derechos del Niño: El niño tiene derecho a expresar su opinión y a ser escuchado cada vez que se tome una decisión que le afecte. Apuesta por incluir en su día a día la diversidad del niño que, a su vez, incluye las diversidades del resto de la ciudadanía tal como afirma Tonucci: quien sea capaz de contemplar las necesidades y deseos de los niños, no tendrá dificultades en tener en cuenta la necesidad del anciano, del minusválido, de personas de otras comunidades (Tonucci, 1999). Es una apuesta por el encuentro intergeneracional de niños y abuelos en las calles de las ciudades. Su puesta en marcha en Huesca se inicia el 25 de marzo de 2011, a propuesta del grupo interdisciplinar La Ciudad de los Niños de la Facultad de Ciencias Humanas y de la Educación con la aprobación en el pleno del Ayuntamiento del proyecto en Huesca y las consiguientes actuaciones como el compromiso de crear el Laboratorio de la Ciudad de las Niñas y los Niños y el Consejo de las Niñas y los Niños.

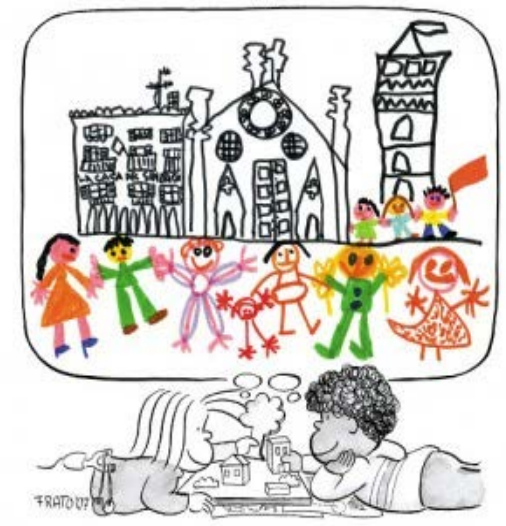

3.2. Los Órganos de participación son:

Uno de los órganos fundamentales del proyecto es El Consejo de las Niñas y los Niños, pero dado que éste no es un proyecto solo de niños y para niños sino que es un proyecto de participación ciudadana y para toda la ciudad, cuenta con otros órganos importantes como son: El Laboratorio "La Ciudad de las niñas y los niños", Grupo de maestros y maestras coordinadores del proyecto en cada escuela, el Grupo de padres y madres y el Grupo mixto de investigación-acción: "Grudimix" con alumnos y alumnas de los grados de Magisterio tanto de Infantil como de 
Primaria de la Facultad de Ciencias Humanas y de la Educación, y el equipo interinstitucional La Ciudad de las niñas y niños.

\subsubsection{Con el Grudimix se trabaja desde:}

-El aprendizaje- servicio: los estudiantes colaboran en la elaboración de proyectos de participación infantil relacionados con la transformación de la ciudad.

- Autoformación compartida: discusión, análisis, reflexión y decisiones inclusivas. Partimos del seminario como método más generalizado y a través de él llevamos a cabo la formación teórica. Dicha formación se realiza dando a los estudiantes veteranos el papel de "formadores" de las nuevas incorporaciones. Además, utilizamos los grupos cooperativos para establecer el diseño y llevar a cabo las sesiones de trabajo. De esta manera, integramos el servicio comunitario con la educación y el autoconocimiento como vía para enriquecer la experiencia educativa.

- Conocimiento teórico-práctico de herramientas de participación.

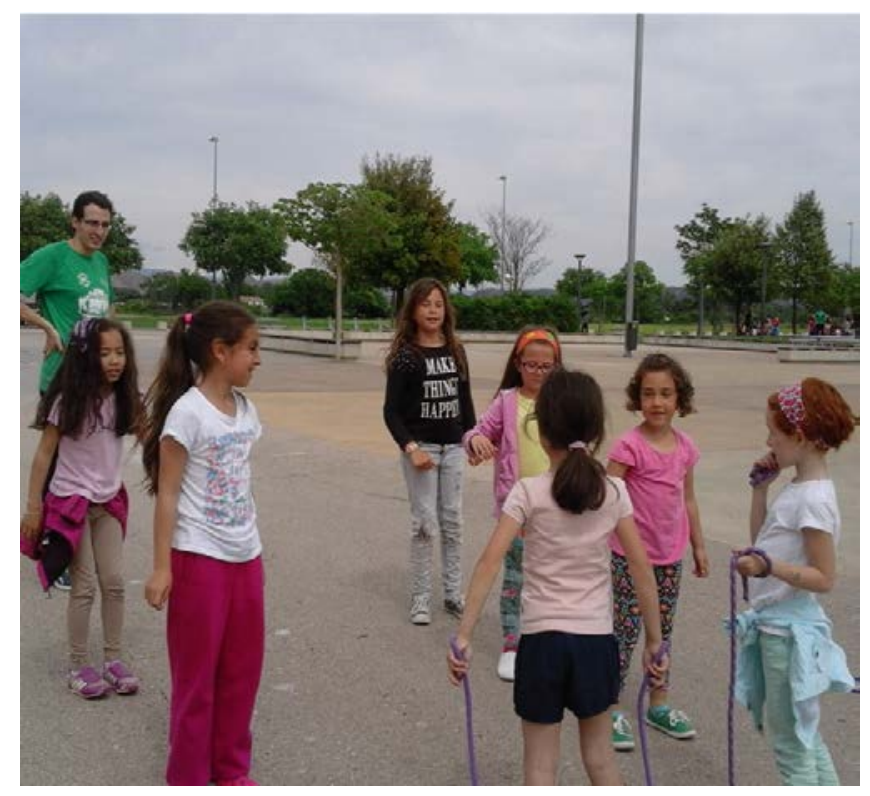

3.3. Necesidad social: escuchar a los niños y niñas para transformar la ciudad

La participación ciudadana es una de las preocupaciones habituales en las sociedades democráticas actuales. 
Tal como señala Novella (2012), en la actualidad la participación infantil está en su mejor momento, porque tiene unas buenas bases legislativas que la reconocen, la defienden y la impulsan. Dicha participación está en boca de todos y todas, pero falta la parte más esencial y es que sea real, que forme parte de nuestra cotidianidad y sobre todo que pensemos en ella como formativa de la identidad de los niños.

Este proyecto quiere hacer presentes a los niños y niñas de nuestro municipio, escuchándoles, haciéndoles partícipes del bienestar común y responsabilizándoles de contribuir al mismo: observando la ciudad con criterios de sostenibilidad y de justicia social y teniendo en cuenta a todas las personas que conviven en la ciudad con sus distintas necesidades. En definitiva, mejorar el espacio urbano para un mayor bienestar para toda la ciudadanía. Si conseguimos esto, estaríamos ante uno de los mejores indicadores de calidad de la ciudad, «la calidad de la ciudad se mide por el grado del ejercicio de la ciudadanía: los ciudadanos hacen la ciudad y la ciudad hace los ciudadanos» (Trilla, 1998: 19).

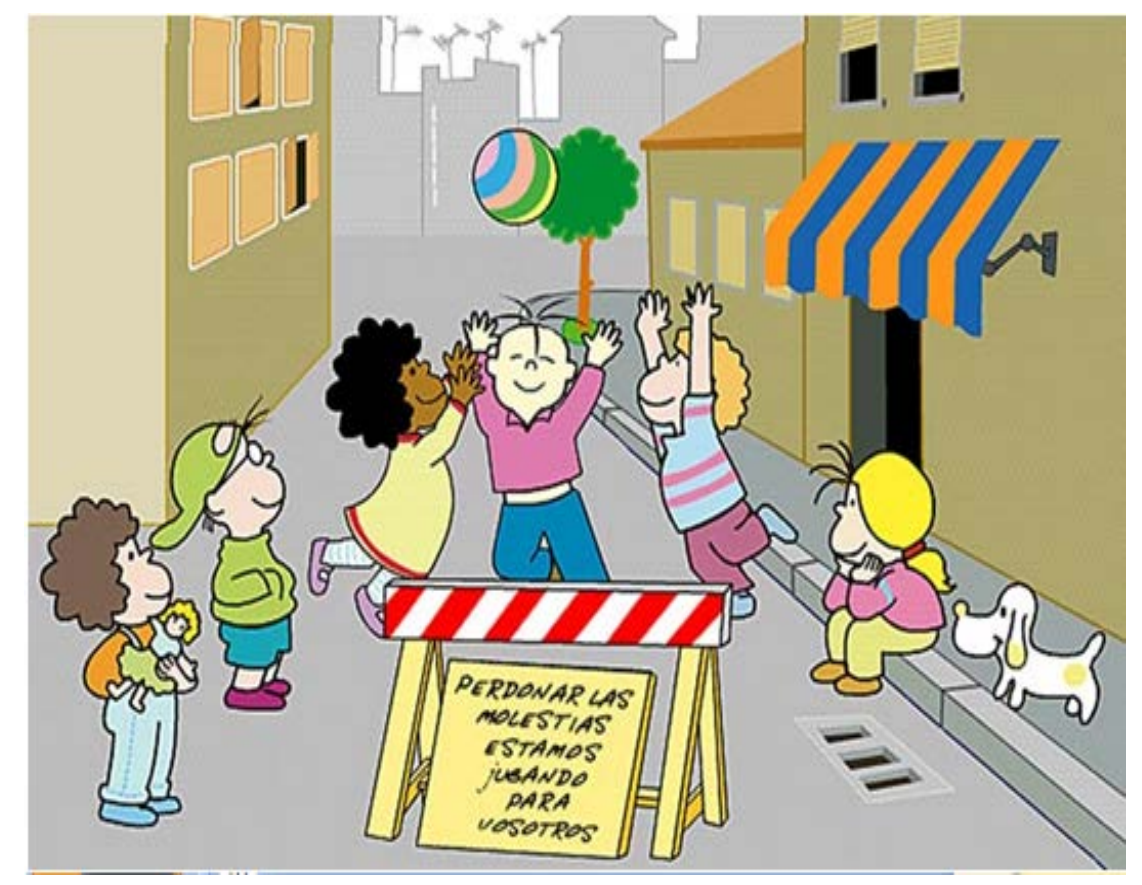

Por otra parte, se ha hablado de que, para los niños, perder la posibilidad de moverse autónomamente en los espacios públicos de su ciudad es un gran obstáculo 
para su crecimiento. Precisamente en el primer Forum Internacional de las ciudades a la medida de los niños, en Nápoles, el entonces presidente del Consejo italiano, Romano Prodi, en 1997, decía: «Ya no es suficiente dar a los niños servicios para la infancia, debemos devolverles las ciudades» (Tonucci, 2004). Por lo que este proyecto promueve, la utilización de la calle como elemento fundamental de convivencia en la ciudad.

\subsection{Actividades del proyecto}

- El Consejo de las Niñas y de los Niños: participan todos los colegios de la ciudad.

-El día del Juego: Uso preferente de las calles de la ciudad para el juego. Participando todos los colegios de la ciudad.

-Los niños y niñas proyectistas: diseño de las niñas y los niños de espacios públicos de la ciudad: Parque del Encuentro, La placeta...

-Planificación compartida: Pintura calle Valentín Carderera, Juegos en línea, Bulevar de Avda. Martínez de Velasco.

-Participación en el entorno hospitalario: el hospital desde el punto de vista de los niños y niñas (espacios, interacción personal, convivencia,...).

-Comercio Amigo y espacio amigo: Red social de cooperación con el proyecto La ciudad de las niñas y los niños

-Todos Juntos a la Escuela: esta experiencia pretende que los niños y las niñas recuperen la tradición de caminar juntos hasta el colegio y moverse con seguridad, autonomía y diversión por las calles, recuperen el uso y disfrute del espacio público y puedan volver a experimentar algo tan natural como abrir la puerta, salir de casa y caminar en busca de otros amigos o amigas. Porque la posibilidad de moverse libremente en la propia ciudad es una forma de participación y de ciudadanía (Tonucci, 2009:11-24).

Estas actividades tienen como objetivo influir tanto en los estudiantes de Magisterio como en las niñas y niños:

\subsubsection{Estudiantes de Magisterio}

- Reflexionar sobre el sentido educativo de la participación, la autonomía y el juego.

- Crear herramientas para favorecer que las niñas y los niños participen de forma activa en la transformación de la ciudad y en el día del juego en la calle.

- Planificar y responsabilizarse del desarrollo de cada actividad. 


\subsubsection{Niñas y Niños}

- Participación en las discusiones y decisiones del Consejo.

- Organizarse e ir con sus amigos y amigas al colegio.

- Buscar los caminos para ir al cole y las cosas que son mejores para su salud en su entorno.

- Intervenir en la transformación de su entorno escolar.

- Organizar y participar en el día del Juego en la calle.

\subsection{Participantes}

\section{Estudiantes de Magisterio}

GRUDIMIX: Participantes en todo el proyecto: 23 estudiantes curso 2016/2017. Niñas y Niños

Consejo: 26 niñas y niños de los 13 colegios de la ciudad de Huesca.

Todos Juntos a la Escuela: Colegios Alcoraz, El Parque, San Viator y Santa Ana de Huesca.

Día del Juego: todos los niños y niñas de todos los colegios.

3.6. Conclusiones: aprendizaje competencial y servicio

\section{Estudiantes de Magisterio}

- Realizar un aprendizaje significativo en capacidades vinculadas a su formación como futuros maestros.

- Desarrollar capacidades básicas como el trabajo en equipo, la responsabilidad, la iniciativa, la resolución de conflictos, el aprender a aprender...

\section{Niñas y niños de la ciudad}

- Aprender a observar críticamente la ciudad.

- Desarrollar las estrategias de participación social.

- Intervenir en su entorno con criterios de beneficio social.

- Colaborar con personas ajenas a su entorno inmediato.

\section{Mejoras para la ciudadanía}

- La mejora de las condiciones de los espacios públicos y también de los espacios verdes en la ciudad tomando como protagonistas a niños y niñas, familias y escuela, cumpliendo una función de visibilidad y sensibilización.

- El aumento de la seguridad en el entorno de la escuela y en las vías de acceso, extendiendo este comportamiento a toda la ciudad. 
- La detección de problemas en el diseño urbano (anchura de aceras y rebaje, iluminación, semaforización, cruces peligrosos, eliminación de obstáculos, etc.).

- La reapropiación del espacio público por parte de los niños y niñas.

\section{Bibliografía recomendada}

Novella (2012). La participación infantil: concepto dimensional en pro de la autonomía ciudadana. Tesi, 13 (2), 380-403.

Tonucci, F. (1996). La città del bambini. Bari. Laterza. Traducción (1997): La ciudad de los niños. Madrid, Fundación Germán Sánchez Ruipérez

Tonucci, F. (2009). ¿Se puede enseñar la participación? ¿Se puede enseñar la democracia? Investigación en la Escuela, $\mathrm{n}^{\circ} 68$.

Tonucci, F. (2004). Cuando los niños dicen ¡Basta! Madrid. Fundación Germán Sánchez Ruipérez.

Trilla, J. (1998). Pensar la ciutat des de l'educació. Document del seminari Projecte educatiu de ciutat. Temes d'Educació, 12, 13-55. 


\title{
4 \\ Atención a la diversidad: \\ Desarrollo de competencias del profesorado inclusivo desde la metodología de ApS.
}

\author{
Sandra Vázquez, Cecilia Latorre y Marta Liesa \\ Universidad de Zaragoza \\ svaztol@unizar.es
}

Las actividades que se enmarcan dentro de la ampliamente conocida como metodología de Aprendizaje-Servicio (en adelante, ApS), tienen cabida no sólo en etapas educativas iniciales sino que, además, pueden ser implementadas en contextos de Educación Superior. Al respecto de ello, Campo (2010) señala que nos hallamos en un momento idóneo para el desarrollo y puesta en marcha de propuestas de ApS que posibiliten a los estudiantes universitarios la implicación en aprendizajes más participativos, y menos individualistas. Incluso en el conocido por todos como "proceso Bolonia", se dispone un punto clave que destaca la relevancia de la dimensión social del contexto universitario.

A lo largo de los años de estudio de Educación Superior, las experiencias de ApS en las que participa el alumnado universitario les permiten desarrollar, además de las competencias específicas de la titulación, otra serie de competencias transversales que resultan esenciales para la estimulación del ámbito social del desarrollo de las personas. Entre todas estas competencias, y en términos generales, Martínez (2005) destaca la capacidad de toma de decisiones, las habilidades sociales para 
trabajar con grupos heterogéneos, el dominio de las Tecnologías del Aprendizaje y la Comunicación y el trabajo en equipo.

El ámbito concerniente a la formación de los docentes supone, tal y como apunta Aramburuzabala y García (2012), uno de los contextos en los que se ha utilizado el ApS como recurso pedagógico de calidad. Las razones de ello atañen, entre otros muchos aspectos, a la oportunidad que tienen estos estudiantes para desarrollar valores positivos vinculados a la aceptación de la diversidad entre las personas, o para comprometerse con la enseñanza (Root, Callagan, y Sepansky, 2002).

Profundizando en la temática que aquí nos ocupa, cabe destacar que la puesta en marcha de diferentes experiencias de ApS que contribuyen al desarrollo de competencias profesionales de los futuros docentes es especialmente relevante en un momento en que se está reclamando a las universidades la incorporación de aprendizajes que integren, de forma pertinente, la preparación para la práctica profesional y para la responsabilidad social de sus estudiantes (Martínez Domínguez, 2014). En los últimos años, autores como Buchanan, Baldwin y Rudisill (2002) destacan el ApS como un recurso altamente valioso en la formación de los futuros docentes apuntando que, a través de experiencias de aprendizaje en el servicio, los estudiantes de magisterio aprenden a ser profesionales reflexivos, sensibles a las cuestiones basadas en la comunidad. Aprenden a reflexionar de forma crítica acerca de sus propios pensamientos, aprendizajes y prácticas.

Más específicamente, los beneficios que encuentra el alumnado universitario en formación para el futuro ejercicio de la docencia, incluyen una serie de competencias que muy bien indican Root, Callagan, y Sepansky (2002) tras la revisión de estudios basados en evidencia empírica que realizan: en primer lugar, los autores mencionan la creencia de estos estudiantes de Magisterio en su propia capacidad para influenciar los logros (en términos de aprendizaje) de sus alumnos. Es decir, que los proyectos de ApS en los que se implican estos estudiantes inciden directamente en la percepción que ellos, como futuros docentes, tienen de sí mismos, de lo que son capaces de hacer y de creer.

Por otro lado, se ha comprobado un aumento del compromiso que manifiestan estos futuros profesionales de la educación, hacia el propio ejercicio de la docencia. Este compromiso se encuentra directamente vinculado al posterior rendimiento y desempeño de estos estudiantes en el ámbito laboral del ejercicio docente. Finalmente, Bates, Drits, Allen y McCandless (2009) destacan la influencia que tiene la participación de estos estudiantes universitarios en experiencias de ApS, en el papel 
promotor de experiencias similares que, posteriormente, pueden desarrollar cuando accedan a la profesión de la docencia. Esto se debe a que el ApS es un aprendizaje experiencial con un elevado impacto en la motivación y en el desarrollo de valores. Durante la última década, se ha resaltado la necesidad de enfocar los proyectos de ApS desde la perspectiva de la justicia social, entendiendo en este sentido que la formación docente requiere ser abordada bajo un enfoque crítico que enfatice la igualdad de oportunidades para todos en el ejercicio de la ciudadanía. Además de ello, el ApS es un modo de enseñanza que resalta la importancia de la realización de servicios voluntarios en pro de las necesidades que se detectan en la comunidad próxima (Martínez-Odría, 2007). Surgen, de este modo, aprendizajes que no resultaría sencillo trabajar de otro modo tales como, por ejemplo, la consideración de las problemáticas sociales presentes hoy en día en nuestra sociedad, o las consideración de la complejidad que entraña el mismo proyecto educativo en el que se está participando (Campo, 2010).

Las acciones de ApS con un enfoque de justicia social se encuentran dirigidas a aquellos colectivos de personas que se ven inmersas en determinados contextos de desventaja social o riesgo de exclusión. En consecuencia, sus actuaciones se focalizan en la necesidad de respetar a la diversidad existente entre las personas, la consideración de la diversidad funcional que se deriva de diferentes funcionalidades motoras, psíquicas, etc., la inclusión educativa y, en definitiva, el respeto a los derechos humanos.

Considerando este componente básico del ApS referido a la labor voluntaria que desemboca en la transformación de la comunidad (Francisco y Moliner, 2010), la función de los estudiantes universitarios del Grado de Maestro que acceden, por ejemplo, a compartir experiencias de convivencia con personas con discapacidad, recobra un papel de esencial importancia. A lo largo de los años de estudio en la etapa universitaria, uno de los contenidos más relevantes que se imparten en la formación de los futuros maestros es la atención a las diversas necesidades que, a día de hoy, presentan las personas con diversidad funcional.

Las actitudes que manifiestan los docentes tienen una clara repercusión no sólo en el desarrollo del autoconcepto de las personas con diversidad funcional, sino también en su proceso de socialización e inclusión (Liesa, Arranz y Vázquez, 2013). En ciertas investigaciones (Avramidis y Norwichi, 2004), los autores encuentran, como uno de los factores que influyen en la actitud de los profesores hacia la integración y la inclusión, el contacto directo con personas con necesidades específicas. Por ello, y dado que "la formación en atención a la diversidad de los estudiantes de 
magisterio es muy escasa y esto puede influir en su actitud hacia la inclusión educativa y social de las personas con discapacidad" (Liesa et al. 2013), surge la necesidad de implementar experiencias de este tipo promovidas desde el ámbito universitario.

Paralelamente al ofrecimiento de un servicio a la comunidad, los estudiantes ponen en práctica diferentes aptitudes conceptuales, procedimentales y actitudinales ligadas a los contenidos que se establecen en diferentes materias del Grado de Maestro, pudiéndose acercar así a auténticas realidades y preparándose para abordar el reto de la diversidad humana. Además, estas experiencias de ApS con personas con discapacidad ayudan a los estudiantes universitarios a ser conscientes de la necesidad de adaptación y reflexión continuada en el momento de llevar a cabo determinadas acciones que pretenden incidir en el entorno en que se desarrolla la vivencia (Francisco y Moliner, 2010; Martínez Domínguez, 2014).

En definitiva, y en la línea de lo señalado por Bender y Jordaan (2007), una oportunidad para reflexionar sobre la importancia de la capacitación de los docentes para atender a la diversidad implicándose en proyectos comunitarios. Además, la participación de los estudiantes en experiencias de ApS mantiene una relación directa con su papel promotor de tales actividades en el momento en que ejerza la profesión docente (Bates et al. 2009). A la vez que se aprende, se desarrollan servicios de calidad a la comunidad. No olvidemos que, en palabras de Mendía Gallardo (2012), es el servicio quien mejora al aprendizaje, lo motiva, dota de sentido y le permite extraer nuevos aprendizajes.

Los efectos positivos que reportan las experiencias de ApS en la formación de los futuros docentes no sólo se trasladan al ámbito más puramente cognitivo sino que, también, se manifiestan como experiencias emocionales beneficiosas pues, de acuerdo a lo expuesto por Switzer, Simmons, Dew, Regalski y Wang (1995), son tareas gracias a las que es posible aumentar la autoestima, la autoconfianza y la competencia en el área social. Así pues, y como bien recogen Aramburuzabala, García y Elvias (2013, p.2) apoyándose en los fundamentos expuestos por Billig y Freeman (2010):

Cuando los alumnos, futuros maestros, participan en proyectos de aprendizaje-servicio, desarrollan una visión más realista de la profesión, son más sensibles a las necesidades de sus alumnos, entienden mejor el aprendizaje social y emocional que puede servir para apoyar el aprendizaje académico de los alumnos, y les ayuda a adaptarse y mantenerse dentro de la profesión cuando llegan a maestros. 
Aprender a ser un docente participativo y comprometido con la sociedad actual no es, ni mucho menos, un proceso que se adquiera de forma espontánea. Consecuentemente, para llegar a serlo se necesita disponer de oportunidades que posibiliten, precisamente, estos aprendizajes. Un estudiante universitario que participe en estas experiencias de ApS, que se vea sumergido intensamente en su realidad y complejidad, difícilmente volverá a apreciar sus estudios y su profesión del mismo modo que antes (Campo, 2010). Tiene, así, la bella oportunidad de ampliar su perspectiva profesional y social, de experimentar valores como el respeto y la solidaridad, de dar auténtico sentido y significado a los contenidos más puramente académicos $\mathrm{y}$, en definitiva, de experimentar un crecimiento como persona.

\section{Bibliografía recomendada}

Aramburuzabala, P. y García, R. (2012). El aprendizaje-servicio en la formación de maestros. Revista del Congrés Internacional de Docència Universitària $i$ Innovació (CIDUI), 1, 1-15. 1, 1-15.

Aramburuzabala, P., García, R. y Elvias, S. (2013). Aprendizaje-Servicio para la promoción de la Justicia Social en la educación. En J. Gázquez, M. Pérez, M.M. Molero y R. Parra (Eds.), Investigación en el ámbito escolar: un acercamiento multidimensional a las variables psicológicas y educativas (pp. 147-152). España: Grupo Editorial Universitario.

Avramidis, E. y Norwichi, B. (2004). Las actitudes de los profesores hacia la integración y la inclusión: revisión de la bibliografía sobre la materia. Entre dos mundos: revista de traducción sobre discapacidad visual, 25, 25-44.

Bates, A.K., Drits, D., Allen, C. y McCandless, P. (2009). Service learning as an instructional strategy for the preparation of teachers. The Journal of Effective Teaching, 9, 5-23.

Bender, G. y Jordaan, R. (2007). Student perceptions and attitudes about Community Service-Learning in the teacher training curriculum. South African Journal of Education, 27, 631-654.

Buchanan, A.M., Baldwin, S.C. y Rudisill, M.E. (2002). Service learning as scholarship in teacher education. Educational Researcher, 31(8), 30-36.

Campo, L. (2010). El aprendizaje servicio en la Universidad. En M. Martínez (Ed.), Aprendizaje servicio y responsabilidad social en las universidades (pp. 8191). Barcelona: Ediciones Octaedro.

Francisco, A. y Moliner, L. (2010). El aprendizaje servicio en la Universidad: una estrategia en la formación de ciudadanía crítica. Revista Electrónica Interuniversitaria de Formación del Profesorado, 13(4), 69-77. 
Capítulo4. Atención a la diversidad: Desarrollo de competencias del profesorado inclusivo desde la metodología de ApS.

Liesa, M., Arranz, P. y Vázquez, S. (2013). Un programa basado en la metodología del aprendizaje servicio que mejora las actitudes de los estudiantes del grado de Magisterio hacia la inclusión. Revista Interuniversitaria de Formación del Profesorado, $76(27,1), 65-82$.

Martínez Domínguez, B. (2014). Aprendizaje-Servicio y Educación Inclusiva. Educación y futuro, 30, 183-208.

Martínez Odría, A. (2005). Service Learning o Aprendizaje Servicio. Una propuesta de incorporación curricular del voluntariado [Tesis Doctoral]. Facultad de Filosofía y Letras. Departamento de Educación. Universidad de Navarra.

Martínez Odría, A. (2007). Service-Learning o Aprendizaje-Servicio. La apertura de la escuela a la comunidad local como propuesta de educación para la ciudadanía. Bordón, 59(4), 611-626.

Mendía Gallardo, R. (2012). El Aprendizaje-Servicio como una estrategia inclusiva para superar las barreras al aprendizaje y la participación. Revista Educación Inclusiva, 5(1), 71-82.

Root, S., Callahan, J. y Sepanski, J. (2002). Building teaching dispositions and service- learning practice: A multi-site study. Michigan Journal of Community Service-Learning, 8, 50-60.

Switzer, G.E., Simmons, R.G., Dew, M.A., Regalski, J.M. y Wang, C. (1995). The effect of a schoolbased helper program on adolescent self-image, attitudes, and behavior. The Journal of Early Adolescence, 15, 429-455. 


\title{
5 \\ Recreos cooperativos e inclusivos: Una oportunidad de aprender contribuyendo.
}

\author{
Alberto Aibar, Azucena Lozano, Marta Liesa, Eduardo Ibor, Nieves Moyano \\ y Sandra Vázquez. \\ Universidad de Zaragoza \\ aibar@unizar.es
}

\subsection{Introducción teórica}

El tiempo de recreo es un periodo lectivo en el que el alumnado muestra un enorme deseo por divertirse y jugar activamente, siempre dentro de un espacio donde las características del propio patio y su equipamiento, así como las normas, la seguridad y las interacciones con sus compañeros son de-terminantes esenciales para desarrollar ese ocio libre y activo (Caro, Altenburg, Dedding y Maidy Chinapaw, 2016). Sin embargo, en ocasiones el patio de recreo puede resultar un espacio hostil donde el alumnado no experimente esa deseada diversión, sino todo lo contrario. Situaciones de estrés, bullying o aislamientos son escenarios más habituales de lo normal en los patios de recreo. La promoción y modificación de los determinantes que influyen en la realidad del recreo puede implicar la mejora de los niveles de actividad física de los alumnos, la oportunidad de juego, la percepción de competencia, la aceptación social por parte de sus compañeros y las habilidades sociales (Bundy, Engelen, Wyver, Tranter, Ragen, Bauman et al., 2017), lo que a su vez está relacionado con los niveles de bienestar del alumnado. Considerando estos hechos, son múltiples los proyectos de intervención en centros escolares a nivel internacional donde el foco se sitúa en generar recreos saludables, activos y pacíficos (ejemplo: HAPPY study; Cot- 
ton, Dudley, Jackson, Winslade y Atkin, 2017). Una reciente revisión sobre la efectividad de este tipo de programas de intervención (Mayfield, Child, Weaver, Zarret, Beets y Moore, 2017) muestra su potencial efectividad, así como la enorme complejidad de este tipo de intervenciones para conseguir los efectos deseados en contextos reales. A partir de esta realidad descrita en la literatura internacional surge teóricamente el proyecto de Recreos Cooperativos e Inclusivos, cuya descripción es el objetivo fundamental de este capítulo.

\subsection{Necesidad contextual}

Los proyectos deben comprenderse y enmarcarse dentro una realidad contextual que no podemos obviar. El contexto educativo de la ciudad de Huesca, y concretamente, la realidad de sus espacios de recreo, constituye la ubicación contextual donde entender esta propuesta de actuación educativa. Las primeras acciones se remontan al curso escolar 2011-2012 donde a través de una primera experiencia piloto comenzó a desarrollarse el proyecto. Esta primera experiencia surgió a partir de una serie de necesidades educativas en el espacio de recreo que fueron detectadas por parte del Equipo de Orientación Educativa y Psicopedagógica (EOEP) de la Hoya de Huesca.

Los profesionales del EOEP detectaron cómo el recreo, un teórico espacio de placer y diversión para el alumnado, se convertía en ocasiones de manera paradójica para algunos niños y niñas en un momento de soledad y tensión no deseada. Un momento dentro del horario escolar dedicado al juego libre que para algunos alumnos suponía un momento contradictoriamente nada placentero. La visible falta de integración o el aislamiento social manifiesto por parte de algunos alumnos en ese periodo escolar, junto a la pre-dominancia de actividades lúdicas de carácter mayoritariamente masculinas y de carácter discriminante, hizo replantearse al EOEP la necesidad de intervenir y diseñar acciones concretas para la resolución de esta cuestión. Esta necesidad se transformó y dio lugar a la iniciativa de "Recreos cooperativos e inclusivos" que lleva desarrollándose y conformándose como una propuesta con entidad propia desde hace más de seis cursos escolares. Si bien esta iniciativa cuenta con diferentes objetivos específicos, el objetivo general de la misma es favorecer la inclusión y socialización equilibrada de todos los niños y niñas en el espacio de recreo a través de propuestas lúdica cooperativas e inclusivas.

\subsection{Recreos cooperativos e inclusivos}

El proyecto de "Recreos cooperativos e inclusivos" se viene desarrollan-do en la ciudad de Huesca como una propuesta de intervención educativa en los recreos de algunos colegios de dicha localidad desde el curso 2011/2012 a través de una experiencia 
piloto en un solo centro. Desde ese curso, son numerosos los centros educativos que se han ido uniendo a esta propuesta y que de manera autónoma han ido desarrollando acciones concretas de intervención en sus espacios de recreos.

Con el objeto de facilitar la comprensión en líneas generales de en qué consiste este proyecto, podemos decir que cada uno de los centros que se incluye dentro de esta iniciativa diseña de manera autónoma las situaciones lúdicas que se llevarán a cabo en el espacio de recreo. La dinamización y/o el diseño de dichas acciones corre a cargo de los maestros responsables, habitualmente los maestros de Educación Física del centro, y de los alumnos de Magisterio, tanto del Grado de Infantil como del de Primaria, que realizan las prácticas escolares en ese centro educativo en concreto. La colaboración de los alumnos y alumnas de Magisterio dentro de una dinámica de aprendizaje servicio resulta fundamental para poder dinamizar y manejar correctamente un número elevado de alumnos de primaria. Cabe destacar que esta iniciativa se circunscribe fundamentalmente durante dos espacios temporales a lo largo del curso escolar, un primero coincidente con el periodo de prácticas II de Magisterio (noviembre-enero) y un segundo con el periodo de prácticas III y de mención de los Grados (febrero-mayo). No obstante, y en función de la organización y funcionamiento interno de cada centro, la iniciativa puede prolongarse a lo largo de otros momentos del curso escolar. Para comprender bien la dimensión de este proyecto, nos apoyaremos en las cifras del curso escolar 16/17 donde seis colegios públicos de la ciudad de Huesca participa-ron en la iniciativa. Según la memoria del pasado curso, un total de 296 alumnos de Educación Primaria se vieron beneficiados directamente de las acciones llevadas a cabo en el periodo de recreo por 54 alumnos de los Grados de Magisterio en Educación Infantil y Primaria de la Facultad de Ciencias Humanas y de la Educación de Huesca.

Profundizando en la comprensión del proyecto, procede detallar de manera más profunda las seis fases sobre las que se sustenta la organización interna de la propuesta cada curso escolar que es llevada a cabo. A saber:

- $\quad$ Fase 1: Detección de necesidades

- Fase2: Contacto con profesorado de los colegios colaboradores

- Fase 3: Formación inicial teórico-práctica de los alumnos en la Facultad de Ciencias Humanas y de la Educación de Huesca.

- $\quad$ Fase 4: Dinamización de los recreos en los periodos de prácticas es-colares.

- $\quad$ Fase 5: Evaluación del proyecto: informes de los centros.

- $\quad$ Fase 6: Difusión del proyecto. 
Pasamos a continuación a detallar y explicar en qué consisten cada una de estas seis fases.

Fase 1. Detección de necesidades: En una primera fase del curso el EOEP detecta aquellos centros donde existe una mayor necesidad de imple-mentar este tipo de estrategia y donde existe una disposición por parte del profesorado para llevarlo a cabo. En caso de confluir estas circunstancias se accede a la segunda fase.

Fase2. Contacto con profesorado de los colegios colaboradores: Se establece un contacto previo con los profesores de los centros colaboradores informándoles del proceso formativo que van a seguir los alumnos y alumnas de Magisterio en prácticas escolares. A partir de este contacto se favorece cualquier tipo de interacción comunicativa que pueda contribuir a mejorar la dinámica propia del proyecto.

Fase 3. Formación inicial teórico-práctica de los alumnos en la Facultad de

Ciencias Humanas y de la Educación de Huesca: Los alumnos y alumnas que, tanto de Prácticas II ( $1^{\circ}$ cuatrimestre) como de Prácticas III y/o de mención ( $2^{\circ}$ cuatrimestre), van a realizar su periodo formativo en los centros participantes de esta iniciativa asisten a dos jornadas de formación inicial en la Facultad de Ciencias Humanas y de la Educación. Una primera jornada consiste en una formación general sobre actividades y juegos cooperativos que se especifica de manera más detallada a través de actividades dirigidas a infantil y $1^{\circ}$ y $2^{\circ}$ de Educación Primaria en una primera parte de la formación y de actividades dirigidas al alumnado de $3^{\circ}$ a $6^{\circ}$ de Educación Primaria en la segunda fase de la jornada formativa. La segunda jornada de formación inicial versa sobre actividades y juegos lúdicos inclusivos para toda la etapa de Educación Primaria. Ambas jornadas tienen una carácter teórico-práctico.

Fase 4. Dinamización de los recreos en los periodos de prácticas escolares: En función de la organización interna y de las características propias de cada uno de los centros escolares, los recreos son dinamizados con la colaboración de los alumnos y alumnas de Magisterio y supervisados por los responsables implicados de cada uno de los centros. La tipología de actividad, el número de sesiones y la duración de estas varía en función de cada uno de los colegios. De igual manera, su organización ha sufrido lógicas modificaciones a lo largo de cada uno de los cursos escolares en lo que este proyecto se ha ido llevando a cabo.

Fase 5. Evaluación del proyecto: informes de los centros: Una vez finalizada la dinamización de los recreos, durante el mes de junio, cada uno de los centros escolares hace llegar a la Facultad de Ciencias Humanas y de la Educación un informe 
con una evaluación tanto cuantitativa como cualitativa de la intervención. Estos informes nos permiten recabar datos del número de participantes, del número de alumnos implicados y de los puntos fuertes y puntos débiles de cada una de las actuaciones en los diferentes centros.

Fase 6. Difusión del proyecto: Esta experiencia se difunde a través de diferentes canales informativos dentro de Jornada divulgativas, publicaciones específicas a nivel educativo o foros de formación permanente del profesorado. Dentro de esta fase de difusión se contempla avanzar en estrategias de reflexión conjuntan que permitan mejorar el diseño y puesta en funcionamiento de este proyecto educativo.

\subsection{Evaluación del proyecto y prospectivas de futuro}

En términos cuantitativos, el proyecto permite intervenir de manera activa sobre unos 300 alumnos y alumnas de Educación Primaria a lo largo de un prolongado espacio de tiempo, tanto en el primer como en el segundo cuatrimestre de clase, lo cual se podría tildar de muy positivo. La dinamización de los recreos para este alumnado se consigue gracias a la participación de unos 60 alumnos y alumnas de Magisterio en Educación Primaria, lo cuales a su vez también están experimentando ineludiblemente un proceso formativo satisfactorio como ciudadanos críticos, activos y responsables con su entorno (Francisco y Moliner, 2010).

A nivel cualitativo los informes de los centros nos arrojan un balance fundamentalmente positivo de la actividad. Si bien hay algún centro que expresa que "el resultado final de la actividad varía en función de la experiencia previa de los alumnos en dinámica de grupos de niños (campamentos y similares)", la mayoría de ellos siguen "valorando muy positivamente la actividad" y "destacando el interés de los alumnos de prácticas" para seguir llevando a cabo la dinamización de los recreos. Los centros confirman la orientación del proyecto, el cual permite fomentar "aspectos cooperativos frente a situaciones más competitivas que se están creando en el día a día". Todo ello gracias en parte a "la buena disposición y alto grado de implicación de los alumnos y alumnas de Magisterio para diseñar, organizar y llevar a cabo la actividad". Hasta la fecha actual la valoración del proyecto en líneas generales se considera positiva y año tras año se sigue trabajando para mejorar aquellos aspectos mejorables que se detectan en la dinámica de evaluación entre los centros escolares.

Las prospectivas de futuro de este proyecto resultan halagüeñas teniendo en cuenta el importante número de participantes, tanto de alumnado como de profesorado, y su 
implicación en el desarrollo y mejora de los aspectos organizativos claves del proyecto. Su principal camino de desarrollo es la coordinación inter-centros y en consecuencia el enriquecimiento mutuo en la dinamización de los recreos donde se promuevan valores de cooperación e inclusión entre los alumnos y alumnas de Educación Primaria. El proyecto busca fomentar estrategias de diálogo y participación conjunta que favorezcan el establecimiento de sinergias entre diferentes profesionales de los centros educativos de la ciudad de Huesca.

\subsection{Conclusiones}

Los recreos cooperativos e inclusivos suponen un proyecto colaborativo entre Universidad y centros educativos de Educación Primaria que permite el trabajo coordinado de ambas instituciones en la promoción de espacios de recreo que favorezcan y predispongan al conjunto del alumnado a experimentar sensaciones satisfactorias a partir del abordaje de estrategias lúdica de carácter cooperativo e inclusivo.

\section{Bibliografía recomendada}

Bundy, A., Engelen, L., Wyver S, Tranter P, Ragen J, Bauman A, Baur L, Schi1ler W, Simpson JM, Niehues AN, Perry G, Jessup G y Naughton G. (2017). Sydney Playground Project: A Cluster-Randomized Trial to Increase Physical Activity, Play, and Social Skills. 87(10):751-759. doi: 10.1111/josh.12550.

Caro, H.E., Altenburg, T.M., Dedding, C., y Maidy, M.J. (2016). Dutch Primary Schoolchildren's Perspectives of Activity Friendly School Playgrounds: A Participatory Study. Int J Environ Res Public Health. 13(6): 526. doi: 10.3390/ijerph13060526.

Cotton, W., Dudley, D., Jackson, K., Winslade, M., y Atkin, J. (2017). Rationale and protocol paper for the Healthy Active Peaceful Playgrounds for Youth (HAPPY) study. BMC Public Health. 26;17(1):520. doi: 10.1186/s12889-0174445-y.

Francisco, A. y Moliner, L. (2010). El Aprendizaje Servicio en la Universidad: una estrategia en la formación de ciudadanía crítica. REIFOP, 13 (4), 69-77.

Mayfield, C.A., Child, S., Weaver, R.G., Zarrett, N., Beets, M.W., y Moore, J.B. (2017). Effectiveness of a Playground Intervention for Antisocial, Pro-social, and Physical Activity Behaviors. J Sch Health. 87(5):338-345. doi: 10.1111/josh.12506. 
6

\title{
Campus oportunidades para la in- clusión: oportunidades para el aprendizaje de servicio (ApS).
}

\author{
Elías Vived, Jorge Arbués y Ana García-Carpintero. \\ Asociación Down Huesca y Universidad de Zaragoza \\ evived@unizar.es
}

\subsection{Introducción}

El aprendizaje servicio constituye un enfoque pedagógico que promueve el compromiso de los estudiantes, los profesores y la comunidad educativa en general con diferentes situaciones sociales, culturales, educativas, medioambientales, etc., en las que se pretende resolver determinadas necesidades, desarrollando proyectos solidarios que facilitan determinados valores, actitudes, procedimientos y conocimientos. Se trata de una práctica educativa que permite conectar con distintas parcelas de la realidad, con el fin de mejorar diferentes situaciones (sociales, educativas, ambientales, culturales, etc.).

El proyecto Campus Oportunidades para la Inclusión es un proyecto pionero que pretende dar respuesta a las necesidades de las personas con discapacidad intelectual, en su etapa adulta, en materia de formación o educación permanente en torno a diferentes dominios (personal, socio-cultural, laboral, etc.), dentro del marco del aprendizaje a lo largo de la vida. Pero a su vez, este proyecto está orientado también a las/os estudiantes de Magisterio, que pueden participar en los diferentes talleres impulsados en el proyecto, ofreciéndoles una formación complementaria en tono a la diversidad, la inclusión y la práctica de estrategias de cooperación y apoyo. 
El proyecto Campus Oportunidades, que se inicia en el curso 2015-16 (aunque ya hay una larga etapa de vinculación de los jóvenes de la Asociación Down Huesca con la Facultad de Ciencias Humanas y de la Educación), ha permitido el impulso de espacios de relación, aprendizaje e innovación y constituye una oportunidad de aprendizaje-servicio para los estudiantes universitarios y para los jóvenes con síndrome de Down o con otras discapacidades intelectuales (SD/DI). El objetivo general del proyecto consiste en proponer acciones formativas que permitan a las personas adultas con SD/DI la posibilidad de adquirir, actualizar, completar o ampliar sus competencias para su desarrollo personal, social y profesional en Universidades, consideradas como escenarios inclusivos y de responsabilidad social. Paralelamente, ofrecer a los estudiantes universitarios la oportunidad de convivir, relacionarse en diversidad y desarrollar competencias eficaces vinculadas la inclusión escolar y social.

Los referentes conceptuales de este proyecto se vinculan con el modelo de apoyos de la Asociación Americana de Discapacidades Intelectuales y del Desarrollo; calidad de vida; autodeterminación y autonomía personal; accesibilidad universal, adaptabilidad de los contextos y diseño para todos; vida independiente, y modelo social de la discapacidad. El contexto curricular viene constituido por los proyectos de vida independiente, configurados por cuatro componentes principales: inclusión social, empleo, vivienda y formación permanente, todos ellos implicados por la autodeterminación de cada persona. Este enfoque actual de intervención con los adultos con DI trata de dar una respuesta sistemática, coherente con los nuevos planteamientos y nuevas normativas, tomando como referencia los proyectos de vida independiente, la autodeterminación y la inclusión social, que son los ámbitos que se van a potenciar en este proyecto.

La Convención internacional de los derechos de las personas con discapacidad (ONU, 2006) plantea, en el punto 5 del artículo 24 (sobre la educación), que los Estados asegurarán que las personas con discapacidad tengan acceso general a la educación superior, la formación profesional, la educación para adultos y el aprendizaje durante toda la vida sin discriminación y en igualdad de condiciones con las demás. A tal fin, los Estados Partes asegurarán que se realicen ajustes razonables para las personas con discapacidad.

Este plan se inscribe dentro de las medidas que garantizan la igualdad de oportunidades y la accesibilidad a entornos inclusivos (en el trabajo, en la vivienda, en la comunidad, en la formación). Esta formación y aprendizajes para adultos con 
$\mathrm{SD} / \mathrm{DI}$ debe indagarse en diferentes contextos comunitarios e inclusivos (universidades, centros culturales, centros de adultos, otras instituciones sociales, etc.). En este proyecto consideramos que la Universidad puede hacer una gran aportación como espacio formativo en el que puedan cooperar jóvenes universitarios y jóvenes con SD/DI, así como técnicos de las Asociaciones y profesores de distintas Facultades. Los beneficios van a ir en doble dirección: hacia los futuros maestros (u otros profesionales afines) y hacia las personas con SD/DI.

El proyecto Campus Oportunidades para la Inclusión se compone de un conjunto de talleres para el desarrollo personal, social y cultural cuyas finalidades básicas son: ofrecer los recursos necesarios para alcanzar el máximo desarrollo posible de las capacidades, potenciar el aprendizaje en cooperación y diversidad, facilitar la convivencia entre jóvenes con SD/DI y estudiantes universitarios y fomentar la inclusión social.

En definitiva, este proyecto pretende dar respuesta a dos realidades importantes: por un lado, complementar la formación de los maestros en su tramo inicial, entrando en contacto directo con la realidad de los jóvenes con SD/DI, compartiendo diferentes actividades con este colectivo de diversidad; por otro lado, indagar nuevos caminos para que estas personas tengan oportunidades y apoyos necesarios que les permitan avanzar en su inclusión educativa, social, cultural y laboral. Tanto estudiantes como las personas con discapacidad se encuentran acompañados por profesorado implicado en los diferentes talleres y por profesionales de las Asociaciones de discapacidad.

\subsection{Objetivos}

- Promover acciones de diseño y planificación de talleres formativos en los que participan personas con SD/DI y estudiantes universitarios.

- Desarrollar en distintas Facultades los diferentes talleres formativos que se proponen y que se hayan diseñado, en los que conviven, cooperan y aprenden juntos tanto jóvenes con SD/DI como estudiantes universitarios.

- Definir estrategias que permitan transferir las experiencias llevadas a cabo en el marco del proyecto Campus en distintas Universidades a otras Universidades y organizaciones de la Red DOWN ESPAÑA.

- Divulgar la experiencia y los proyectos desarrollados en la comunidad, promoviendo acciones de sensibilización (en centros escolares, sociales, culturales, etc.) en las que tengan especial relevancia y protagonismo las personas con $\mathrm{SD} / \mathrm{DI}$. 
- Promover medidas de colaboración con las familias.

- Promover acciones de formación y coordinación con los profesionales, voluntarios y alumnado en prácticas que colaboran en el desarrollo del proyecto.

- Promover acciones de investigación e innovación educativa tendentes a avanzar en una oferta de aprendizaje a lo largo de la vida (en el contexto de la CDPD).

- Elaborar los materiales didácticos precisos para un desarrollo eficaz de las actuaciones propuestas en los diferentes talleres.

\subsection{Antecedentes}

El proyecto Campus Oportunidades para la Inclusión inició su itinerario durante el curso 2015-2016, de la mano de Down España, Down Huesca y Down Lleida. Durante el curso 2016-17 se incorporaron Down Valencia, Down Castellón y Down La Rioja. Aunque el proyecto Campus Oportunidades para la Inclusión inicia su andadura en el curso 2015-16, el inicio de un trabajo sistemático con adultos con discapacidad en la Facultad se sitúa en la investigación, desarrollada por el grupo de investigación EDI (Educación y Diversidad) de la Universidad de Zaragoza, sobre comprensión lectora durante los años 2008-10, creando un Club de Lectura Fácil en la Facultad en 2009 y continúa en el proyecto de innovación educativa Formación para la Autonomía Personal y la Vida Independiente (Díaz y Cols., 2013).

Vived (2015) explica una parte del itinerario realizado por jóvenes con SD/DI en la Universidad de Zaragoza y expone algunas experiencias que pueden considerarse como precursoras del proyecto Campus Oportunidades para la Inclusión. En efecto, en el curso 2011-12 se puso en marcha el proyecto de Formación para la Autonomía y la Vida Independiente (FAVI) para personas adultas con discapacidad intelectual, apoyado por el Centro Nacional de Investigación e Innovación Educativa del MECD, y contando con la colaboración de Down España y otras entidades de la Red Down. Este proyecto perduró hasta el curso 2013-14.

El proyecto FAVI permitió realizar un trabajo interno en las Asociaciones participantes de revisión conceptual, metodológica y operativa, con una orientación clara hacia el desarrollo de la autodeterminación, la inclusión y la vida independiente. Se trataba de reflexionar sobre los contenidos y la ubicación de la formación permanente de adultos con discapacidad intelectual, una formación a lo largo de la vida que podría ubicarse no solo en las asociaciones, sino en los centros de educación 
de adultos, en los centros culturales y sociales, en la Universidad. A través del proyecto de Formación para la Autonomía y la Vida Independiente se pretendió indagar cómo debe articularse la formación permanente de las personas con SD/DI, una formación a lo largo de la vida que responda a sus necesidades de aprendizaje, de relaciones amplias y diversas y de participación e inclusión. El programa FAVI se planteó como un estudio piloto, de innovación educativa, que permitió la reflexión y la investigación-acción sobre actividades llevadas a cabo en las Asociaciones con los jóvenes y con los adultos (Vived, 2013).

En un reciente trabajo, Cabezas y Flórez (2015) presentaron varias experiencias sobre educación postsecundaria de personas con discapacidad intelectual en entornos universitarios. Las experiencias, recogidas en el trabajo señalado, que se están desarrollando en nuestro país son las siguientes:

- Programa PROMENTOR, desarrollado en la Universidad Autónoma de Madrid y promovido por la Fundación Prodis.

- Proyecto DEMOS, puesto en marcha por la Universidad Pontificia Comillas y la Fundación Síndrome de Down de Madrid.

- Conquistando espacios de ciudadanía: programa de formación laboral para personas con discapacidad intelectual en el espacio universitario. Este proyecto se estableció a través de la colaboración de la Asociación Uribe Costa con la Universidad de Deusto.

- Proyecto REDDO. Este proyecto surge de la colaboración entre la Facultad de Educación de la Universidad Complutense de Madrid y el Servicio TIC de Down Madrid.

- Programa CAPACITAS. Este programa se lleva a cabo a través de la colaboración de la Fundación GMP con la Universidad Católica San Antonio de Murcia.

- ESPAZO COMPARTIDO: Programa de formación socio-laboral para personas con discapacidad cognitiva. Se trata de un proyecto de colaboración universidad-empresa-tercer sector, impulsado por la Fundación Universidade da Coruña con la colaboración de la Asociación Down Coruña y la Universidad Andrés Bello de Chile.

- UNIDIVERSIDAD: Talleres para la convivencia, el aprendizaje cooperativo y la inclusión. Proyecto desarrollado en la Universidad de Zaragoza (Facultad de Ciencias Humanas y de la Educación) e impulsado por la Asociación Down Huesca y la Federación Down España. Desde el curso 201516 se denomina Campus Oportunidades para la Inclusión. 


\subsection{Contenido}

El proyecto se desarrolla a través de talleres de desarrollo personal, social y cultural (de 20 a 40 h. de duración cada uno) en los que participan jóvenes con SD/DI y estudiantes universitarios. Los talleres se constituyen en escenarios de participación y aprendizaje e inciden en dos grupos: a) en las personas con discapacidad, a las que se ofrecen oportunidades de participación social y educativas (en línea con una propuesta de aprendizaje a lo largo de la vida); b) en los estudiantes de Magisterio, a los que se pretende ofrecer y organizar experiencias en determinadas situaciones de diversidad.

Dirigidos a jóvenes y adultos con SD/DI y a estudiantes de Magisterio, los talleres constituyen escenarios de convivencia, aprendizaje e inclusión social. Fomentan las relaciones interpersonales en diversidad y se estructuran en grupos cooperativos heterogéneos (configurados por jóvenes con discapacidad y estudiantes universitarios).

Durante el curso 2015/16 los talleres que se llevaron a cabo fueron los siguientes: Taller de fotografía, Taller de poesía, Taller conversacional: facetas de nuestras vidas, Taller de derechos y valores, Taller de periodistas.

Durante el curso 2016/17 los talleres que se plantearon fueron: Taller de fotografía, Taller de lectura y creatividad, Taller conversacional, Taller de educación emocional, Taller de relaciones interpersonales, Taller de inglés.

Durante el curso 2017/18 los talleres que se proponen son: Talleres de expresión plástica, Taller de poesías y relatos, Taller de conversaciones y conferencias, Taller de inteligencia emocional, Taller de voluntariado, Taller de educación sexual, Taller de cine, video y juegos

En cada taller se propone el desarrollo de uno o más proyectos con un planteamiento de proyección y divulgación social de lo que se trabaja en cada uno de ellos. A modo de ejemplo: el taller de fotografía finaliza con una exposición fotográfica; el taller de lectura y creatividad literaria culmina con la publicación de textos de poesías, cuentos o narraciones; el taller de voluntariado y participación social concluye con la participación en sesiones de cuentacuentos en las bibliotecas públicas, o en talleres colaborativos de poesías en centros escolares; el club de periodistas con la colaboración en un programa de radio (Los bandidos de la Hoya en Radio Huesca); etc. 
En estas actividades de proyección y divulgación, los jóvenes con SD/DI son los protagonistas (proyecto Hablamos de nosotros: qué aportamos las personas con síndrome de Down); y en este sentido, un aspecto que conviene destacar es la colaboración que los jóvenes con SD/DI ofrecen en diferentes contextos (p.e., con los alumnos de primaria o secundaria en talleres colaborativos de poesías, organizados en centros escolares); participación en jornadas, ofreciendo una mesa redonda sobre actualidad de las personas con SD/DI; actividades de diálogo estructurado entre grupos de jóvenes con SD/DI y jóvenes universitarios; etc. En estas acciones de proyección también los estudiantes universitarios colaboran con los jóvenes con SD/DI. Y ambos colectivos participan en acciones de aprendizaje servicio y colaboran en su desarrollo.

Los profesores de estos talleres son fundamentalmente profesionales de la Asociación Down y también profesores de la Facultad (en la Facultad de Ciencias Humanas y de la Educación han colaborado 3 profesores). También han colaborado en estas funciones alumnado de Magisterio y otros expertos en distintas disciplinas que voluntariamente han querido participar.

\subsection{Participantes}

Durante el curso 2016-17 el número de jóvenes con SD/DI participantes en los talleres fue de $36 \mathrm{y}$ el número de estudiantes universitarios que participaron en los diferentes talleres fue de 39, de los cuales 7 procedían del Seminario de Atención a la Diversidad y los 32 restantes estaban vinculados a los contenidos prácticos de 3 asignaturas del Grado de Magisterio, llevados a cabo a través de experiencias de aprendizaje-servicio.

\subsection{Metodología}

Los planteamientos didácticos del desarrollo metodológico de las actividades de los diferentes talleres están fundamentados en los siguientes enfoques: a) modelo didáctico mediacional, b) aprendizaje cooperativo, c) modelo de apoyos, d) aprendizaje basado en proyectos y e) aprendizaje-servicio.

A través de este proyecto se ha pretendido incorporar estos planteamientos metodológicos en la formación permanente de adultos con SD, reflexionando sobre contenidos, metodologías, ubicación, apoyos, papel de los adultos con DI en el diseño y desarrollo de su propio currículo, etc. Ello nos lleva a indagar también estrategias 
que faciliten la cooperación interinstitucional (entre Universidades y Asociaciones vinculadas a Down España).

Otro aspecto que nos interesa es la generalización y transferencia de los aprendizajes, y para ello tratamos de vincular escenarios formales de aprendizaje con escenarios no formales e informales. El desarrollo de los conocimientos derivados de la práctica se gestionará a través de metodologías de investigación-acción y a través de proyectos de innovación docente.

Las actividades no solo van dirigidas a los jóvenes con SD/DI y a los estudiantes, sino también a las familias, a los profesionales de las Asociaciones y voluntarios y alumnado en prácticas y a los centros escolares.

\subsection{Resultados}

\section{A. Diseño y desarrollo de talleres educativos}

En los dos primeros años de funcionamiento del proyecto se han diseñado y elaborado distintos talleres que responden a las necesidades, deseos y expectativas de los jóvenes participantes; estos talleres son propuestos por los profesores y también por los propios jóvenes. Cada uno de los talleres pretende desarrollar diversas competencias de los jóvenes participantes (jóvenes con SD/DI y estudiantes universitarios). Con los talleres que se proponen se quiere incidir en una formación para la autodeterminación, la inclusión social y la vida independiente, que contribuya a que estas personas accedan al empleo, participen de forma activa en la sociedad y tengan la oportunidad de emanciparse de sus familias si así lo desean; todo ello con los apoyos (naturales y/o profesionales) que en cada caso precisen.

En estos dos años iniciales de puesta en funcionamiento del proyecto Campus Oportunidades para la Inclusión se ha trabajado en estas direcciones:

a. Concreción definitiva de los respectivos talleres para cada periodo: cinco talleres para el periodo 2015-16; seis talleres para el periodo 2016-17 y se han propuesto para el periodo 2017-18 siete talleres.

b. Concreción de las orientaciones didácticas para cada proyecto educativo que se plantee. Estas orientaciones, además de las características del taller, están determinadas fundamentalmente por los cinco enfoques metodológicos señalados. 
c. Diseño y concreción de las medidas formativas con respecto a las familias, a los técnicos de las asociaciones, a los voluntarios y a los estudiantes en prácticas.

d. Definición de criterios para la elaboración de materiales didácticos. Se pone especial énfasis en la metodología de lectura fácil.

\section{B. Actuaciones de proyección/ sensibilización social: Recitales, Talleres,...}

Las acciones que se han emprendido como proyección y sensibilización, en la mayoría de la cuales el protagonismo recae en las propias personas con síndrome de Down, durante los dos años de duración del proyecto, han sido las siguientes:

- Presentación del proyecto en jornadas, congresos, relacionados con la temática planteada.

- Elaboración de dos capítulos para su publicación en textos educativos.

- Conexión con la Secretaría de Estado de Educación y Formación Profesional, con las Direcciones Provinciales de Educación, con DOWN ESPAÑA, con otras entidades relacionadas, para definir medidas de divulgación: páginas web, cursos, etc.

- Formación a los profesionales de las entidades organizadas en la Red de Vida Independiente de DOWN ESPAÑA.

- Desarrollo de dos jornadas (una en mayo de 2016 y otra en mayo de 2017) de sensibilización en la localidad de Binéfar (Huesca). Estas jornadas, consideradas como oportunidades para innovar en materia de estrategias de proyección y sensibilización, se dirigen a centros escolares (colegios de primaria e IES), centros sociales (organizaciones de discapacidad), culturales (biblioteca municipal), organizaciones empresariales, administraciones públicas y sociedad en general.

- Los jóvenes participantes en el proyecto han realizado charlas y recitales de poesía en numerosos centros educativos y también en algunas organizaciones culturales y en actos sociales. A modo de ejemplo, de enero a julio de 2017 se llevaron a cabo 24 recitales en las siguientes localidades: Huesca, Monzón, Barbastro, Alcañiz, Fonz, Zaragoza y Binéfar.

- Taller colaborativo de poesías desarrollado en el colegio de Grañén, entre febrero y junio de 2017 , en el que participaron 29 alumnos de $5^{\circ}$ y $6^{\circ}$ de primaria, 6 jóvenes con SD y un grupo de estudiantes de Magisterio.

\section{Producción literaria de los jóvenes con SD/DI}


- Poesías de amor y amistad (DOWN ESPAÑA, 2017). Libro de 108 poesías elaborado por los jóvenes de la Asociación Down Huesca

- Poesías de convivencia, cooperación e inclusión (Down Huesca, 2018). Libro de 170 poesías elaborado por los jóvenes de la Asociación Down Huesca en colaboración con alumnos de $5^{\circ}$ y $6^{\circ}$ de primaria.

- Marín, D. (2017). Cosas que me han pasado y algunos cuentos. Huesca: Editorial Pirineos.

- Mur, D. (2017). Los Héroes de la Justicia. Huesca: Editorial Pirineos.

\section{Materiales didácticos de apoyo}

- Programa de Educación en Valores, configurado por tres textos: Orientaciones didácticas / Cuaderno de trabajo grupal / Cuaderno de trabajo personal. Todos estos documentos se encuentran en la página web de DOWN ESPAÑA (nuestras publicaciones/educación).

- Proyecto pedagógico vinculado al texto Poesías de amor y amistad: Orientaciones didácticas / Cuaderno de trabajo grupal / Cuaderno de trabajo personal. Todos estos documentos se encuentran en la página web de DOWN ESPAÑA (nuestras publicaciones/educación).

- Proyecto pedagógico vinculado al texto Poesías de convivencia, cooperación e inclusión: Orientaciones didácticas / Cuaderno de trabajo grupal / Cuaderno de trabajo personal.

- Taller de poesías. Guía didáctica.

\section{E. Producción de estudiantes universitarios:}

Durante el curso 2015-16 se llevaron a cabo 2 TFG (Grado de Magisterio) vinculados a distintas ámbitos relacionados con el proyecto Campus. Durante el curso 2016-17 se desarrollaron 3 TFM (Master: Estudios avanzados de la comunicación y del lenguaje y sus patologías) y 1 TFG 


\subsection{Conclusiones}

A partir de la experiencia desarrollada durante los años precedentes podemos señalar algunas consideraciones relativas al funcionamiento de los talleres y de los jóvenes participantes en los mismos:

A. Marcos de cooperación entre jóvenes con SD/DI y estudiantes universitarios: Un aspecto esencial de los talleres ha sido la organización de grupos cooperativos para abordar las actividades propuestas. En estos grupos cooperativos participan los jóvenes de la Asociación Down Huesca y los estudiantes de Magisterio.

B. Los talleres colaborativos como escenarios ideales para construir competencias de futuros profesores: A través de estrategias docentes de aprendizaje-servicio, a los estudiantes universitarios se les propone compartir con los jóvenes con SD/DI, en grupos cooperativos, el desarrollo de las actividades planteadas en cada taller. De este modo experimentan no solo los contenidos vinculados al dominio de diferentes áreas (lenguaje, creatividad literaria, inteligencia emocional, comprensión lectora, habilidades sociales, inclusión escolar, etc.), sino también contenidos relativos a distintas metodologías como el aprendizaje cooperativo, el aprendizaje basado en proyectos, el enfoque mediacional y el modelo de apoyos.

C. Creatividad, emoción y valores: Son tres ámbitos esenciales en el desarrollo de todas las personas y tres ámbitos que han estado presentes en todo momento en el desarrollo de los talleres. La presencia de las personas con síndrome de Down contribuye a fomentar estas competencias.

D. Protagonismo de los jóvenes con síndrome de Down: Un aspecto esencial del taller es su consideración como oportunidad para fomentar el protagonismo de los jóvenes con síndrome de Down y este objetivo se consigue tanto en el diseño y desarrollo de los talleres como por el hecho de que participen en las acciones de proyección y sensibilización (publicaciones hechas por los propios jóvenes, charlas sobre diferentes facetas de sus vidas, participación en jornadas, recitales, talleres organizados en centros escolares, etc.). Es importante que las personas con síndrome de Down se visibilicen y la sociedad conozca su creatividad, sus anhelos y sus realidades de primera mano, sin mediación.

E. Formación interna e innovación en escenarios inclusivos universitarios como medida de atención a la diversidad: Los talleres del proyecto plantean para los jó- 
venes participantes oportunidades de desarrollo de competencias vinculadas a diferentes áreas de desarrollo (lenguaje oral, lenguaje escrito, relaciones interpersonales y cooperación, habilidades sociales, creatividad y emocionalidad, valores, etc.). Y lo hacen a través de una serie de actividades planteadas a nivel de todo el grupo, pequeños grupos cooperativos (la mayor parte de las actividades) e individuales. Las secuencias didácticas planteadas en cada taller nos parecen innovadoras y eficaces en los procesos desarrollados y en los resultados obtenidos. La puesta en funcionamiento de los talleres en el marco universitario facilita relaciones y cooperación en diversidad e incide en indagar nuevas medidas de atención a la diversidad (diseño universal del aprendizaje, enfoque mediacional, modelo de apoyos, aprendizaje cooperativo, aprendizaje basado en proyectos, aprendizaje-servicio, acción tutorial, seminarios de formación, agrupaciones flexibles, etc.), tan necesarias para las/os futuras/os maestras/os de la escuela inclusiva.

F. Ámbitos de proyección (libros, recitales, etc.): Pero el planteamiento pedagógico no se centra únicamente en el trabajo interno del aula universitaria, sino que promueve la identificación de proyectos que permitan trasladar lo realizado en clase a la comunidad. En este sentido, es importante identificar, en cada taller y desde el principio, proyectos consensuados y vinculados con las temáticas del Taller y en el que se implican todos los participantes: charlas y conferencias, recitales de poesías, elaboración de libros y documentos, exposiciones, etc. Estos proyectos, que reflejan el trabajo llevado a cabo en cada taller, tienen una orientación de proyección de los resultados hacia la comunidad. Estos proyectos permiten el desarrollo de una mayor implicación y compromiso de los alumnos en las actividades propuestas a lo largo de las sesiones de cada taller, que van orientadas al desarrollo del proyecto definido.

G. Contenidos vinculados a los enfoques didácticos: En los Talleres se plantean novedosas secuencias didácticas centradas no solo en los diferentes contenidos de cada taller, sino que se vinculan a distintos enfoques didácticos que son determinantes en las prácticas pedagógicas. En esta experiencia hemos planteado cinco enfoques: modelo de apoyos, enfoque mediacional, aprendizaje cooperativo, aprendizaje basado en proyectos y aprendizaje servicio. El desarrollo de los talleres nos permite establecer algunas reflexiones desde la práctica en torno a dichos enfoques.

H. Marcos de cooperación entre entidades: Responder a las necesidades y retos que supone la organización de un proyecto como el Campus Oportunidades para la Inclusión, que se está experimentado en la Facultad de Ciencias Humanas y de la Educación de la Universidad de Zaragoza, requiere la cooperación de las distintas 
organizaciones implicadas. Así, no solo la colaboración de la Asociación Down Huesca con la Facultad resulta imprescindible para garantizar una eficaz organización, sino que se requiere la participación colaborativa de muchas entidades como Down España y otras organizaciones de la red Down, otras universidades relacionadas con estas asociaciones, centros escolares, el propio MECD, entidades sociales y culturales para la organización de recitales, etc. Es evidente que avanzar en la creación de redes colaborativas en actividades de innovación y sensibilización contribuye al desarrollo de sociedades más inclusivas.

I) Por dónde seguir:

- Consolidar la vinculación de diferentes enfoques didácticos desarrollados en los talleres y que permiten la concreción de secuencias didácticas diversificadas y enriquecidas con nuevas experiencias que permitan seguir añadiendo diferentes componentes y contenidos a la propuesta pedagógica.

- Indagar, de forma sistemática, instrumentos de evaluación que permitan valorar determinadas variables, teniendo presente que dicha evaluación no debe ir dirigida únicamente a los alumnos sino a todos los componentes de los talleres.

- Establecer una ligazón entre los proyectos definidos en cada taller con medidas de sensibilización y profundización de la inclusión escolar y social. Estos proyectos irán dirigidos, fundamentalmente, a la comunidad escolar y a la sociedad en general.

- Profundizar en la cooperación entre facultades, asociaciones y centros escolares, fomentando la propuesta de talleres colaborativos en los centros escolares.

\section{Bibliografía recomendada}

Cabezas, D. y Flórez, J. (Dirs.) (2015). Educación postsecundaria en entorno universitario para alumnos con discapacidad intelectual: experiencias y resultados. Madrid: Fundación Iberoamericana Down 21 y Fundación Prodis.

Díaz, M., González-Simancas, A., Matía, A., Vived, E. y Cols. (2013). Formación para la Autonomía Personal y la Vida Independiente. Guía general. Madrid: Down España y Ministerio de Educación, Cultura y Deporte.

O.N.U. (2006). Convención Internacional de los Derechos de las Personas con Discapacidad. Recuperado de http://www.un.org/disbilities/documents/convetion.pdf. 
Vived, E. (2013). Síndrome de Down y adolescencia: avanzando hacia la inclusión social y la vida independiente. En D. Sánchez-Teruel y M.A. Robles-Bello (Coords.), Transformando problemas en oportunidades: Evaluación e intervención psicosocial y educativa en la infancia y adolescencia. Jaén: Publicaciones de la Universidad de Jaén.

Vived, E. (2015). Unidiversidad: espacios universitarios para la convivencia, el aprendizaje y la inclusión social. Experiencia en Huesca. En D. Cabezas y J. Flórez (Dirs.), Educación postsecundaria en entorno universitario para alumnos con discapacidad intelectual: experiencias y resultados. Madrid: Fundación Iberoamericana Down 21 y Fundación Prodis. 


\title{
El Aprendizaje Servicio: entre la responsabilidad social universita- ria y la solidaridad de las organi- zaciones de la sociedad civil.
}

\author{
Rafael Díaz ${ }^{1}$, María Sierra ${ }^{2}$ y Sergio Gallego ${ }^{1}$ \\ ${ }^{1}$ Facultad de Ciencias Humanas y de la Educación de Huesca \\ ${ }^{2}$ Facultad de Ciencias Sociales y del Trabajo de Zaragoza \\ Universidad de Zaragoza \\ rdf@unizar.es
}

\subsection{Resumen}

Presentamos en este documento la descripción y los resultados obtenidos tras la implementación de un proyecto de aprendizaje-servicio fundamentado en la intervención en el bajo rendimiento académico de alumnos-as de Educación Primaria. La actividad consiste en la realización de apoyo a niños y niñas en su proceso de aprendizaje.

Los resultados obtenidos se orientan en una doble dirección. La actividad trata de beneficiar a dos colectivos: alumnos-as de Educación Primaria con problemas de aprendizaje y dificultad para obtener éxito académico y alumnos-as universitarios del Grado de Maestro que desean ampliar su experiencia aportando sus conocimientos teórico-prácticos durante su actividad estudiantil, al mismo tiempo que son útiles a la comunidad a la que pertenecen. 
Se pretende conseguir un doble objetivo: aumentar la eficacia en el estudio para la obtención de mejores resultados en los alumnos-as de primaria e incrementar la práctica docente en los alumnos futuros maestros aumentando su desarrollo social y personal. Además se favorece el fomento de la solidaridad a través de la implicación de diferentes instituciones públicas y privadas de la comunidad.

La experiencia se ha sometido a observación, recopilando datos y analizándolos a lo largo de estos primeros cuatro años de mantenimiento de la actividad, desde 2014.

Palabras Clave: Aprendizaje-servicio, implementación de aprendizajes, factores de protección, apoyo escolar, responsabilidad social, práctica solidaria.

\subsection{Introducción}

Un estudio realizado a partir de la recopilación y análisis de datos donde se fusiona la implementación de los aprendizajes adquiridos por alumnos-as del Grado de Maestro mediante y la prestación de un servicio a la comunidad para conseguir mejorar los resultados académicos de alumnos-as de primaria, destinatarios del servicio. Al mismo tiempo aglutina en una misma actividad la responsabilidad social de una institución educativa, la Universidad de Zaragoza y la práctica de la solidaridad de una organización no lucrativa, la Asociación Ibón de Drogodependencias, que se plantea como objetivo incidir en el fracaso escolar como factor de riesgo de las adicciones, incidiendo de manera preventiva antes de la adolescencia.

El proyecto se lleva a cabo con una metodología basada en aprendizaje- servicio. El aprendizaje-servicio se define como "una estrategia de enseñanza y aprendizaje que integra un servicio a la comunidad significativo, con instrucción y reflexión para enriquecer la experiencia de aprendizaje, enseñar responsabilidad cívica y fortalecer a las comunidades" (National Service Learning Clearing Hause, s.f. En Woolfolk, A.E 2010: 335). Y como afirman Martín, Rubio Batlle y Puig, (2010: 20) "es una propuesta educativa que combina procesos de aprendizaje y de servicio a la comunidad en un solo proyecto bien articulado, donde los participantes aprenden a trabajar en necesidades reales del entorno, con la finalidad de mejorarlo"

La actividad se realiza en Sabiñánigo, uno de los núcleos más importantes del sector industrial localizado en el Alto Gállego, la comarca pirenaica más industrializada de la provincia de Huesca. 
Los ámbitos desde los cuales se lleva a cabo esta actividad son el educativo y el comunitario, involucrando a diferentes instituciones para llevar a cabo una intervención conjunta que favorezca la implicación de distintos mediadores sociales que actúan en la comunidad, tutores de los colegios, psicólogos, políticos etc... En el proyecto participa la dirección y profesorado de los Colegios de Educación Infantil y Primaria de Sabiñánigo: CEIP Monte Corona, CEIP Puente Sardas y Colegio Santa Ana.

Tiene el apoyo de la Concejalía de Educación del Ayuntamiento de Sabiñánigo, a partir de su presentación en el Consejo Escolar Municipal.

Los colegios facilitan la transmisión de información a los padres sobre el servicio, que sus hijos tienen la posibilidad de recibir. Los tutores informan sobre las necesidades concretas de apoyo académico de sus alumnos-as, respecto a las materias en las que es necesario un apoyo extraordinario.

Este proyecto trata de incidir en la prevención de las drogodependencias. El modelo que sirve de base a esta intervención, lo constituye la teoría del riesgo (Beck, 1998) y su idea central: trabajar con factores y conductas de riesgo y actuar sobre ellos tratando de prevenir las posibles consecuencias dañinas para la salud (Corona y Peralta, 2011) mediante el desarrollo y aplicación de factores de protección.

\subsection{Descripción Del Proyecto}

Un proyecto que tiene como punto de partida el diálogo entre la Universidad y la Sociedad. Sus inicios son consecuencia de la observación de la realidad por parte de dos instituciones, una pública y otra privada. Tras la constatación de unas necesidades sociales y educativas deciden implicarse para modificar esa realidad y tratar de mejorarla implementando los recursos que tienen al alcance.

Desde la Universidad de Zaragoza, esta actividad ha sido coordinada por el Doctor Rafael Díaz Fernández, profesor de la asignatura Psicología de la Educación, del Grado de Maestro de la Facultad de Ciencias Humanas y de la Educación (Campus de Huesca) y desde el Centro de Prevención y Promoción de la Salud de la Asociación Ibón de Drogodependencias por la Doctora María Sierra Berdejo.

Se detectan una serie de necesidades, dos de ellas constituyen el objeto de este proyecto basado en la metodología de aprendizaje-servicio: la necesidad de poner en práctica los conocimientos teórico-prácticos adquiridos en la universidad por un grupo de alumnos-as con vocación docente y de servicio (Arranz, 2015), por otra 
parte, la necesidad de apoyo de alumnos-as de primaria para afianzar sus conocimientos y prevenir el fracaso escolar (Fernández Enguita, 2010), añadiendo factores de protección (Díaz y Sierra, 2008) como es la satisfacción personal y familiar que generan los buenos resultados académicos y con ello disminuyendo el riesgo de adicciones en la adolescencia.

Estas necesidades, no tan manifiestas, que subyacen a esta iniciativa se fundamentan en el reconocimiento científico de que uno de los factores de protección frente al consumo de drogas, lo constituye el éxito académico en primaria y secundaria. La Asociación Ibón de Drogodependencias con sus veinte años de dedicación a la prevención dirigida a niños-as y jóvenes, constata también este hecho, a través de su centro de atención y prevención a las adicciones.

La experiencia se inició en el curso 2013/2014, hace cinco años. En su quinto año consecutivo de ejecución, es una actividad totalmente sistematizada y esperada por quienes participan en ella: profesores de los C.E.I.P., padres, alumnos-as de primaria y alumnos-as universitarios.

La actividad se realizaba los viernes de $17 \mathrm{~h}$ a $19 \mathrm{~h}$ y los sábados de $10 \mathrm{~h}$ a $12 \mathrm{~h}$ y de16 a $18 \mathrm{~h}$ horas, desde finales de enero hasta finales de mayo, y siempre tras los primeros resultados de la primera evaluación. Se impartió en espacios cercanos a los domicilios de los niños-as. Se disponía para ello de tres espacios diferentes: aulas de formación de la Asociación Ibón y aulas del Ayuntamiento de Sabiñánigo (Casa de la Cultura de Puente Sardas y Centro de Educación de Adultos).

Mediante instrumentos de recogida de datos como la entrevista y el cuestionario a los profesores-tutores, a los padres y a los estudiantes-tutores, y técnicas como la observación directa y el seguimiento de la actividad hemos obtenido los resultados que presentamos a continuación.

\subsection{Resultados}

En aquellos-as niños-as que realizaron la actividad de manera continuada, se produjo un cambio en las calificaciones, aumentando éstas, con respecto a las obtenidas en la primera evaluación.

Se constató un importante aumento de la motivación hacia las tareas escolares en los niños-as y mejora en la actitud ante el aprendizaje. 
La atención individualizada les ha ayudado a sentirse protagonistas de su aprendizaje, aumentando su interés por aprender, participar, trabajan con mayor agrado y aprender disfrutando.

Los padres han manifestado su satisfacción y siguen demandando el servicio cada año desde el inicio.

Los profesores esperan cada año que continúe la actividad ya que observan la utilidad que representa para sus alumnos-as.

Acercamiento a la realidad social a través de la implicación en la comunidad entre diferentes miembros e instituciones públicas y privadas.

Desarrollo de estrategias de intervención en la dinámica de interacción profesoralumno dentro de una amplia diversidad cultural.

Potenciación de la capacidad de responsabilidad derivada del rol social cómo miembros de una comunidad.

Conocimiento de las posibilidades de comunicación en el aula y experiencias de diálogo con madres y padres.

Adquisición de un conocimiento práctico sobre las necesidades educativas y dificultades de aprendizaje de los alumnos-as de primaria.

Ampliación de la experiencia respecto a la organización, distribución de tiempos y adaptación a las necesidades diferentes de cada niño-a.

Constatación y reconocimiento de las ventajas de la atención individualizada. El trabajo en grupos reducidos, máximo 3 ó 4 alumnos-as presenta mayores ventajas para ambos colectivos.

Se ha comprobado la utilidad de los descansos para facilitar la recuperación y el mantenimiento de la atención.

\subsection{Conclusiones}

El Aprendizaje y Servicio Solidario constituye un proyecto educativo de reconocida 
utilidad social que además aporta el camino hacia la educación ciudadana en contextos mixtos, formales y no formales, donde se desarrollan acciones de solidaridad y al mismo tiempo de aprendizajes donde todas las partes reciben y dan algo que al otro le falta.

Por otra parte, el Aprendizaje y Servicio Solidario tiene en sí mismo el valor de activar y capacitar para la adquisición de competencias y habilidades para la vida y nos enseña a todos-as los que participamos a mejorar nuestra práctica de trabajo en equipo. Al mismo tiempo facilita la interacción entre las instituciones para mejorarla realidad, involucrando para ello a los diferentes miembros de la comunidad, y generando comunidades educadoras.

Con este proyecto hemos conseguido al mismo tiempo, incrementar la formación en valores sociales e individuales, fortalecer la responsabilidad social de diferentes instituciones y prestar un servicio a miembros de la comunidad, niños-as con dificultades para obtener éxito académico, por diferentes motivos. Se consigue, además, un beneficio mutuo entre alumnos-as universitarios y alumnos-as de educación primaria y esperamos también un futuro más saludable para las nuevas generaciones de adolescentes.

\section{Bibliografía recomendada}

Arranz. P, (2015). El Aprendizaje-Servicio en la formación de Docentes. En Vázquez, S., Liesa, M., Revilla, A. (coords.), El Aprendizaje-servicio: Diálogo Universidad y sociedad (p. 8). Facultad CC.HH. y de la Educación. Universidad de Zaragoza.

Beck, U. (1998). La sociedad del riesgo. Madrid. Paidós.

Corona, F., y Peralta, E. (2011). Prevención de conductas de riesgo. Rev. Med. Clin. Condes, 22(1) 68-75.

Díaz, R y Sierra, M. (2008). Análisis teórico sobre prevención de drogodependencias en el marco de la educación para la salud: factores de riesgo y de protección. Acciones e Investigaciones Sociales. Zaragoza.

Fernández Enguita, M. (2010). Fracaso y abandono escolar en España. Fundación La Caixa. Barcelona.

Martín, X., Rubio, L., Batlle, C. y Puig, J. M. (2010). ¿Qué es aprendizaje servicio? En X. Martín y L. Rubio (eds.) Prácticas de ciudadanía. Diez experiencias de aprendizaje servicio. Barcelona, Octaedro.

Woolfolk, A. E (2010). Psicología Educativa (11 $\left.1^{\mathrm{a}} \mathrm{ed}\right)$. (p.335.). Mexico: Prentice-Hall Hispanoamericana. 


\title{
8 \\ Propuesta futura de ApS: cyberbullying e inteligencia emocional.
}

\author{
Eva M. Lira, Mara Socolovski y Ana Moreno \\ Universidad de Zaragoza \\ evalira@unizar.es
}

El cyberbullying es un fenómeno que está recibiendo un incremento de atención por parte de las instituciones, los investigadores, los docentes, y los medios de comunicación entre otros, debido a sus consecuencias potencialmente devastadoras (Wong, Cheung y Xiao, 2018). En el informe de 2016 realizado por el Cyberbullying Research Center de los Estados Unidos, se encontró que el 33.8\% de los alumnos de entre 12 y 17 han sido víctimas en algún momento de su vida, y el 11.5\% han estado involucrados de un modo u otro en el fenómeno. A nivel europeo, la OMS (2016) advierte que España está a la cabeza en cyberbullying, en el ranking (7/42) que incluye a 42 países de Europa y América del Norte. En España, tal y como se extrae del estudio que realizó Moreno (2016) para la OMS a 31.061 alumnos de 408 centros de todas las comunidades autónomas, el bullying tradicional ha dado paso al cyberbullying. En este sentido, uno de los resultados más relevantes de Moreno (2016), además de la disminución del bullying en pro del cyberbullying, fue el doble rol que están asumiendo los alumnos en los centros, donde son simultáneamente víctimas y acosadores, entrando en una espiral de violencia en las aulas. Más concretamente, en Aragón se han realizado diversos estudios de bullying y cyberbullying durante los años 2006, 2011 y 2017, los cuales dibujan un panorama esperanzador, lo cual pone de manifestó los resultados beneficiosos, derivados del interés que el fenómeno está suscitando en los últimos años. 
Por lo tanto, aunque algunos medios se hacen eco de que el fenómeno ha incrementado en un $240 \%$ en España en los últimos dos años (Fundación de Ayuda a Niños y Adolescentes en Riesgo, ANAR, 2017) en cierto modo este resultado, aunque alarmante, puede estar indicando que el fenómeno ha dejado de estar silenciado, lo cuál es el primer paso para poder eliminarlo o neutralizarlo. A pesar de ello, el bullying es una triste realidad desde hace años, sólo en 2016 la Fundación ANAR (Ayuda a Niños y Adolescentes en Riesgo) registró 1.207 casos de acoso escolar reales, lo que supone un aumento del $87,7 \%$ en el último año.

Tradicionalmente el fenómeno de bullying se consideraba típicamente masculino (Buelga y Pons, 2012), la investigación apunta a que los niños suelen acosar de una forma más directa (Sharma, Kishore, Sharma y Duggal (2017) y las niñas de una forma más indirecta o ciberbullying (Garaigordobil, 2011). Otros estudios apuntan a un rol de acosador offline de los chicos frente a una victimización online de las chicas (Beckman, Hagquist y Hellström, 2013), o se atribuye el rol de acosador a los chicos y el de víctimas en chicas (Calmaestra, 2011).

Por otro lado, el acoso escolar o bullying se cobra la vida de 200 mil jóvenes y niños al año entre personas de 6 a 21 años, según un informe conjunto realizado por la Organización Mundial de la Salud (OMS) junto a la ONG Internacional Bullying Sin Fronteras (2017), siendo los más frecuentes, la ansiedad, depresión, trastorno psicosomático, pudiendo llegar estas consecuencias incluso al suicidio. Por tanto, entre el 70 y $80 \%$ de las víctimas de acoso desarrollan un trastorno mental tales como ansiedad, depresión y quejas psicosomáticas (Empresa de medios de comunicación en Palma de Mallorca, EFE, 2016). También el agresor, muestra tener conductas agresivas, consumir determinadas sustancias o abuso de las mismas, y/o desarrollar trastornos de personalidad. Así, aunque la urgencia viene dada por la prevención secundaria centrada predominantemente en las víctimas, los agresores también son menores de edad, debido a que el cyberbullying es una violencia entre iguales, y es relevante poner énfasis en la prevención tanto primaria como secundaria para eliminar de forma efectiva el fenómeno.

Por lo tanto, esta propuesta futura de aprendizaje de servicio (ApS) se fundamenta en cierto modo en la cifras de alarma social en torno a la prevalencia de este devastador fenómeno y en los resultados de investigación derivados de los Trabajos Fin de Master (TFM) llevados a cabo por alumnas de la facultad de Ciencias Humanas y de la Educación de la Universidad de Zaragoza, cuyos resultados ponen de manifiesto que la inteligencia emocional (IE) es capaz de aminorar las consecuencias en estrés de la 
victimas de bullying y por otro lado que las agresoras chicas manifiestan más quejas psicosomáticas que los agresores chicos. Esto puede ser debido a que las chicas tienen mayores niveles de IE, y esta capacidad de empatía o comprender como se siente la víctima podría ser el primer paso para que disminuyan e incluso desaparezcan las conductas de acoso. Así pues, la inteligencia emocional parece tener un rol crucial en la prevención primaria y secundaria, que podría ayudar a las víctimas de acoso a gestionar las devastadoras consecuencias del mismo. Tal y como manifestó Fernández Berrocal (2017), que junto con Bisquerra son los dos autores más reconocidos en España en torno a IE, en el II Congreso Internacional de Inteligencia Emocional y Bienestar (CIEB), que se celebró en Zaragoza el pasado mes de mayo, los profesores que llevan a cabo programas de entrenamiento de inteligencia emocional, para llevarlo a cabo de manera efectiva, han de ser previamente inteligentes emocionalmente. Por lo tanto, el entrenamiento en maestros resulta crucial para que ellos puedan ser entrenadores de alumnos inteligentes emocionalmente capaces de crear un clima de bienestar cuyo objetivo sea nivel de bullying cero, que es el único nivel aceptable.

Además, recientemente la universidad de Zaragoza indicó que los maestros debían ser instruidos previamente para poder instruir a los niños. En este sentido se solicitó y ha sido concedido a la facultad de Ciencias Humanas y de la Educación De Huesca un proyecto de innovación docente cuyo objetivo es la mejora de competencias emocionales de los maestros de infantil y primaria para el año académico 2017-2018. Finalmente, otro de los aspectos que sustentan esta propuesta de ApS futura, es el proyecto de convivencia en Aragón contra el acoso escolar en el que también participa profesorado de la facultad de Ciencias Humanas y de la Educación de Huesca que el Gobierno de Aragón junto con la Universidad de Zaragoza están llevando a cabo desde el año 2006, 2011 y 2017 y en este momento se están analizando los datos del 2017.

García y Cotrina (2015), realizan una articulación de la Responsabilidad Social en el ámbito universitario del aprendizaje de servicio (ApS), ya apuntado por diversos autores tales como Battle (2013), cuyas propuestas en el ámbito educativo son relevantes en todas las etapas desde la educación infantil hasta la universidad, pero que centradas en el contexto universitario resultan cruciales sobre todo en la formación inicial del profesorado (García y Cotrina, 2012; García y Sánchez, 2016). En este sentido, García y Calleja (2017) ponen de manifiesto la relevancia de la adquisición grupal de las habilidades en inteligencia emocional en la fase inicial de formación universitaria, desarrolladas a través de experiencias de ApS, permitiendo este tipo de aprendizaje, ser parte activa de su propio proceso de aprendizaje y su relevancia en 
Capitulo 8. Propuesta futura de ApS: cyberbullying e inteligencial emocional.

la articulación de la responsabilidad social universitaria (García y Cotrina, 2015).

\section{Bibliografía recomendada}

Fernández-Berrocal, P y Ruiz-Aranda, D. (2008). La inteligencia emocional en la educación. Revista electrónica de Investigación Psicoeducativa, 6, 421-436.

Garaigordobil, M. (2011). Prevalencia y consecuencias del ciberbullying: una revisión. Universidad de País Vasco: España.

García, M. G., y Calleja, L. S. (2017). El aprendizaje servicio y el desarrollo de las competencias emocionales en la formación inicial del profesorado. Contextos Educativos. Revista de Educación, 20, 127-145.

Ortega, R. (2010). Treinta años de investigación y prevención del bullying y la violencia escolar. En R. Ortega (Ed.), Agresividad Injustificada, Bullying y Violencia Escolar (pp. 15-30). Madrid: Alianza Editorial. 


\title{
9
}

\section{El rol de la inteligencia emocional (IE) y la autoeficacia (AF) en la relación entre el ciberbullying "victimización" y el estrés, la an- siedad y la depresión.}

\author{
Loreto Tomey, Eva M. Lira, Mara Socolovski y Ana Moreno \\ Universidad de Zaragoza \\ evalira@unizar.es
}

Resumen

El objetivo de este trabajo es analizar s El rol de la inteligencia emocional [claridad emocional (CE), atención emocional (AE) y reparación emocional (RE)] y la autoeficacia (AF) en la relación entre el ciberbullying "victimización" (CB) y el estrés, la ansiedad y la depresión. Para ello, se analizó una muestra constituida por 37 participantes de $6^{\circ}$ de Educación Primaria, en un centro público de Huesca. Los resultados mostraron que el $\mathrm{CB}$ correlacionó negativamente con la $\mathrm{CE}$ y positivamente con ansiedad y edad. La AF correlacionó positivamente con la IE general y con CE y RE) y de forma negativa con el estrés, la ansiedad y la depresión. La AE correlacionó positivamente con la RE, el estrés, la ansiedad y la edad. La CE correlacionó de forma negativa con la edad. La RE estuvo negativamente relacionada con la depresión. Además, a mayor estrés, mayor ansiedad y depresión, y además 
los participantes de mayor edad tienen más estrés. Por último la ansiedad correlacionó de forma positiva con depresión. Por otro lado, la media de las mujeres en AF, IE global, CE y RE fue mayor que en los hombres, y la media de CB, AE, estrés, ansiedad y depresión fue mayor en hombres que en mujeres, pero no de forma significativa. Los estudiantes con alta IE tuvieron niveles más bajos de CB, estrés depresión y mayores niveles de AF y ansiedad. No obstante, esta diferencia solo fue significativamente para AF. Las personas con alta AF tuvieron niveles más bajos de CB, estrés, depresión, y ansiedad y mayores de IE global, AE, CE, y RE. No obstante, esta diferencia solo fue significativamente diferente para la variable de CB, IE, CE, y RE. También se encuentra una relación curvilínea en forma de U invertida entre edad y CB. La IE amortigua los efectos de la CB en el estrés. La relación entre $\mathrm{CB}$ y ansiedad es menos fuerte en las personas con alta IE, aunque este efecto modulador no resultó ser significativo. No se encontraron resultados significativos para la relación entre CB y depresión modulada por IE.

Palabras clave: ciberbullying "victimización”, inteligencia emocional, autoeficacia, estrés, ansiedad, y depresión

\subsection{Introducción}

Las Tecnologías de la Información y la Comunicación (TICs) han cambiado la forma en la que nos relacionamos con los demás (Fernández, Martínez y García, 2017). Los niños, adolescentes y jóvenes acceden a ellas cada vez a edades más tempranas, utilizándolas en diferentes contextos para iniciar y mantener nuevas relaciones (Pérez y Vicario-Molina, 2016). No obstante, a pesar de las múltiples ventajas atribuidas a las TICs, una mala utilización de las mismas puede tener consecuencias negativas, que podrían agravarse en la pre-adolescencia y la adolescencia (Carbonell, Fúster, Chamarro y Oberst, 2012; Tkhostov, Emelin y Rasskazova, 2014). Tal y como indican Carbonell, Castellana y Oberst (2010) un uso excesivo de Internet, que puede tener consecuencias negativas especialmente a personas con necesidades emocionales especiales, jóvenes y adolescentes. Así, Castellana, Sánchez-Carbonell, Graner y Beranuy (2007) sugieren que un uso inadecuado entre escolares podría derivar en desadaptaciones conductuales. En este sentido, la Asociación para Investigación de los Medios de Comunicación (AIMC, 2016) indica en su último informe que el tiempo de conexión ha aumentado en más de 4 horas de media. La mayoría de los niños, preadolescentes, adolescentes y jóvenes tienen en sus casas acceso a internet, ya sea desde el móvil, tablet u ordenador (INE, 2014) con el que pueden jugar y entretenerse, pero también pueden acceder a Internet con 
otros fines. Si los jóvenes y adolescentes han sido educados desde pequeños en la correcta utilización de las tecnologías las consecuencias negativas podrían no darse, pero deben saber qué es lo que se pueden encontrar en Internet y lo que deben y no deben hacer con estas herramientas. En el estudio acerca del equipamiento y uso de las TICs en los hogares españoles llevado a cabo en 2011 e informado en 2012 (INE, 2012) se obtuvieron los siguientes datos: el 91.5\% de los jóvenes entre 16 y 25 años accedieron por lo menos una vez a la semana a Internet en los tres meses previos al estudio, datos que se asemejan mucho a los de un rango de edad más bajo, de 12 a 15 años. El porcentaje de niños de 12 años que habían accedido a internet en las mismas circunstancias que los anteriores era de un $87.5 \%$. Garmendia, Garationandia, Martínez y Casado (2011) indican que la media de tiempo que los niños de 15 años invierten al día en internet es de 71 minutos aproximadamente, aumentando el tiempo en 20 minutos más diarios, a los 16 años. Estos datos son referidos a niños y adolescentes sin tener en cuenta el género. Sánchez y de Frutos (2012), muestran diferencias de tiempo y de uso en función del género en los adolescentes en la utilización de las redes sociales, las diferencias de tiempo no son tan significativas como las de uso. Sin embargo, Viñas (2009) no encuentra a penas diferencias entre hombres y mujeres, aunque los porcentajes sean diferentes. No obstante, Sanchez-Martínez y Puime (2010) mostraron un mayor porcentaje de mujeres que usa internet, concretamente el $94.5 \%$ frente al $91.3 \%$ de hombres. En el año 2012, las niñas lideraban en el acceso a internet con una penetración del $60 \%$ frente a un $54 \%$ de los niños, no obstante aunque la brecha se mantiene, es algo menor, 65,5\% para las niñas y $63,1 \%$ para los niños (AIMC, 2017). Actualmente las actividades que llaman la atención de los adolescentes son sobretodo relacionadas con el uso de internet y con los videojuegos (Viñas, 2009), dada esta actividad, la preocupación va aumentando por las repercusiones que puede tener un uso excesivo de internet en la condición de un adolescente. Un uso continuado y compulsivo de internet puede afectar a sus vidas a corto y largo plazo (Widyanto y Griffiths, 2006). En la clasificación de adicciones, la de internet, se pude englobar dentro de dos grupos por la diversidad de términos con la que la nombran los investigadores, Young (1998) la enmarca en una adicción no química o psicológica. Young (1999) habla de un trastorno del control de impulsos concretado en el juego patológico. Viñas Poch en su artículo uso autoinformado de internet en adolescentes: perfil psicológico de un uso elevado de la red (2009) habla de las adicciones a internet, con datos de diferentes estudios y propone diferentes cifras para determinar cuándo se podría hablar de adicción; en el año 2000, Morahan-Martin y Schumacher hallaron un promedio de 8,5 horas en personas consideradas patológicas, más adelante Estalló (2001) determinó que entre 7 y 14 horas semanales pueden 
ser adaptativas para el uso de internet. Aunque otros autores como Shapira, Goldsmith, Keck, Khosla y McElroy (2000) concluyeron que con un promedio de entre 3-4 horas diarias, se estaría hablando de un uso excesivo de internet, que puede obstaculizar la actividad social/escolar del individuo. Tal y como hemos indicado previamente los españoles se conectan a los medios un promedio de 4 horas y media a internet por motivos no profesionales en concreto 246 minutos (AIMC, 2016). En el estudio llevado a cabo por Jiménez, Orenes y Pais (2012) los jóvenes dedican dos horas al día a internet. Por lo tanto, si tenemos en consideración que a partir de 3 horas podría considerarse un uso excesivo de internet, estamos ante un panorama de dimensiones desconocidas hasta el momento cuyas consecuencias deberían ser analizadas, ya que este aumento en el uso de internet, continua imparable en nuestros días. También, se observan transformaciones en cuanto al dispositivo líder de conexión a internet. Así, tal y como indica el AIMC (2017) el smartphone se afianza como dispositivo líder en conexión a internet (85\%), seguido por el ordenador portátil $(82 \%)$ y la tablet $(72 \%)$. Por otro lado, Castellana, Sanchez Carbonell, Graner y Beranuy (2007) exponen en su trabajo que el uso de Internet que hace el adolescente puede hacerse problemático y afectar al correcto desarrollo de la vida diaria cuantas más horas esté conectado. En los últimos estudios que se han realizado acerca del uso de las TIC's en adolescentes muestran que un $90 \%$ de ellos las usa principalmente para la comunicación on-line pero debido a las actitudes que los menores están tomando con las TICs se están exponiendo a un escenario de numerosos riesgos con efectos emocionales y sociales perjudiciales (Marciales y Cabra, 2011; Van den Eijinden, Meerkerk, Vermulst, Spijkerman y Engels, 2008; Young, 1998), que si no saben manejar, pueden desembocar en situaciones poco agradables para ellos. Este creciente acceso a la tecnología electrónica de los menores, y la participación de estos en distintas redes sociales, que generalmente son para adultos, han favorecido una nueva tipología de violencia entre iguales, el $\mathrm{ci}$ berbullying o ciberacoso, y que constituye una amenaza para la salud individual y comunitaria de los niños, pre-adolescentes y adolescentes (Kiriakidis y Kavoura, 2010).

Cualquier niño, niña o adolescente víctima o testigo de un acto violento, además de sufrir la consecuencia dolorosa inmediata, interioriza una experiencia negativa mediante la cual aprende el mecanismo de la conducta violenta (Garaigordobil, 2011, p.234).

Las graves consecuencias del fenómeno de acoso es uno de los motivos por los que las conductas de acoso y maltrato entre iguales es un tema de preocupación social, 
ya que va creciendo cada día un poco más. Además, no solo las consecuencias afectan a las víctimas y a los agresores en la etapa de adolescencia y juventud sino que pueden dejar graves secuelas para su vida adulta. Algunas de las consecuencias reales de las agresiones virtuales $(C B)$, pueden ser muy destructivas para las personas que son víctimas, es más, las consecuencias pueden llegar hasta el suicidio en el peor de los casos al igual que en el bullying, y se debe tener en cuenta que cada día hay más casos que acaban de esta forma (Schwartz, 2010). Por supuesto, el suicidio es la consecuencia más extrema que podemos encontrar en los casos de acoso escolar, pero antes de llegar a este punto se pueden observar muchas otras consecuencias a partir de conductas de $C B$, las víctimas pasan por situaciones muy devastadoras para la estabilidad mental de una persona, y por tanto es devastador a nivel personal, social, familiar y académico entre otros.

Tal y como recoge la guía A.S.I para prevención del CB (2012) las víctimas de agresiones sufren: depresión y otros problemas psicológicos, el desarrollo de una autoestima más baja, volviéndose desconfiados y vulnerables y malas relaciones en su entorno familiar (p. ej., pudiendo culpar a este entorno de una falta de apoyo). Las consecuencias pueden ser cada vez más graves dependiendo del tipo de acoso que la persona esté sufriendo. En algunos casos la víctima comienza a consumir sustancias nocivas, para evadirse de la situación en la que se encuentra, además puede comenzar una etapa de absentismo escolar, o incluso puede llegar a convertirse en agresor en el mundo real y volverse agresivo. Polo del Río, León del Barco, Felipe y Gómez (2013), en su artículo CB en el tercer ciclo de Educación Primaria: variables moduladoras y consecuencias sobre la ansiedad también indican algunas de las consecuencias que sufren las víctimas del $C B$, haciendo hincapié sobre todo en las alteraciones en los comportamientos y en los sentimientos, que pueden llegar hasta la aparición de desórdenes emocionales como estrés, ansiedad y depresión, además de problemas para integrarse en el grupo de iguales debido al aislamiento y a la exclusión social (Polo del Río et al., 2013).

$\mathrm{Y}$ aunque las consecuencias negativas afectan en mayor medida a las víctimas, los otros roles, que se han mencionado anteriormente, las pueden sufrir. Las personas que ocupan el rol de observadores también pueden llegar a desarrollar fuertes sentimientos de culpabilidad, al ver las consecuencias de los actos agresivos en las víctimas. Garaigordobil en su artículo prevalencia y consecuencias del CB: una revisión describe como se sienten las víctimas y los agresores, y las consecuencias que tiene el CB para ambos roles: 
Las ciber-víctimas tienen sentimientos de ansiedad, depresión, ideación suicida, estrés, miedo, baja autoestima, sentimientos de ira y frustración, sentimientos de indefensión, nerviosismo, irritabilidad, somatizaciones, mientras que los ciber-agresores muestran falta de empatía, conducta agresiva y delictiva, superior consumo de alcohol y drogas, dependencia de las tecnologías y absentismo escolar (2011, p.233)

Aunque en los últimos años han crecido mucho los casos de $C B$, no se pueden condenar todas las relaciones sociales que se establecen por medio de las tecnologías a ser adversas para los jóvenes en general. Se debe tener en cuenta que las redes sociales las utilizan millones de jóvenes y que desde el punto de vista de las habilidades y relaciones sociales de los adolescentes, pueden ser también beneficiosas para todos. Kraut, Kiesler, Boneva, Cummings, Helgeson y Crawford (2002) y Valkenburg y Peter (2009) consideran que para los jóvenes que no tienen ningún problema con las habilidades sociales, internet y las redes sociales son una manera más de comunicarse o hacer amistad con otros jóvenes y que usan estas tecnologías sobre todo para acceder a redes sociales y para mandar mensajes instantáneos. Además hay que tener en cuenta que los niños y adolescentes que tienen más dificultades en las habilidades sociales también se pueden aprovechar de las tecnologías para promover relaciones con otros jóvenes sin tener que perjudicar a los otros ni a ellos mismos. Por lo que se debe tener presente que no solo hay que definir lo perjudicial de las TICs sino también los aspectos positivos que proporcionan estas herramientas. Podemos considerar el espacio cibernético un sitio donde los jóvenes con menos habilidades sociales se sienten más desinhibidos que en una situación real, cara a cara con otros individuos (Schouten, Valkenburg y Peter, 2007). Pero siempre se tiene que tener presente que cuanto más tiempo se pasa un adolescente o un joven manteniendo relaciones sociales por medio de internet más vulnerable es a la hora de padecer o ejercer CB (Navarro y Yubero, 2012). Así, Marciales y Cabra dicen que el CB tienen un efecto igual o más negativo en los adolescentes que el bullying tradicional y las víctimas pueden llegar a sufrir problemas psicológicos y sociológicos por mucho tiempo (2012, p.718).

Elipe et al. (2012), indican que cuando se comparan ambos fenómenos, el del bullying y el del $C B$, se puede observar que tienen algunas características comunes y no solo en que ambas son una forma de acoso escolar sino que también comparten la intencionalidad agresiva, los roles protagonistas y la repetición a lo largo del tiempo, por tanto en cierto modo comparten las consecuencias. Beran y Li (2007) 
añaden que también existe una característica común que es el desequilibrio de poder entre los diferentes roles que se acogen en el acoso escolar. Se debe tener en cuenta que, al ser dos modalidades de acoso escolar, aunque se diferencien en algunos aspectos, tienen consecuencias parecidas en las personas afectadas por estos fenómenos, Garaigordobil, habla de un desajuste psicosocial y psicopatológico (2011, p.244), en ambos casos junto con soledad de las personas implicadas, exclusión y probabilidad de rechazo social en el rol de la víctima. En el artículo $C B$ : competencia social, motivación y relaciones entre iguales, Romera, Cano, GarcíaFernández y Ortega-Ruíz, indican que el desarrollo de conductas sociales competentes, la motivación social, y la aceptación de los iguales constituyen una construcción multifacética y jerárquicamente organizada que explica el ajuste social en los grupos de iguales (2015, p.72). Se define ajuste social como el grado en que la persona se involucra en comportamientos sociales competentes que terminan proporcionando buena adecuación entre su conducta y su contexto social inmediato (Crick y Dodge, 1994, pp.74-101). Tanto en el bullying como en el $C B$, uno de los factores que influye en que las personas sean víctimas y agresores o estén implicadas en este tipo de acoso, es el déficit en habilidades sociales. Según el Manual para Formadores de Voluntariado de Castilla La Mancha, se definen las habilidades sociales como la capacidad de ejecutar aquellas conductas aprendidas que cubren nuestras necesidades de comunicación interpersonal y/o responden a las exigencias y demandas de las situaciones sociales de forma efectiva. Además concretan que las habilidades sociales se adquieren con las experiencias, no son una característica de la persona, sino de las conductas que las personas tienen, y se debe tener en cuenta que toda conducta es susceptible de aprendizaje. Se puede hablar de un déficit en las habilidades sociales más por parte de las víctimas que los agresores y una carencia o niveles muy bajos de habilidades emocionales por parte de los agresores, pero es un rasgo que tienen en común ambas formas de acoso y que se puede ver en los comportamientos de las personas implicadas tal y como indican Romera et al. (2015), esta característica se llama competencia social. Otra de las características que comparten el bullying y el $C B$, en relación a los agresores, es la motivación social. Muchos son los casos en los que los agresores de ambas formas de acoso, son chicos y chicas que buscan un reconocimiento por parte de sus compañeros, intentando encontrar una posición más alta entre sus compañeros y llegando a desarrollar conductas agresivas para conseguirlo. Algunos estudios han tenido en cuenta factores como el personal y contextual, y han descubierto que el clima social y la empatía en el que se desarrollan y crecen los niños y los adolescentes, están relacionados en ambos tipos de acoso (Casas, Del-Rey y Ortega Ruíz, 2013). Se debe tener en cuenta que los dos tipos de acoso escolar son un problema 
muy grave que implica violencia entre menores de edad y que el porcentaje de escolares implicados en ambos fenómenos en el año 2010 fueron superiores al 60\% (Hinduja y Patchin, 2010; Twyman, Saylor, Taylor y Comeaux, 2010). Se debe tener presente que la implicación en ambos fenómenos denota la expresión de cierto desajuste emocional cuyo mantenimiento en el tiempo puede generar consecuencias muy negativas, y evidentemente, diferenciales para víctimas y agresores (Elipe et al., 2012, p.171).

Tal y como ocurre en el bullying tradicional, las dos variables que se estudian para conocer al alumno que se implica en este tipo de agresiones, tanto bullying como $C B$, son la edad, el género y el nivel educativo. En cuanto a la edad de los agresores en ambas formas de acoso, se puede observar que hay un punto álgido en la preadolescencia, y en los primeros cursos de educación secundaria (Lucas, Pérez y Giménez, 2016). En cuanto a las diferencias en $C B$ y del bullying en función del sexo, también se puede encontrar alguna diferencia como por ejemplo en los casos de bullying tradicional, hay un porcentaje muy elevado de víctimas chicos, por el contrario se ha detectado que hay muchos más casos de $C B$ en el género femenino. (Lucas et al. 2016).

La IE aunque es un concepto relativamente reciente, está adquiriendo cierta relevancia en el ámbito organizacional y educativo. Salovey y Mayer (1990, p.239) lo definen como una parte de la inteligencia social que incluye la capacidad de controlar nuestras emociones y las de los demás, discriminar entre ellas y usar dicha información para guiar nuestros pensamientos y nuestros comportamientos. El constructo es difundido y adquiere cierta importancia en el ámbito organizacional con la edición del best seller de Goleman (1995) que lo definió desde su modelo más enfocado al mundo empresarial como un conjunto de destrezas, actitudes, habilidades y competencias que determinan la conducta de un individuo, sus reacciones o sus estados mentales (García y Giménez, 2010). Por tanto el constructo ha evolucionado y ha sido desarrollado y aplicado en diversos campos tanto educacionales, organizacionales como en ámbitos de la salud (Bisquerra, 2000). Además de los modelos de habilidades de Salovey y Mayer (1990), los modelos denominados mixtos incluyen según Fernández y Extremera (2006) el modelo de Goleman (1995) y el de Bar-On (1997) que define IE como un conjunto de capacidades, competencias y habilidades no cognitivas que influencian la habilidad propia de tener éxito al afrontar aspectos del medio ambiente (García y Giménez, 2010). En los últimos años se han realizado numerosos estudios en el ámbito de la educación relacionados con los beneficios de la IE (IE) en la adaptación socio-escolar de los 
estudiantes (Morales y Zafra, 2013) por ejemplo, lo que podría llevar a plantear que podría desempeñar un importante rol en el fenómeno de $C B$. En este sentido, la IE se considera una herramienta educativa de innovación cuya finalidad es el desarrollo de competencias emocionales que contribuyan a un mejor bienestar personal y social por tanto el modelo educativo va en la línea de proporcionar al alumno el desarrollo cognitivo y el desarrollo emocional adecuado (Bisquerra, 2003). La ausencia de IE da lugar o facilita la aparición de problemas de conductas entre los estudiantes (Fernández y Ruiz, 2008) tales como relaciones interpersonales conflictivas, deterioro en el bienestar psicológico, bajo rendimiento académico y aumento de las conductas disruptivas en el aula. Por tanto, la IE según Goleman (1995) podría favorecer en los estudiantes el control de impulsos y gestionar adecuadamente las emociones negativas, favorecer el desarrollo de competencias sociales e interpersonales, autorrealización, motivación y capacitar a los alumnos a la resolución de problemas de tipo emocional de un modo equilibrado disminuyendo sus niveles de ansiedad y estrés, y gestionando las emociones de tristeza para que no desemboquen en depresión.

La inteligencia emocional (IE) ha suscitado un gran interés en el ámbito educativo como una vía para mejorar el desarrollo socioemocional de los alumnos. Las primeras publicaciones que aparecieron realizaron multitud de afirmaciones sobre la influencia positiva de la IE en el aula. El único inconveniente fue que todas estas aseveraciones no estaban avaladas por datos empíricos contrastados que demostrasen (Extremera y Berrocal, 2014, p. 1).

En base a los resultados previamente expuestos se plantean las siguientes hipótesis de trabajo:

Hipótesis 1. Los niveles de $C B$ (víctimas), AF, inteligencia emocional (atención emocional, claridad emocional, reparación emocional), estrés, ansiedad y depresión, serán diferentes en función del sexo.

Hipótesis 2. Los participantes con altos niveles de IE (IE) tendrán mayores niveles de $\mathrm{AF}$ y menores niveles de $C B$ (victimización), estrés, ansiedad y depresión que los participantes con niveles bajos de IE.

Hipótesis 3. Los participantes con altos niveles de AF tendrán mayores niveles de inteligencia emocional (IE) (atención emocional, claridad emocional y reparación emocional) y menores niveles de $C B$ (victimización), estrés, ansiedad y depresión que los participantes bajos en AF. 

invertida.

Hipótesis 4. La relación entre la edad y el $C B$ será curvilínea en forma de U

Hipótesis 5. La relación entre $C B$ y las variables de estrés, ansiedad y depresión estará modulada por la IE y la AF.

\subsection{Participantes}

La muestra objeto de estudio en esta investigación ha sido constituida por 37 participantes de $6^{\circ}$ de Educación Primaria, en un centro de carácter público de la ciudad de Huesca. La selección de la muestra viene dada por el interés de conocer si a edades tan tempranas ya comienzan a experienciarse el fenómeno de CB dentro de las aulas. La selección de la muestra está realizada al azar y no se ha excluido a ningún alumno. El rango de edad de la muestra en el estudio va de 11 a 14 años. El promedio de edad de la muestra en el estudio es de 11.75 años $(\mathrm{DT}=.80) .16 \mathrm{de}$ los 37 participantes tienen 11 años, representando el 39\% de la muestra, 15 participantes tienen 12 años (36.6\%), y 5 participantes tienen 13 años $(12.2 \%)$ y 1 participante tiene 14 años (2.4\%). Del total 15 participantes son varones, representando el $36.6 \%$ de la muestra y 22 participantes son mujeres, que constituyen el $53.7 \%$ de la muestra total en el estudio.

\subsection{Medidas}

Ciberbullying "Victimización”: Se utilizó la Escala de victimización (CBQ-V) de Estévez, Villardón, Calvete, Padilla y Orue (2010). Adolescentes víctimas de CB: prevalencia y características. Psicología conductual. Esta escala consta de 10 ítems adaptados de la clasificación de Willard (2006) que describen 10 formas en las que se podía sufrir $\mathrm{CB}$ como "Enviarme mensajes amenazantes o insultantes por internet", "colgar imágenes mías en internet que pueden ser humillantes (por ejemplo, vistiéndome en el vestuario del gimnasio)", y "escribir en internet bromas, rumores, chismes o comentarios que me ponían en ridiculo, etc.". El tipo de respuesta era de tipo Likert de 5 anclajes de (1) nunca, (2) poco, (3) nivel medio, (4) bastante y (5) mucho. El coeficiente alfa fue de .89.

Autoeficacia: Se utilizó la Escala de autoeficacia generalizada (adaptación española) de Baessler, J. y Schwarzer, R. (1996). La medida de la autoeficacia quedó recogida a través de 10 ítems que describían 10 formas de autoeficacia. Algunos ejemplos de estos ítems son: "Puedo encontrar la manera de obtener lo que quiero, aunque alguien se me oponga", "puedo resolver problemas dificiles si me esfuerzo 
lo suficiente", "me es fácil persistir en lo que me he propuesto hasta llegar a alcanzar mis metas", y "tengo confianza en que podría manejar eficazmente acontecimientos inesperados". El tipo de respuesta era de tipo Likert de 5 anclajes desde (1) nunca a (5) mucho. El coeficiente alfa fue de .86.

Estrés percibido: La medida del estrés percibido se analizó a través de 9 ítems de la versión española (2.0) de Perceived Stress Scale (PSS) de Cohen, Kamarck y Mermelstein, (1983). Algunos ejemplos son: “¿Con qué frecuencia has estado afectado por algo que ha ocurrido inesperadamente?, Ccon qué frecuencia has sentido que esta todo fuera de tu control? El tipo de respuesta era de tipo Likert de 5 opciones de respuesta, y las posibles respuestas eran (1) nada, (2) poco, (3) nivel medio, (4) bastante y (5) mucho. El coeficiente de fiabilidad alfa es alto .85 .

Inteligencia Emocional: Para medir la inteligencia emocional se utilizaron 24 ítems, de la TMMS-24 (Trait Meta-Mood Scale) del grupo de investigación de Salovey y Mayer (1995). Esta escala contiene tres dimensiones clave de la IE, con 8 ítems cada una de ellas: Atención emocional, Claridad de sentimientos y Reparación emocional. Alguno de los ejemplos de ítems son los siguientes: "Presto mucha atención a los sentimientos", "Siempre puedo decir cómo me siento", "Intento tener pensamientos positivos, aunque me sienta mal". El tipo de respuesta era de tipo Likert de 5 opciones de respuesta, y las posibles respuestas eran (1) nada, (2) poco, (3) nivel medio, (4) bastante y (5) mucho. El coeficiente de fiabilidad alfa es alto .82 .

Atención Emocional: La medida de la Atención Emocional se analizó a través de 8 ítems de de la TMMS-24 (Trait Meta-Mood Scale) del grupo de investigación de Salovey y Mayer (1995). Algunos de los ejemplos de ítems son los siguientes: "Dejo que mis sentimientos afecten a mis pensamientos", "Presto mucha atención a como me siento". El tipo de respuesta era de tipo Likert de 5 opciones de respuesta, y las posibles respuestas eran (1) nada, (2) poco, (3) nivel medio, (4) bastante y (5) mucho. El coeficiente de fiabilidad alfa es alto .86 .

Claridad emocional: La medida de la Atención Emocional se analizó a través de 8 ítems de de la TMMS-24 (Trait Meta-Mood Scale) del grupo de investigación de Salovey y Mayer (1995). Algunos de los ejemplos de ítems son los siguientes: "Frecuentemente puedo definir mis sentimientos", "A veces puedo decir cuáles son mis emociones". El tipo de respuesta era de tipo Likert de 5 opciones de respuesta, y las posibles respuestas eran (1) nada, (2) poco, (3) nivel medio, (4) bastante y (5) mucho. El coeficiente de fiabilidad alfa es alto .74. 
Reparación Emocional: La medida de la Reparación Emocional se analizó a través de 8 ítems de de la TMMS-24 (Trait Meta-Mood Scale) del grupo de investigación de Salovey y Mayer (1995). Algunos de los ejemplos de ítems son los siguientes: "Aunque me sienta mal, procuro pensar en cosas agradables", "Tengo mucha energía cuando me siento feliz". El tipo de respuesta era de tipo Likert de 5 opciones de respuesta, y las posibles respuestas eran (1) nada, (2) poco, (3) nivel medio, (4) bastante y (5) mucho. El coeficiente de fiabilidad alfa es alto .73.

Ansiedad: Para medir la ansiedad se utilizaron 9 ítems de la Escala de Ansiedad y Depresión de Goldberg (E.A.D.G) (1979). Algunos de los ejemplos de ítems son los siguientes: “ ¿Ha estado muy preocupado por algo?”, “ ¿Ha estado preocupado por su salud?". El tipo de respuesta era de tipo Likert de 5 opciones de respuesta, y las posibles respuestas eran (1) nada, (2) poco, (3) nivel medio, (4) bastante y (5) mucho. El coeficiente de fiabilidad alfa es alto .77 .

Depresión: Para medir la depresión se utilizaron 9 ítems de una sub escala de la Escala de Ansiedad y Depresión de Goldberg (E.A.D.G) (1979), que mide la depresión solamente. Algunos de los ejemplos de ítems son los siguientes: "¿Se ha sentido usted desesperanzado, sin esperanzas?”, “'Se ha estado despertando demasiado temprano?". El tipo de respuesta era de tipo Likert de 5 opciones de respuesta, y las posibles respuestas eran (1) nada, (2) poco, (3) nivel medio, (4) bastante y (5) mucho. El coeficiente de fiabilidad alfa es alto .81 .

\subsection{Analisis de datos}

A través del SPSS se calcularon los índices de fiabilidad, considerando una fiabilidad adecuada a partir de un coeficiente de fiabilidad (alfa de Crombach) por encima de.70 (Nunnally, 1978), y también se calcularon los parámetros de centralización (medias aritméticas) y dispersión (desviación estándar). También se calcularon las correlaciones entre todas las variables usando el programa SSPS mediante el coeficiente de correlación $r$ de Pearson. La variable sexo, debido a que es una variables dicotómica se codifico como $(0=$ chico; $1=$ chica $)$. A continuación, se realizó una prueba t para muestras independientes para comprobar si había diferencias significativas entre las medias de las variables según el sexo. Además se realizó una prueba t para analizar si las personas que puntuaban alto en IE tenían diferentes niveles de autoeficacia, ciberbullying, ansiedad, estrés, y depresión que las personas con niveles bajos de IE. También, se realizó esta prueba para comparar los resultados en función de los participantes que puntuaron alto y bajo en autoeficacia. 
Por último, mediante el SPSS se midieron las interacciones, es decir, cómo la relación entre la variable dependiente y la independiente podía estar modulada por una variable dependiente moduladora. Para ello, se utilizó el método de Hayes (2013) descrito en el siguiente sitio web, http://afhayes.com/spss-sas-and-mplus-macrosand-code.html. Así, la significación menor de $\mathrm{p}<.10$ nos muestra que es significativa la interacción estudiada. En los efectos de interacción el límite convencional del nivel de $\mathrm{p}$ es de .10. Este nivel de $\mathrm{p}$ ha sido sugerido por varios investigadores (Caplan y Jones, 1975; Champoux y Peters, 1987; Rodríguez, Bravo, Peiró y Schaufeli (2001) para proteger al test de la probabilidad de cometer un error Tipo II cuando se realizan los análisis de modulación.

\subsection{Resultados}

Los descriptivos (medias y desviaciones típicas) de cada una de las variables estudiadas, y las correlaciones, se muestran en la tabla 1.

Tabla 2. Medias de las variables del estudio en función del sexo.

\begin{tabular}{|c|c|c|c|c|c|c|}
\hline Variables & Sexo & $\mathrm{N}$ & $\begin{array}{l}\mathrm{Me}- \\
\text { dia }\end{array}$ & DT & $\mathrm{t}$ & gl \\
\hline \multirow[t]{2}{*}{ Ciberbullying } & Mujer & 22 & 1.17 & .49 & & \\
\hline & Hombre & 15 & 1.21 & .54 & -.24 & 35 \\
\hline \multirow[t]{2}{*}{ Autoeficacia } & Mujer & 22 & 3.48 & .72 & & \\
\hline & Hombre & 15 & 3.43 & .78 & .22 & 35 \\
\hline \multirow[t]{2}{*}{ IE } & Mujer & 22 & 3.36 & .62 & & \\
\hline & Hombre & 15 & 3.22 & .51 & .73 & 35 \\
\hline \multirow{2}{*}{$\mathrm{AE}$} & Mujer & 22 & 2.78 & .80 & & \\
\hline & Hombre & 15 & 2.84 & .88 & -.25 & 35 \\
\hline \multirow[t]{2}{*}{$\mathrm{CE}$} & Mujer & 22 & 3.61 & .77 & & \\
\hline & Hombre & 15 & 3.43 & .75 & .70 & 35 \\
\hline \multirow[t]{2}{*}{ RE } & Mujer & 22 & 3.70 & .70 & & \\
\hline & Hombre & 15 & 3.38 & .68 & 1.36 & 35 \\
\hline \multirow[t]{2}{*}{ Estrés } & Mujer & 22 & 2.27 & .66 & & \\
\hline & Hombre & 15 & 2.64 & .71 & -1.61 & 35 \\
\hline \multirow[t]{2}{*}{ Ansiedad } & Mujer & 22 & 2.24 & .67 & -1.56 & 35 \\
\hline & Hombre & 15 & 2.60 & .74 & & \\
\hline \multirow[t]{2}{*}{ Depresión } & Mujer & 22 & 1.66 & .55 & -1.96 & 35 \\
\hline & Hombre & 15 & 2.08 & .77 & & \\
\hline
\end{tabular}


Capitulo 9. El rol de IE y AF en la relación CB- estrés, ansiedad y depresión.

Tabla 1. Correlaciones de las variables consideradas en el estudio.

\begin{tabular}{|c|c|c|c|c|c|c|c|c|c|c|c|c|c|}
\hline & $\mathrm{M}$ & DT & 1 & 2 & 3 & 4 & 5 & 6 & 7 & 8 & 9 & 10 & 11 \\
\hline 1. $\mathrm{CB}$ & 1.19 & .48 & 1 & & & & & & & & & & \\
\hline 2. $\mathrm{AF}$ & 3.46 & .70 & -.27 & 1 & & & & & & & & & \\
\hline 3. IE & 3.30 & .55 & -.24 & $.42^{* *}$ & 1 & & & & & & & & \\
\hline 4. $\mathrm{AE}$ & 2.81 & .78 & .18 & .08 & $.71^{* *}$ & 1 & & & & & & & \\
\hline 5. CE & 3.54 & .72 & $-.52^{* *}$ & $.36^{*}$ & $.76^{* *}$ & .21 & 1 & & & & & & \\
\hline 6. $\mathrm{RE}$ & 3.57 & .67 & -.22 & $.55^{* *}$ & $.81^{* *}$ & $.35^{*}$ & $.54^{* *}$ & 1 & & & & & \\
\hline 7. Estrés & 2.42 & .66 & .30 & $-.36^{*}$ & -.05 & $.43^{* *}$ & -.30 & -.30 & 1 & & & & \\
\hline 8. Ans & 2.38 & .67 & $.31^{*}$ & $-.38^{*}$ & .15 & $.40^{*}$ & -.05 & -.05 & $.62^{* *}$ & 1 & & & \\
\hline 9. Depre & 1.83 & .64 & .30 & $-.51^{* *}$ & -.22 & .13 & -.22 & $-.45^{* *}$ & $.57^{* *}$ & $.78^{* *}$ & 1 & & \\
\hline 10. Sexo & .60 & .50 & -.04 & .04 & .12 & -.04 & .12 & .23 & -.26 & -.26 & -.32 & 1 & \\
\hline 11. Edad & 11.76 & .80 & $.41^{*}$ & -.12 & .03 & $.39^{*}$ & $-.37^{*}$ & -.00 & $.41^{*}$ & .26 & .25 & -.12 & 1 \\
\hline
\end{tabular}

Nota: Ciberbullying "CB"; Autoeficacia "AF"; Inteligencia emocional "IE"; Atención emocional "AE"; Claridad/ Comprensión emocional "CE”; Reparación/Regulación emocional "RE"; Ansiedad "Ans"; Depresión "Depre". ** La correlación es significativa en el nivel 0,01 (2 colas). *La correlación es significativa en el nivel 0,05 ( 2 colas). 
La media de las mujeres en autoeficacia (mujeres: $\mathrm{M}=3.48, \mathrm{DT}=.72$; hombres $\mathrm{M}=3.43$, $\mathrm{DT}=.78$ ), inteligencia emocional global (mujeres: $\mathrm{M}=3.36$, $\mathrm{DT}=.62$; hombres $\mathrm{M}=3.22, \mathrm{DT}=.51$ ) y en las dimensiones de claridad (mujeres: $\mathrm{M}=3.61$, $\mathrm{DT}=.77$; hombres $\mathrm{M}=3.43 \mathrm{DT}=.75$ ) y reparación emocional (mujeres: $\mathrm{M}=3.70$, $\mathrm{DT}=.70$; hombres $\mathrm{M}=3.38 \mathrm{DT}=.68$ ) fue mayor que en los hombres. Por otro lado, la media de los hombres en CB "victimización" (mujeres: M=1.17, DT=.49; hombres $\mathrm{M}=1.21, \mathrm{DT}=.54$ ), la dimensión de $\mathrm{IE}$ de atención emocional (mujeres: $\mathrm{M}=2.78, \mathrm{DT}=.80$; hombres $\mathrm{M}=2.84, \mathrm{DT}=.88$ ), estrés (mujeres: $\mathrm{M}=2.27, \mathrm{DT}=.66$; hombres $\mathrm{M}=2.64$, $\mathrm{DT}=.71$ ), ansiedad, (mujeres: $\mathrm{M}=2.24$, $\mathrm{DT}=.67$; hombres $\mathrm{M}=2.60, \mathrm{DT}=.74$ ), y depresión (mujeres: $\mathrm{M}=1.66$, $\mathrm{DT}=.55$; hombres $\mathrm{M}=2.08$, $\mathrm{DT}=.77$ ) fue mayor en hombres que en mujeres.

La hipótesis 1 planteaba que los niveles de $\mathrm{CB}$ (victimas), autoeficacia, inteligencia emocional, atención emocional, claridad emocional, reparación emocional, estrés, ansiedad y depresión serían diferentes en función del sexo. Tal y como se observa en la tabla las diferencias no fueron significativamente diferentes. Por tanto, se rechaza la $\mathrm{H} 1$.

La hipótesis 2 planteaba que los participantes con altos niveles de IE tendrían mayores niveles de autoeficacia y menores niveles de CB (victimas), estrés, ansiedad y depresión que los participantes bajos en IE. Los resultados muestran que las personas con alta IE tuvieron niveles más bajos de CB (altos IE: $\mathrm{M}=1.14$, $\mathrm{DT}=.42$; bajos IE: $\mathrm{M}=1.27$, $\mathrm{DT}=.57$ ), estrés (altos IE: $\mathrm{M}=2.35$, $\mathrm{DT}=.65$; bajos IE: $\mathrm{M}=2.54$, DT=.67), depresión (altos IE: $\mathrm{M}=1.76$, $\mathrm{DT}=.64$; bajos IE: $\mathrm{M}=1.94$, $\mathrm{DT}=.64$ ), y mayores niveles de autoeficacia (altos IE: $\mathrm{M}=3.71$, DT=.63; bajos IE: $\mathrm{M}=3.06$, DT=.62) y ansiedad (altos IE: $\mathrm{M}=2.43$, DT=.71; bajos IE: $\mathrm{M}=2.32$, $\mathrm{DT}=.63)$. No obstante, esta diferencia solo fue significativamente diferente para la variable de autoeficacia $(\mathrm{t}=3.21, \mathrm{gl}=39, \mathrm{p}<.01)$. Por tanto, se acepta la H2 parcialmente.

La hipótesis 3 planteaba que los participantes con altos niveles de autoeficacia tendrían mayores niveles de IE (atención, claridad y reparación) y menores niveles de $\mathrm{CB}$ (victimización), estrés, ansiedad y depresión que los participantes bajos en autoeficacia. Los resultados muestran que las personas con alta autoeficacia tuvieron niveles más bajos de $\mathrm{CB}$ (altos en autoeficacia: $\mathrm{M}=1.03$, $\mathrm{DT}=.08$; bajos en autoeficacia: $\mathrm{M}=1.31$, DT $=.61$ ), estrés (altos autoeficacia: $\mathrm{M}=2.22$, $\mathrm{DT}=.72$; bajos en autoeficacia: $\mathrm{M}=2.58, \mathrm{DT}=.58$ ), depresión (altos autoeficacia: $\mathrm{M}=1.62$, $\mathrm{DT}=.48$; bajos en autoeficacia: $\mathrm{M}=2.00, \mathrm{DT}=.71$ ), y ansiedad (altos autoeficacia: $\mathrm{M}=2.25$, 
$\mathrm{DT}=.66$; bajos en autoeficacia: $\mathrm{M}=2.49, \mathrm{DT}=.68)$, y mayores niveles de IE global (altos autoeficacia: $\mathrm{M}=3.57$, $\mathrm{DT}=.44$; bajos en autoeficacia: $\mathrm{M}=3.10, \mathrm{DT}=.54$ ), la dimensión de atención emocional (altos autoeficacia: $\mathrm{M}=2.88$, DT=.75; bajos en autoeficacia: $\mathrm{M}=2.75, \mathrm{DT}=.82$ ), claridad emocional (altos autoeficacia: $\mathrm{M}=3.84$, $\mathrm{DT}=.53$; bajos en autoeficacia: $\mathrm{M}=3.30, \mathrm{DT}=.76$ ) y reparación emocional (altos autoeficacia: $\mathrm{M}=3.99$, DT=.51; bajos en autoeficacia: $\mathrm{M}=3.24$, DT=.59). No obstante, esta diferencia solo fue significativamente diferente para la variable de $\mathrm{CB}$ $(\mathrm{t}=-2.14, \mathrm{gl}=23,04, \mathrm{p}<.05)$. Por tanto, se acepta la $\mathrm{H} 3$ parcialmente, inteligencia emocional considerada de manera global $(\mathrm{t}=3.01, \mathrm{gl}=39, \mathrm{p}<.05)$, y en las dimensiones de claridad emocional $(\mathrm{t}=2.52, \mathrm{gl}=39, \mathrm{p}<.05)$ y reparación emocional $(\mathrm{t}=$ $4.30, \mathrm{gl}=39, \mathrm{p}<.01)$. Por tanto, se acepta la $\mathrm{H} 3$ parcialmente.

Tabla 3. Medias y prueba t de muestras independientes de las variables del estudio en función de la IE.

\begin{tabular}{lllllll}
\hline & IE & $\mathrm{N}$ & Media & $\begin{array}{c}\text { Desvia- } \\
\text { ción es- } \\
\text { tándar }\end{array}$ & $\mathrm{t}$ & $\mathrm{gl}$ \\
\hline \multirow{2}{*}{ Ciberbullying } & Alta IE & 25 & 1.14 & .42 & & \\
& Baja IE & 16 & 1.27 & .57 & -.85 & 39 \\
Estrés & Alta IE & 25 & 2.35 & .65 & & \\
\multirow{5}{*}{ Ansiedad } & Baja IE & 16 & 2.54 & .67 & -.89 & 39 \\
& Alta IE & 25 & 2.43 & .71 & & \\
& Baja IE & 16 & 2.32 & .63 & .49 & 39 \\
\multirow{5}{*}{ Autoeficación } & Alta IE & 25 & 1.76 & .64 & & \\
& Baja IE & 16 & 1.94 & .64 & -.90 & 39 \\
& Alta IE & 25 & 3.71 & .63 & & \\
& Baja IE & 16 & 3.06 & .62 & $3.22 * *$ & 39 \\
\hline
\end{tabular}

$* * p<.01$. La correlación es significativa en el nivel 0,01 ( 2 colas); $* p<.05$ La correlación es significativa en el nivel 0,05 ( 2 colas $)$ 
Tabla 4. Medias y prueba t de las variables del estudio en función de la autoeficacia.

\begin{tabular}{|c|c|c|c|c|c|c|}
\hline & Autoeficacia & $\mathrm{N}$ & Media & $\begin{array}{l}\text { Desvia- } \\
\text { ción están- } \\
\text { dar }\end{array}$ & $\mathrm{t}$ & $\mathrm{gl}$ \\
\hline \multirow{2}{*}{$\begin{array}{l}\text { Ciberbullying } \\
\text { "victimiza- } \\
\text { ción" }\end{array}$} & $\begin{array}{l}\text { Alta autoefi- } \\
\text { cacia }\end{array}$ & 18 & 1.03 & .08 & & \\
\hline & $\begin{array}{l}\text { Baja autoefi- } \\
\text { cacia }\end{array}$ & 23 & 1.31 & .61 & $-2.14 *$ & 23.05 \\
\hline \multirow{2}{*}{ Estrés } & $\begin{array}{l}\text { Alta autoefi- } \\
\text { cacia }\end{array}$ & 18 & 2.22 & .72 & & \\
\hline & $\begin{array}{l}\text { Baja autoefi- } \\
\text { cacia }\end{array}$ & 23 & 2.58 & .58 & -1.75 & 39 \\
\hline \multirow{2}{*}{ Ansiedad } & $\begin{array}{l}\text { Alta autoefi- } \\
\text { cacia }\end{array}$ & 18 & 2.25 & .66 & & \\
\hline & $\begin{array}{l}\text { Baja autoefi- } \\
\text { cacia }\end{array}$ & 23 & 2.49 & .68 & -1.11 & 39 \\
\hline \multirow{2}{*}{ Depresión } & $\begin{array}{l}\text { Alta autoefi- } \\
\text { cacia }\end{array}$ & 18 & 1.62 & .48 & & \\
\hline & $\begin{array}{l}\text { Baja autoefi- } \\
\text { cacia }\end{array}$ & 23 & 2.00 & .71 & -1.88 & 39 \\
\hline \multirow{2}{*}{ IE } & $\begin{array}{l}\text { Alta autoefi- } \\
\text { cacia }\end{array}$ & 18 & 3.57 & .44 & & \\
\hline & $\begin{array}{l}\text { Baja autoefi- } \\
\text { cacia }\end{array}$ & 23 & 3.10 & .54 & $3.01 * *$ & 39 \\
\hline \multirow{2}{*}{$\mathrm{AE}$} & $\begin{array}{l}\text { Alta autoefi- } \\
\text { cacia }\end{array}$ & 18 & 2.88 & .75 & & \\
\hline & $\begin{array}{l}\text { Baja autoefi- } \\
\text { cacia }\end{array}$ & 23 & 2.75 & .82 & .52 & 39 \\
\hline \multirow{2}{*}{$\mathrm{CE}$} & $\begin{array}{l}\text { Alta autoefi- } \\
\text { cacia }\end{array}$ & 18 & 3.84 & .53 & & \\
\hline & $\begin{array}{l}\text { Baja autoefi- } \\
\text { cacia }\end{array}$ & 23 & 3.30 & .76 & $2.52 *$ & 39 \\
\hline \multirow{2}{*}{ RE } & $\begin{array}{l}\text { Alta autoefi- } \\
\text { cacia }\end{array}$ & 18 & 3.99 & .51 & & \\
\hline & $\begin{array}{l}\text { Baja autoefi- } \\
\text { cacia }\end{array}$ & 23 & 3.24 & .59 & $4.30 * * *$ & 39 \\
\hline
\end{tabular}

** $p<.01$. La correlación es significativa en el nivel 0,01 ( 2 colas); $* p<.05$ La correlación es significativa en el nivel 0,05 ( 2 colas) 
La hipótesis 4 planteaba una relación curvilínea entre la edad y el CB. Los resultados muestran que la relación es lineal $(\mathrm{F}=7.24, \mathrm{p}<.01)$ y curvilínea $(\mathrm{F}=5.64, \mathrm{p}<.01)$ (véase tabla 5) por lo tanto se acepta la $\mathrm{H} 4$.

Tabla 5. Resultados del análisis de regresión para ciberbullying "victimización”.

\begin{tabular}{|c|c|c|c|c|c|c|c|c|}
\hline \multirow[b]{2}{*}{ Ecuación } & \multicolumn{4}{|c|}{ Resumen del modelo } & \multicolumn{4}{|c|}{ Estimaciones de parámetro } \\
\hline & $\mathrm{R}^{2}$ & $\mathrm{~F}$ & df1 & $\mathrm{df} 2$ & Sig. & Cte. & b1 & b2 \\
\hline Lineal &, 171 & 7,240 & 1 & 35 &, 011 & $-1,905$ & ,263 & \\
\hline $\begin{array}{l}\text { Cuadrá- } \\
\text { tico }\end{array}$ & ,249 & 5,645 & 2 & 34 &, 008 & 25,761 & $-4,345$ & ,191 \\
\hline
\end{tabular}

Nota: La variable independiente es EDAD. $* \mathrm{p}<.05 * * \mathrm{p}<.01$

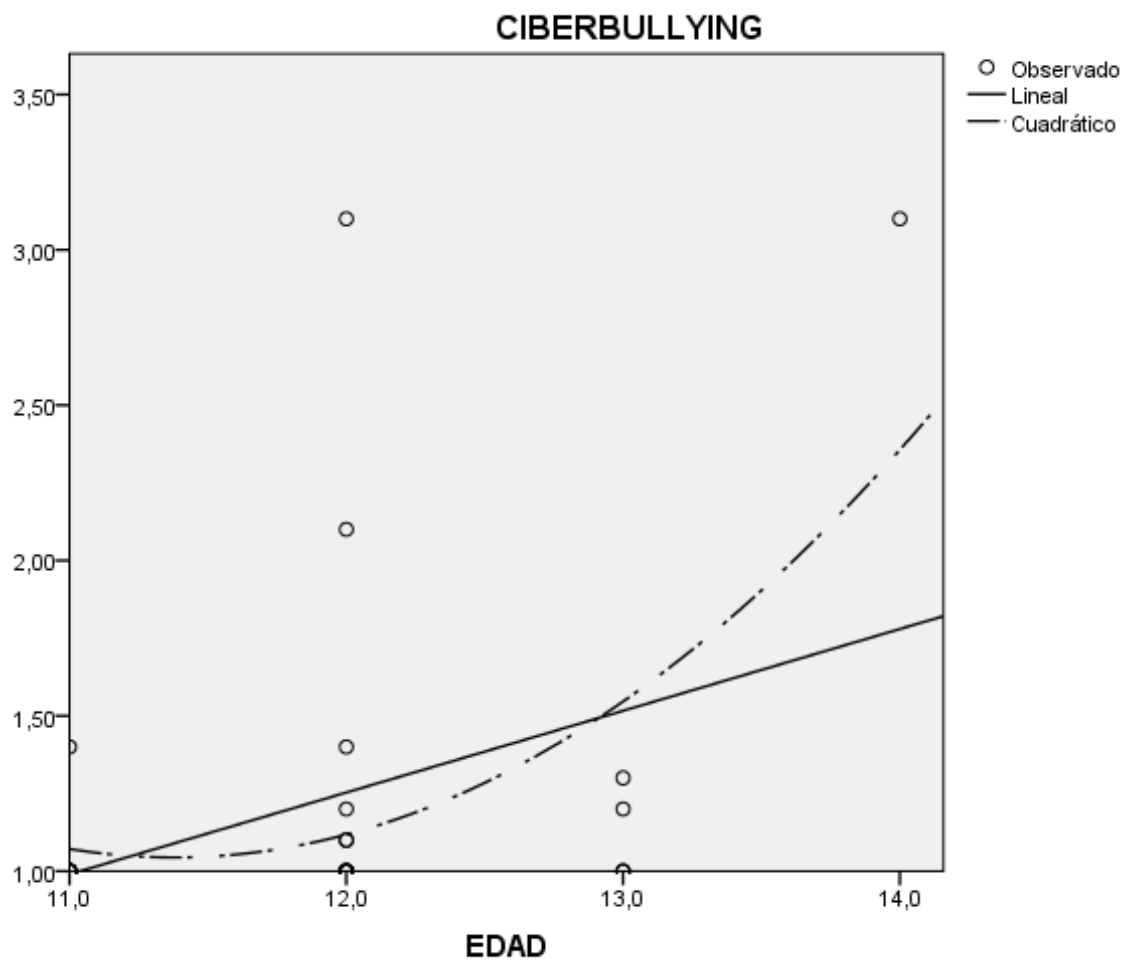

Figura 1. Relación curvilínea entre la edad y el ciberbullying 
La hipótesis 5 planteaba que la relación entre ciberbullying y las variables de estrés, ansiedad y depresión estarían modulada por IE. Los resultados muestran que a mayor ciberbullying mayores niveles de estrés $(\mathrm{B}=2.82, \mathrm{p}<.05)$ y que la relación entre ciberbullying y estrés esta modulada por la IE $(\mathrm{B}=-.79, \mathrm{p}<.10)$. De tal modo, que a mayor victimización mayores niveles de estrés cuando la IE fue baja, niveles moderados de IE amortiguaron la influencia del ciberbullying "victimización" en estrés aminorando la relación positiva entre ciberbullying "victimización" y estrés. Sin embargo en los participantes cuyos niveles de IE fue alto el ciberbullying tuvo una relación negativa con estrés. Por tanto la H5 se acepta para la variable de estrés.

Tabla 6. Resultados del análisis de regresión para estrés.

\begin{tabular}{lll}
\hline Variable & $\mathrm{B}$ & $\Delta \mathrm{R}^{2}$ \\
\hline Inteligencia emocional (IE) & .98 & \\
Ciberbullying "víctimas" (CB) & $2.82 *$ & \\
IE * CB & $-.79 \dagger$ & $.16 \dagger$ \\
\hline Nota: B son los coeficientes de regresión no estandarizados. $\uparrow^{\dagger}<.10 * \mathrm{p}<.05 * * \mathrm{p}<.01$
\end{tabular}

Figura 2. Resultados del análisis de regresión para estrés. 


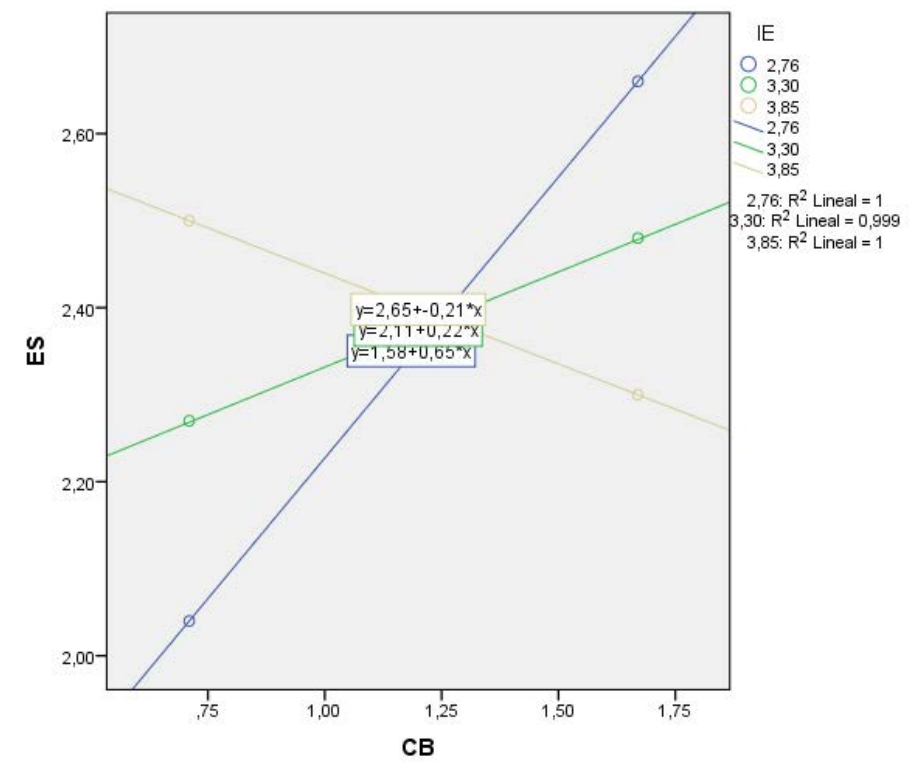

Nota. CB "Ciberbullying", ES "Estrés" e IE "Inteligencia emocional" Los resultados no muestran una relación entre ciberbullying y ansiedad modulada por la IE ( $\mathrm{B}=-.32$, ns). Tal y como muestra la figura a mayor ciberbullying mayor ansiedad, siendo esta relación más fuerte para los participantes que obtuvieron niveles bajos en IE que en los que obtuvieron niveles altos, no obstante aunque los resultados se han graficado para visualizar el patrón de la relación, los resultados no son significativos y no pueden ser tenidos en consideración. Por tanto la H5 se rechaza para la variable de ansiedad.

Tabla 7. Resultados del análisis de regresión para ansiedad.

\begin{tabular}{llc}
\hline Variable & $\mathrm{B}$ & $\Delta \mathrm{R}^{2}$ \\
\hline Inteligencia emocional (IE) & .67 & \\
Ciberbullying "víctimas" (CB) & 1.49 & $.16 \dagger$ \\
$\mathrm{IE} * \mathrm{CB}$ & -.32 & \multicolumn{1}{c}{${ }^{\dagger}$} \\
\hline Nota: B son los coeficientes de regresión no estandarizados. $\dagger<.10 * \mathrm{p}<.05 * * \mathrm{p}<.01$
\end{tabular}

Figura 3. Resultados del análisis de regresión para ansiedad. 


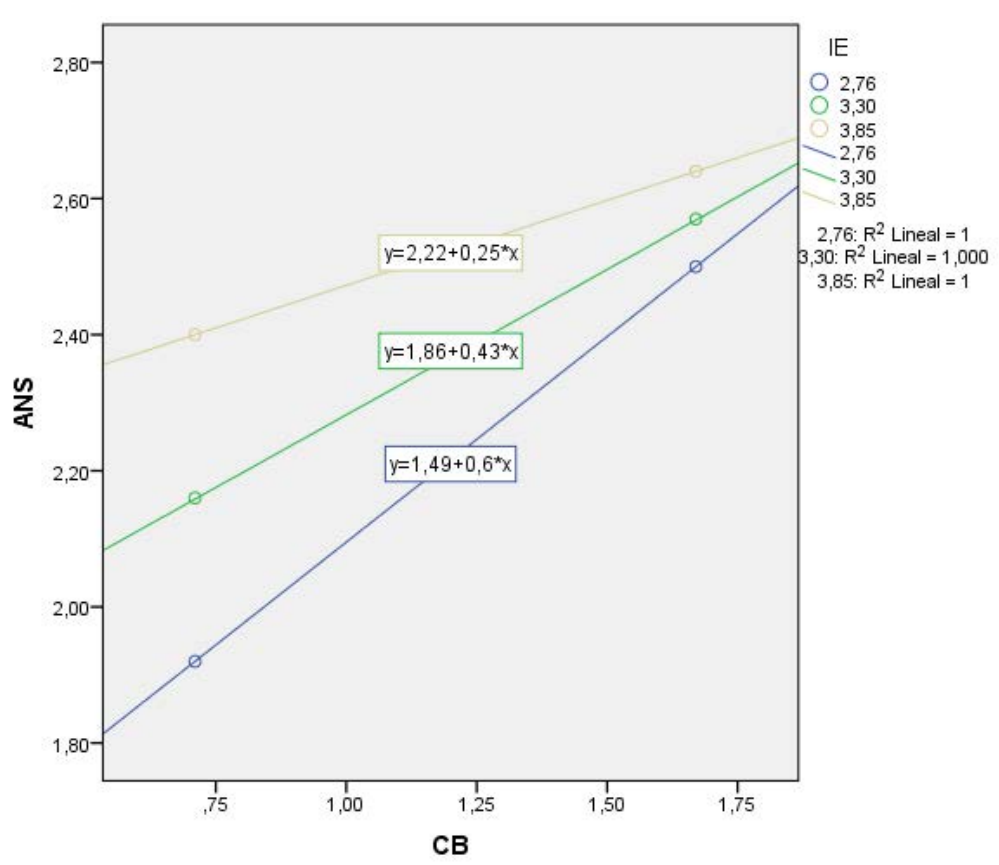

Nota. CB "Ciberbullying", ANS "Ansiedad" e IE "Inteligencia emocional" Los resultados no muestran una relación entre ciberbullying y depresión modulada por la IE ( $\mathrm{B}=-.37, \mathrm{~ns})$. Tal y como muestra la figura la relación entre ciberbullying y depresión fue positiva en los casos de niveles bajos de IE, esta relación positiva fue aunque más débil en los casos de IE moderada, y prácticamente nula en los casos de alta IE. Por tanto, parece que la tendencia indica que la IE podría amortiguar la relación entre ciberbullying y depresión, no obstante los resultados han de ser tomados con cautela ya que no alcanzan el nivel de significación requerido. Por tanto la H5 se rechaza para la variable de depresión.

Tabla 8. Resultados del análisis de regresión para depresión.

\begin{tabular}{lll}
\hline Variable & $\mathrm{B}$ & $\Delta \mathrm{R}^{2}$ \\
\hline Inteligencia emocional (IE) & .26 & \\
Ciberbullying “víctimas" (CB) & 1,47 & \\
$\mathrm{IE} * \mathrm{CB}$ & -.37 & .13 \\
\hline Nota: B son los coeficientes de regresión no estandarizados. $\dagger<.10^{*} \mathrm{p}<.05 * * \mathrm{p}<.01$
\end{tabular}

Figura 4. Resultados del análisis de regresión para depresión. 


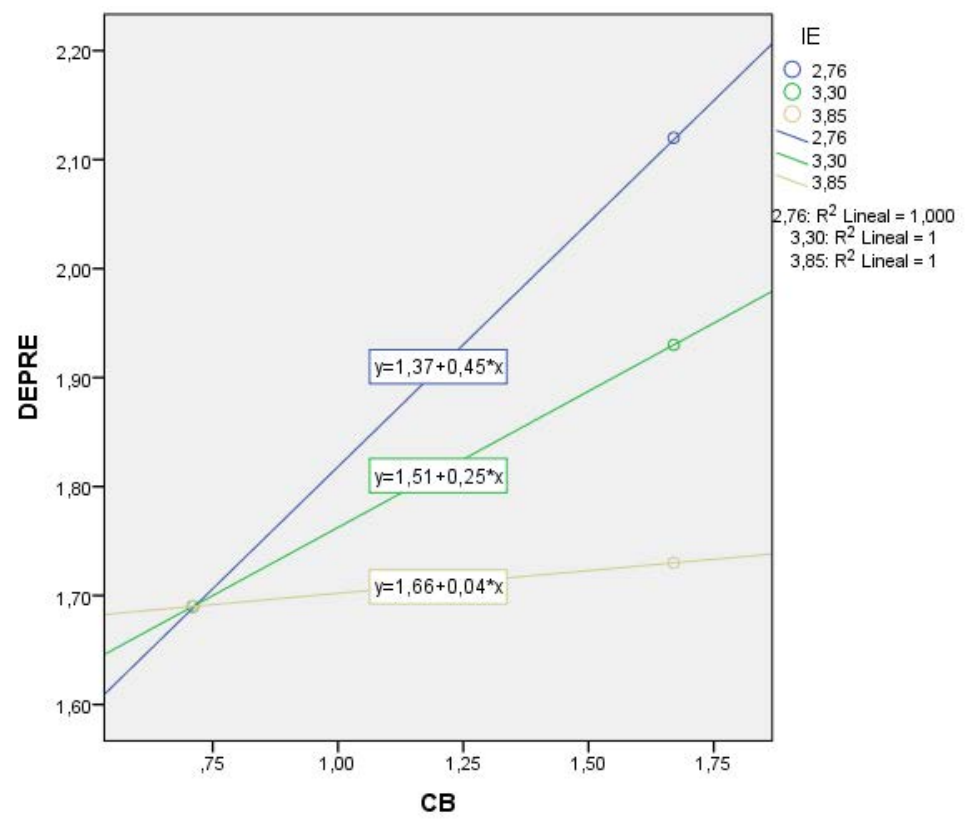

Nota. CB "Ciberbullying”, DEPRE "Depresión" e IE "Inteligencia emocional"

\subsection{Discusión}

El objetivo de este estudio era comprobar si los alumnos con mayores niveles de inteligencia emocional y autoeficacia, tienen menores niveles de $C B$, bullying, estrés, ansiedad y depresión. La hipótesis 1 planteaba que los niveles de $C B$ (víctimas), bullying, autoeficacia, inteligencia emocional, claridad emocional, reparación emocional, estrés, ansiedad y depresión, serían diferentes en función del sexo. Los resultados indican que las diferencias no fueron significativamente diferentes. Estos resultados están en línea con lo obtenido en estudios previos como el de Cardozo, Dubini, Fantino, Serra y Ramallo Torres (2016). No apoyan los resultados obtenidos en otros estudios como el de Avilés (2010) y otros estudios que defienden que sí que hay diferencias en función del sexo (Manson, 2008) y el de Gimenez, Maquilón y Arnaiz (2015). La hipótesis 2 planteaba que los participantes con altos niveles de inteligencia emocional tienen mayores niveles de autoeficacia y menores niveles de $C B$ (víctimas), estrés, ansiedad y depresión que los participantes bajos 
en inteligencia emocional. Los resultados indican que las personas con alta inteligencia emocional tuvieron niveles más bajos de $C B$, estrés, depresión y mayores niveles de autoeficacia y ansiedad, aunque esta diferencia solo fue significativamente diferente para la variable de autoeficacia. Estos resultados están en línea con lo obtenido en estudios previos como el de Fernandez-Berrocal, Ramos, y Extremera (2001), en el que de forma general se explica que los niveles altos de inteligencia emocional correlacionan positivamente con los niveles de autoeficacia y de forma negativa con los niveles de estrés. Además otro estudio de Dawda y Hart (2000) muestra que la inteligencia emocional y la depresión correlacionan de forma negativa. Difieren las conclusiones y los resultados encontrados en otros estudios como el de Vilariño, Amado y Alves (2013), en el que se realiza un estudio en una muestra de estudiantes y muestra que cuanto mayor es el nivel de inteligencia emocional mayores son los niveles de ansiedad y estrés. La hipótesis 3 planteaba que los participantes con altos niveles de autoeficacia tienen mayores niveles de inteligencia emocional (atención emocional, claridad emocional y reparación emocional) y menores niveles de $C B$ (víctimas), estrés, ansiedad y depresión que los participantes bajos en autoeficacia. Los resultados indican que las personas con alta autoeficacia tuvieron niveles más bajos de $C B$, estrés, depresión y ansiedad y mayores niveles de inteligencia emocional global, la dimensión de atención emocional, claridad emocional, y reparación emocional. Esta diferencia solo fue significativamente diferente para la variable de $C B$. Estos resultados están en línea con lo obtenido en estudios previos como el de Ferragut y Fierro (2012), en el que se encuentran correlaciones positivas entre el bienestar personal de los estudiantes y los componentes de Inteligencia Emocional de Claridad Emocional y Reparación. La hipótesis 4 planteaba que hay una relación curvilínea entre la edad y el $C B$. Los resultados indican que la relación entre la edad y el $C B$ es curvilínea. Estos resultados están en línea con lo obtenido en estudios previos, como el de Ortega, Calmaestra y Mora (2008). Aunque otros estudios no apoyan los resultados encontrados como el de Feliz-Mateo, Soriano-Ferer, Godoy-Mesas y Sancho-Vicente. (2010). La hipótesis 5 planteaba que la relación entre el $C B$ y las variables de estrés, ansiedad y depresión estarían moduladas por la inteligencia emocional. Los resultados indican que a mayor $C B$ "victimización" los niveles de estrés son mayores también. Y por lo tanto que a mayor victimización mayor es el nivel de estrés cuando la inteligencia emocional es baja. Además los niveles moderados de inteligencia emocional amortiguan la influencia del $C B$ "victimización" en estrés, aminorando la relación positiva entre el $C B$ "victimización" y el estrés. Además en los participantes que tenían niveles de inteligencia emocional altos, el $C B$ tuvo una 
relación negativa con estrés. Estos resultados están en línea con lo obtenido en estudios previos como el de Domínguez-Alonso, Domínguez-Rodríguez, López-Pérez, Rodríguez-González (2016) y el de Castellanos, Itzel y Gámez (2016), que además de estar de acuerdo con la correlación positiva de $C B$ y estrés, también muestra una correlación positiva entre ansiedad, depresión y $C B$.

El presente estudio presenta limitaciones que deberían ser tenidas en consideración, es un estudio de corte transversal y futuros estudios deberían analizar los datos longitudinalmente. Los datos se han recogido mediante el uso de cuestionario, por tanto futuros estudios deberían incluir medidas objetivas y de diversas fuentes. Otra limitación del estudio es que únicamente se han considerado las percepciones de los estudiantes, futuros estudios deberían incluir otros agentes de la comunidad educativa y del ámbito familiar. Además, también deberían analizarse antecedentes, consecuencias y otros posibles moduladores en diferentes roles de los implicados en el fenómeno de CB como son los acosadores y observadores. No obstante, a pesar de las limitaciones del presente estudio sus resultados permiten dibujar un panorama esperanzador y que podrían ser tenidos en consideración en la prevención primaria y secundaria.

\subsection{Conclusiones}

Una vez finalizado este estudio y analizados los resultados de la investigación, en relación con los objetivos planteados y las hipótesis formuladas para este trabajo concreto se pueden exponer las siguientes conclusiones. En primer lugar, la inteligencia emocional y la autoeficacia parecen desempeñar un importante rol amortiguador de los dañinos efectos del $C B$. En segundo lugar, el fenómeno de $C B$ tiene una relación curvilínea con la edad, sin embargo, el fenómeno cada vez más se está dando a edades más tempranas y debido a las implicaciones y secuelas del fenómeno tanto en el momento en el que se vivencia como en el futuro, los profesionales del ámbito educativo y los investigadores deberían aunar esfuerzos para erradicarlo o al menos minimizar su aparición y sus efectos. En tercer lugar, una educación en inteligencia emocional y autoeficacia puede ayudar no solo a controlar el $C B$ sino a tener unos mejores resultados con las propias personas, es decir un buen nivel de inteligencia emocional puede ayudar a combatir el estrés, la depresión y puede llevar también a tener una mejor autoeficacia y en consecuencia mejor clima grupal y 
organizacional. Por lo tanto, educar en inteligencia emocional no solo a los estudiantes, sino a los docentes, las familias e intervenir a nivel de centro (organizacional) de manera que el objetivo sea crear centros educativos emocionalmente saludables.

A modo de conclusión el presente estudio pone de manifiesto que Las personas con alta autoeficacia muestran menores niveles de victimización, hay una relación curvilínea centre la edad y el $C B$ y la inteligencia emocional amortigua el estrés en las victimas de $C B$ de modo que a la luz de estos resultados se dibuja un panorama esperanzador debido a que si se trabaja la IE se podrían aminorar e incluso llegar a eliminar los efectos del estrés en las víctimas de $C B$. En este sentido, el ApS consistiría en que el alumnado de magisterio trabajara en los colegios y analizara longitudinalmente si el estrés en las víctimas de $C B$ disminuye con el tiempo por efecto de su intervención en mejorar los niveles de IE del alumnado.

\section{Bibliografía recomendada}

Álvarez, D., Núñez, J. C. y Dobarro, A. (2013). Cuestionarios para evaluar la violencia escolar en Educación Primaria y en Educación Secundaria: CUVE3 y CUVE3- ESO. Apuntes de Psicología. 31 (2), 191-202. Universidad de Oviedo (España).

Álvarez-García, D., Núñez, J. C., Rodríguez, C., Álvarez, L. y Dobarro, A. (2011). Propiedades psicométricas del Cuestionario de Violencia Escolar-Revisado (CUVE-R). Revista de Psicodidáctica. 16 (1), 59-83. Oviedo.

Avilés, J. M. (2013). Análisis psicosocial del ciberbullying: claves para una educación moral. Papeles del Psicólogo. 34 (1), 65-73.

Castellanos, V.M., Itzel, F. y Gámez, M. (2016). Cyberbullying: Un problema de salud mental entre adolescentes mexicanos. Revista Especializada en Ciencias de la Salud. 19 (1), 5-12.

Cerezo, F., Sanchez, C., Ruiz, C. y Arense, J. J. (2015). Roles en Bullying de adolescentes y preadolescentes, y su relación con el clima social y los estilos educativos parentales. Revista de Psicodidáctica. 20 (1), 139-155.

Elipe, P., Ortega, R., Hunter, S.C. y del Rey, R. (2012). Inteligencia emocional percibida e implicación en diversos tipos de acoso escolar. Psicología Conductual. 20 (1), 169-181. 
Esplugues, J. S. (2007). ¿Qué es violencia? Una aproximación al concepto ya la clasificación de la violencia. Daimon Revista Internacional de Filosofía, 42, 921.

Extremera Pacheco, N., y Fernández-Berrocal, P. (2004). El papel de la inteligencia emocional en el alumnado: evidencias empíricas. Revista electrónica de investigación educativa, 6(2), 1-17.

Fernández, G. D., Martínez, A. J., y García, M. J. C. (2017). Educar la virtualidad. Pixel-Bit. Revista de Medios y Educación, 50, 187-199.

Fernández, J. y Peñalva, A., Irazabal, I., (2015). Hábitos de uso y conductas de riesgo en Internet en la preadolescencia. Revista Científica de Educomunicación, Comunica. 44 (23) 113-120.

Fernández-Berrocal, P., y Extremera, N. (2006). Emotional intelligence: A theoretical and empirical review of its first 15 years of history. Psicothema, 18 (Suplemento), 7-12.

Fernández-Berrocal, P., y Ruiz Aranda, D. (2008). La Inteligencia emocional en la Educación. Electronic journal of research in educational psychology, 6 (2).

Garaigordobil, M. (2011). Prevalencia y consecuencias del cyberbullying: una revisión. International Journal of Psychology and Psychological Therapy. 11 (2), 233-254.

García, C.M., Romera, E.M. y Ortega, R. (2016). Relaciones entre el bullying y el cyberbullying: Prevalencia y co-ocurrencia. Pensamiento Psicológico. 14 (1), 49-61.

Giménez, A.M., Maquilón, J.J. y Arnaiz, P. (2015). Usos problemáticos y agrsivos de las TIC por parte de adolescentes implicados en cyberbullying. Revista de Investigación Educativa. 33 (2), 335-351.

Giménez, A.M., Maquilón, J.J y Arnaiz, P. (2015). Usos problemáticos y agresivos de las TIC por parte de adolescentes implicados en cyberbullying. Revista de Investigación Educativa. 33 (2), 335-351.

Glazer, S., Kożusznik, M. W., y Shargo, I. A. (2012). Global Virtual Teams: A Cure for-or a Cause of-Stress. In The Role of the Economic Crisis on Occupational Stress and Well Being (pp. 213-266). Emerald Group Publishing Limited.

Lucas-Molina, B., Pérez-Albéniz, A. y Gimenez-Dasí, M. (2016). La evaluación del cyberbullying: situación actual y retos futuros. Papeles del Psicólogo. 37 (1), 27-35.

Maquilón, J. J., Giménez, A.M., Hernández, F. y García, A. (2011). La victimización en las dinámicas de ciberbullying en centros educativos de la Región de Murcia. International Journal of Developmental and Educational Psychology. 1 (2), 265-275. 
Navarro, R. y Yubero S. (2012). Impacto de la ansiedad social, las habilidades sociales y la cibervictimización en la comunicación online. Escrito de Psicología. $5(3), 4-15$.

Ortega, R., Elipe, P., Mora-Merchán, J. A., Genta. M. L., Brighi, A., Guarini, A., Smith, P. K., Thompson, F., y Tippet, N. (2012). The emotional impact of bullying and cyberbullying on victims: a European cross-national study. Aggressive Behavior, 38 (5), 342-356.

Pérez, B. y Vicario-Molina, I. (2016). Cyberbullying en la Educación Primaria: Análisis de la Incidencia de la Victimización y la Búsqueda de Apoyo. Psicología y Educación: Presente y Futuro. 2421-2429.

Polo del Río, M. I., León del Barco, B., Felipe, E. y Gómez, T. (2014). Cyberbullying en tercer ciclo de Educación Primaria: variables moduladoras y consecuencias sobre la ansiedad. Apuntes de Psicología. 32 (1), 5-14.

Romera, E.M., Cano, J. J., García-Fernández, C. y Ortega-Ruiz, R. (2016). Cyberbullying: competencia social, motivación y relaciones entre iguales. Revista Científica de Educomunicación, Comunicar. 48 (24), 71-79.

Salovey, P., y Mayer, J. D. (1990). Emotional Intelligence. Imagination, Cognition and Personality, 9, 185-211.

Sánchez, V., Ortega, R. y Menesini, E. (2012). La competencia emocional de agresores y víctimas de bullying. Anales de Psicología. 28 (1), 71-82.

Vilariño, M., Amado, B.G. y Alves, C. (2013). Menores infractores: un estudio de campo de los factores de riesgo. Anuario de Psicología Jurídica. 23, 39-45. 
Capitulo 9. El rol de IE y AF en la relación CB- estrés, ansiedad y depresión.

Ayuntamient
je Huesca

II Jornadas ApS y responsabilidad social

CLxidy Facultad de Ciencias Humanas y de la Educación de la Universidad de Zaragoza 7 on onventero 2017 iㅛㄹ

El rol de la inteligencia emocional y la autoeficacia en la relación entre el ciberbullying "victimización" y el estrés, la ansiedad y la depresión. Loreto Tomey, Eva M. Lira, Mara Socolovski, y Ana Moreno

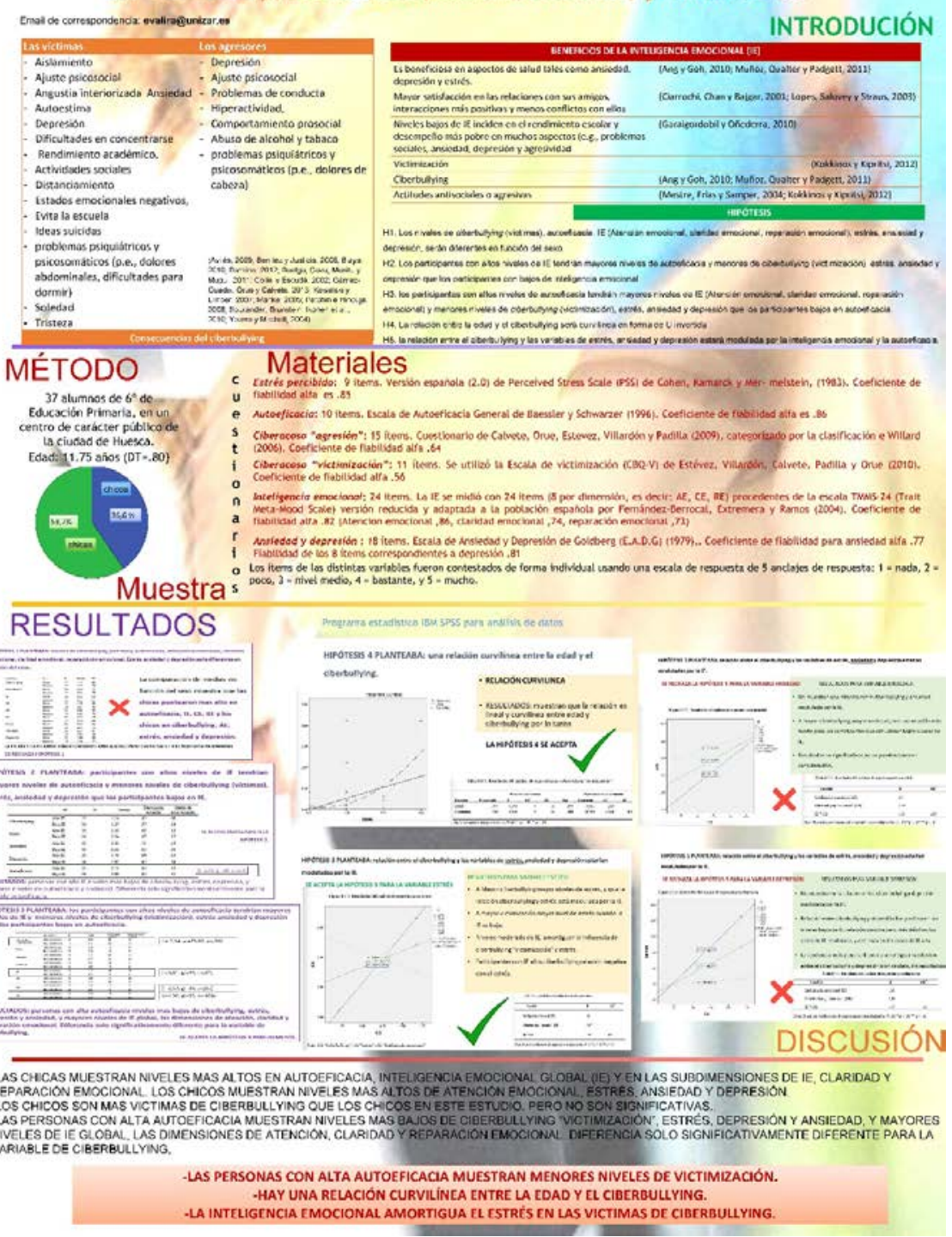




\title{
La relación entre el ciberbullying y las quejas somáticas en función del sexo.
}

\author{
Cristina Artal, Eva M. Lira, Ana Moreno y Mara Socolovski \\ Universidad de Zaragoza \\ evalira@unizar.es
}

\section{Resumen}

El objetivo del presente estudio es analizar la relación entre el ciberbullying "acosadores y victimas" y las quejas somáticas en función del sexo. Para ello, se realizó un estudio con 45 alumnos de dos colegios de Educación Primaria de Aragón. Los resultados mostraron que la media de ciberbullying "agresores y victimización" es mayor en chicos que en chicas, aunque la diferencia no es significativa y prácticamente nula en el caso de "acosadores". La relación entre victimización y quejas somáticas es positiva, sin embargo, esta relación positiva es más marcada en las chicas víctimas de acoso que en los chicos. No obstante, los resultados, aunque se han graficado para observar la tendencia no pueden ser tenidos en consideración debido a que no alcanzan el nivel de significación requerida. Sin embargo, la relación entre chicas acosadoras y quejas somáticas es positiva mientras que esta relación es negativa en chicos acosadores de forma significativa.

Palabras clave: ciberbullying, acosadores, víctimas, quejas somáticas, sexo. 


\subsection{Introducción}

Tal y como informa el Instituto Nacional de Estadística (INE, 2016) el 81,9\% de los hogares españoles tienen conexión a internet. Las Tecnologías de la Información y la Comunicación (TICs), presentan múltiples ventajas tales como la ruptura de las barreras espaciotemporales, la interacción con la información y su utilización como recurso de aprendizaje, y además es una ayuda para los profesores en su metodología (Almenara, 2007; Soto, Senra y Neira, 2009; Domingo Coscollola y Fuentes Agustí, 2010; Domingo y Marquès, 2011). No obstante, también han hecho posible la aparición de fenómenos como el ciberbullying (Hernández Prados y Solano Fernández, 2007; Mondragón, 2013).

El constructo de ciberbullying ha sido utilizado de forma intercambiable con otros constructos relacionados tales como agresión, conflicto y violencia. La Real Academia de la Lengua (RAE) define agresión como un acto de acometer a alguien para matarlo, herirlo o hacerle daño. Según la Convención sobre los Derechos del Niño (CDN), la definición de agresión es: “(...) toda forma de perjuicio o abuso físico o mental, descuido o trato negligente, malos tratos o explotación, incluido el abuso sexual, (...)". Estas definiciones ponen de manifiesto que en ocasiones los constructos de agresividad y violencia se han utilizado de manera intercambiable. Sin embargo, siendo puristas la agresividad es una conducta innata de los seres vivos que surge como respuesta a un estímulo aversivo y se extingue con la retirada del estímulo, no hay intencionalidad de dañar "gratuitamente" (Sanmartín, 2000; Sanmartín, 2002).

Otro de los términos relacionados es el de conflicto, ya que a pesar de tener consecuencias positivas (p.ej., cambio, innovación) y/o negativas (p. ej., enfados) (Lira, Ripoll, Peiró y González, 2007; Lira, Ripoll, Peiró y Orengo, 2008), si no se gestiona de manera adecuada puede dar lugar a una agresión o a algún tipo de violencia. Es por ello que en muchos centros educativos se están realizando actividades para la mediación de conflictos (como prevención primaria para que no derive en violencia) (Delgado-Salazar y Lara-Salcedo, 2008; Fernández, 2010; Chaux, 2011), eligiendo a dos o tres personas por curso o clase, que suelen ser los delegados, para enseñarles las formas o maneras que existen para que los conflictos o roces que puedan aparecer se resuelvan en el menor tiempo posible y de la mejor manera, y una de estas maneras son los pactos. 
Los pactos son dispositivos que permiten tratar los conflictos para una convivencia democrática, como una construcción permanente y colectiva de formas participativas, para responder a los cambios y a las necesidades institucionales (Ruiz, 2006, p. 129)

Por tanto, la violencia es una de las consecuencias en las que podría derivar (o no) un conflicto. La violencia es una acción que se utiliza en muchas situaciones de la vida cotidiana, no tiene por qué ser violencia física, sino que puede ser de tipo indirecto o psicológica, es decir, mediante amenazas, avisos o advertencias (Fernández, 2010). Según la RAE, violencia es la acción violenta o contra el natural modo de proceder. Por tanto, la violencia escolar es un tipo de violencia que tiene lugar en el ámbito educativo (p. ej., colegios e institutos), además al igual que los demás tipos de violencia tiene consecuencias negativas tanto para la víctima como para el agresor (Cava, Musitu y Murgui, 2006). En muchos casos, la influencia de la familia resulta crucial para que se produzca (o no) este comportamiento violento. Las relaciones familiares, por tanto, continúan siendo un elemento relevante en el análisis de la conducta y estilo de vida del niño (Rodrigo et al, 2004).

Por otro lado, uno de los tipos de violencia que ha recibido mucha atención en los últimos años debido a sus nefastas consecuencias es el tipo de violencia que además de ser una conducta dañina e intencional, se realiza de forma repetitiva y continuada en el tiempo entre iguales provocando un hostigamiento en la víctima, denominado bullying o acoso escolar. El fenómeno de bullying no es nuevo, aunque durante años ha permanecido oculto debido a que en muchos casos se intentaba encubrir tanto por parte de las propias víctimas como por los agresores (Fernández, 2010), como por los centros educativos. Las víctimas suelen tener miedo de que nos les ayuden o que el agresor les pueda hacer algo peor de lo que ya le estaba haciendo e incluso vergüenza y culpa, los agresores por vergüenza o, directamente, porque no quieren darse cuenta del mal que ellos mismos están haciendo. En cambio, algunos centros educativos lo hacen para que no les perjudique a la hora de atraer más estudiantes, o para que no se vayan los que están allí, es decir, que no se cree mala publicidad o imagen.

El bullying puede ser de varios tipos: físico, psicológico, verbal, sexual, social o ciberbullying (Gutiérrez y Gutiérrez Gutiérrez, 2009; Cobo y Tello, 2008; López y Chávez, 2011; Gómez Nashiki, 2013; Magaz, Chorot, Santed, Valiente y Sandín, 2016). Según la literatura disponible, el ciberbullying o ciberacoso es un fenómeno nuevo y claramente diferenciado del bullying o un tipo de bullying a través de las 
Tecnologías de Información y Comunicación (TICs), que incluso podría ser la más utilizada en la actualidad por los jóvenes para hacer daño de forma intencionada y repetitiva a sus iguales. Esto podría ser debido, a la cantidad de jóvenes que tienen acceso a cualquier dispositivo electrónico con conexión a internet, casi desde cualquier sitio, como se ha dicho anteriormente, además de que este acoso se puede hacer de forma anónima en muchos casos (Oñederra, 2008; Suárez Vilagran, 2013; Arteaga Bravo, 2014; Morales-Reynoso y Serrano-Barquín, 2014), por lo que en ocasiones no se puede identificar al acosador. Asimismo, en muchos casos, los padres no pueden, por desconocimiento, observar tanto si su hijo/a recibe este acoso o lo realiza, debido a que podría desconocer la actividad en internet de sus hijo/as.

En cuanto a las diferencias en función del sexo, Aricak et al. (2008) analizaron la influencia de las experiencias compartidas sobre el ciberbullying, en una muestra de 249 niños de Turquía, los resultados de este estudio mostraron que el 35,7\% eran acosadores, el 23,8\% eran víctima-agresor, el 5,9\% eran víctimas. Además, la mayoría de los chicos tenían conductas de acosador, y las chicas de víctima. Asimismo, el estudio indicó que el $25 \%$ de las víctimas dijo haberlo comunicado. En este sentido, Rubio, Piserra, y Fonseca Pedrero (2016) analizaron las consecuencias del bienestar emocional en los adolescentes, en una muestra de 1664 niños de La Rioja, los resultados de este estudio indicaron que un $7,7 \%$ de los adolescentes muestran posible riesgo de mala salud mental, siendo más alto entre las chicas. Además, el 2\% de los encuestados afirman que se producen fenómenos de ciberbullying varias veces a la semana en su centro escolar. El 1,8\% de los hombres y el $2,2 \%$ de las mujeres afirmaron que suceden estos fenómenos en los últimos dos meses. En el estudio de O'More (2009) se analizó el ciberbullying, en una muestra de adolescentes de Dublín, los resultados de este estudio sugieren que el 18\% de los encuestados están implicados en conductas de ciberbullying (aunque más chicas). Un 4\% son acosadores y víctimas. En 2009 se informó que: 15,6\% de las chicas son víctimas de acoso, y 6,9\% de chicos. Entre 4-5\% son víctima y acosador, en estos casos son chicos con problemas de comportamiento y déficits emocionales. Li (2007) encuentra en una muestra de 177 niños de Canadá que el 60\% de las ciber-víctimas son mujeres, y 52\%, hombres. Hinduja and Patchin (2008) analizo a las víctimas de ciberbullying en una muestra de 6800 niños de EEUU, los resultados mostraron que el $18 \%$ fueron chicos y 15,6\%, chicas. Del Río, Bringue, Sábaba y Gónzalez (2010) analizaron el ciberbullying en adolescentes, en una muestra de 20941 niños de Argentina, Brasil, Chile, Colombia, México, Perú y Venezuela, los resultados de este estudio mostraron que el 12,1\% había sufrido una forma de ciberbullying, el 13,3\% reconoció haber perjudicado con su móvil. Con respecto al 
sexo: $22,4 \%$ ciber-acosadores hombres, el $13,4 \%$ chicas. El 19,25\% de las víctimas son chicos y chicas, 13,8\%. McLoughlin, Burgess y Meyricke (2009) analizaron una muestra de 349 niños de Australia, los resultados de este estudio mostraron que el $24 \%$ son víctimas de ciberbullying a través de mensajes instantáneos, teléfonos móviles, y en espacios de redes sociales, siendo las niñas más propensas a ello. Félix Mateo, Soriano Ferrer, Godoy Mesas y Sancho Vicente (2010) analizaron la prevalencia del ciberbullying en relación con la edad y el sexo, en una muestra de 1028 niños de Comunidad Valenciana, los resultados de este estudio indicaron que el 3\% de las incidencias que les ocurrieron a los encuestados era de ciberbullying ( $74 \%$ por mensajes con insultos o amenazas y el $26 \%$ por difusión de fotos o videos con vejación o palizas). Además, se observó que las mujeres solían ser más las víctimas y los hombres más los acosadores. León del Barco, Felipe Castaño, Fajardo Bullón y Gómez Carroza (2012) analizaron la influencia del género, la edad y ser usuario de redes sociales en el ciberbullying y sus diferentes tipos, en una muestra de 1700 niños de Extremadura, los resultados de este estudio sugieren que el $6,4 \%$ eran agresores y el $6 \%$, víctimas. Además, se observa que las agresiones suelen ser más a través del móvil que por internet. Noret y Rivers (2006) analizaron la prevalencia del ciberbullying en mensajes y correo electrónico en una muestra de 11000 niños de Reino Unido, los resultados de este estudio sugieren que la frecuencia de haber recibido mensaje de texto o e-mail desagradable o amenazante son: $1,5 \%$ "de vez en cuando", $0,7 \%$ "a menudo", $0,6 \%$ "continuamente". El porcentaje de chicas acosadas en 2002 fue $14,7 \%$, en $2005,21,4 \%$; mayor que en los chicos que en 2002 fue de 12,4\% y en 2005 fue de 11,6\%. Calvete, Orue, Estévez, Villardón y Padilla (2010) analizaron las consecuencias de las modalidades y el perfil de los agresores en el ciberbullying, en una muestra de 1431 niños de Vizcaya, los resultados de este estudio indicaron que el 44,1\% de los encuestados han cometido al menos un acto de ciberbullying, además lo suelen realizar más los hombres. Muñoz Olmos (2015) analizó la influencia entre las distintas formas de expresión de la ira, los procesos de violencia y victimización en el contexto escolar, en una muestra de 2552 niños de Murcia, los resultados de este estudio indicaron que existen diferencias entre hombres y mujeres en cada una de las dimensiones de la violencia escolar, excepto en la ira internalizada. Además, los hombres expresan menos la ira hacia fuera y tienen un menor control de la ira. Sin embargo, no hay diferencias entre cursos en ira internalizada y control de ira. Cardozo, Dubini, Fantino, Serra, y Ramallo (2016) analizaron las diferencias del bullying y el ciberbulling entre colegios públicos y privados, así como su relación con el sexo, en una muestra de 3500 niños de Argentina, los resultados de este estudio indicaron que no hay diferencias significativas entre adolescentes de escuelas privadas y públicas, 
ni entre los roles de víctima y agresor. Tampoco hay diferencias en cuanto al sexo, aunque hay más agresores hombres. Si se hallaron diferencias entre ciber-observadores (encontrando más en las escuelas privadas). En cuanto a la edad, Garaigordobil (2015) analizó la influencia de la edad en el ciberbullying, en una muestra de 3026 niños de País Vasco, los resultados de este estudio mostraron que aumenta el número de agresores y de observadores a medida que aumenta la edad, además de la media de conductas de ciberbullying que se realizan y se perciben. Por tanto, según los estudios de Martínez (2010), Río-Pérez, Sádaba y Bringué (2010), Oliveros, Amemiya, Condorimay, Oliveros, Barrientos y Rivas (2012), Lucas López (2014), Rodas Mosquera, Vázquez Moscoso, Samaniego y Oswaldo (2014), Sabater Fernández y López-Hernáez (2015), Pérez y Vicario-Molina (2016), existen más agresores del sexo masculino que del femenino, y en cambio en la victimización es lo contrario, es decir, hay más mujeres ciber-víctimas que hombres. En cambio, según Morales-Reynoso y Serrano-Barquín (2014) aparecen más mujeres ciber-agresoras que hombres, aunque en el caso de bullying tradicional sigan siendo más acosadores los hombres.

Las principales consecuencias del ciberbullying en las víctimas que han sido identificadas, son: 1) Tensión: esta es debida a la ansiedad que provoca a las víctimas por el temor a encontrarse con los agresores o recibir mensajes, imágenes y videos que les humillen; 2) Autoestima baja: es la carencia de confianza que tiene la persona en sí mismo; 3) Pesimismo: es debido a que las personas se sienten mal consigo mismas, y esto provoca pensamientos negativos; 4) Tristeza: la persona está desanima y se pone a llorar por esta situación; 5) Aversión al ambiente en que se encuentre: la persona intenta mantener aislado del resto; 6) Suicidio: se llega a un punto donde la persona no puede soportar más abusos ni agresividad. Por lo tanto, la comunidad educativa se enfrenta al reto de dar soluciones a estas severas consecuencias de este fenómeno en auge, es decir, crear tareas de prevención e intervención que sirvan para dar respuesta tanto para las consecuencias que tiene en las víctimas, los agresores y los espectadores, como para el propio bullying y/o ciberbullying. Con esto último, se hace referencia a la concienciación de los jóvenes del peligro del uso de las nuevas tecnologías para ejercer violencia, y lo que conlleva realizar acciones de bullying y/o ciberbullying. No obstante, las consecuencias aunque en líneas generales sirven de guía, afectan de manera diferente a cada persona, y esto implica diferentes niveles de sufrimiento. Aunque, este tipo de acoso siempre afectará negativamente a las víctimas, a los agresores y a los testigos en su comportamiento actual y futuro, y con ello tener mayor riego a la hora de sufrir desajustes psicosociales y trastornos psicopatológicos tanto en la adolescencia como 
en la vida adulta. En concreto, el objetivo del presente trabajo es analizar la relación entre el ciberbullying "acosadores y victimas" y las quejas somáticas en función del sexo. Con respecto a las quejas somáticas, Monforte Fuentes (2015), CastroMorales (2011), Novo, Seijo, Vilariño, y Vázquez (2013), Hernández (2017), Rodríguez Puentes y Fernández Parra (2014), Guardiola (2011), Clínicas (2011), Mantecón Contreras (2013), indican que los jóvenes tienen síntomas somáticos al ser víctimas de bullying o ciberbullying. Algunos de los síntomas en estos niños/as son problemas para dormir, dolores de cabeza y de estómago, problemas en el control del esfinter por las noches y cansancio constante. En muchos casos, las mujeres muestran un mayor número de síntomas somáticos que los hombres, cuando sufren ciberbullying o bullying, e incluso cuando son ellas quienes ejercen el bullying. Por lo tanto, en base a los argumentos previamente expuestos se plantean las siguientes hipótesis de trabajo:

Hipótesis 1. Los chicos puntuarán más en agresión y las chicas más en victimización.

Hipótesis 2. Las personas que puntúen por encima de la media en victimización tendrán mayores niveles de quejas somáticas.

Hipótesis 3. Las chicas víctimas de acoso tendrán mayores niveles de síntomas somáticos que los chicos.

Hipótesis 4. Las agresoras chicas tendrán mayores niveles de síntomas somáticos que los chicos.

\subsection{Participantes}

La muestra con que se ha contado para realizar este estudio es de 45 alumnos de $6^{\circ}$ de Educación Primaria de dos colegios de la Comunidad Autónoma de Aragón don edades entre 11 y 13 años, 15 niños tenían 11 años (33.3\%), 28 niños tenían 12 años (62.2\%) y 2 niños tenían 13 años (4.4\%). 20 son niños representando un $44.4 \%$ y 25 son niñas representando un $55.6 \%$ de la muestra total en el estudio.

\subsection{Medidas}

Ciberbullying: Se midió con 6 ítems de los 15 ítems del cuestionario de Calvete, Orue, Estevez, Villardón y Padilla (2009). Algunos de estos ítems son: "colgar imágenes en internet de un conocido/a o compañero/a que pueden ser humillantes (por ejemplo, de cuando se está vistiendo en el vestuario del gimnasio)" y "conseguir la contraseña (nicks, claves, etc.) de otra persona y enviar mensajes con su 
nombre por e-mail que le podían hacer quedar mal ante los demás o crearle problemas con sus conocidos". El tipo de respuesta era de tipo Likert de 5 opciones, las posibles respuestas eran (1) nunca, (2) poco, (3) nivel medio, (4) bastante y (5) mucho. Las categorías de este cuestionario se centraron en las manifestaciones del ciberbullying de la clasificación de Willard (2006) que fue la primera que existió y una de las más consideradas en el estudio de ciberbullying. El coeficiente alfa fue de .71, para ello se tuvieron que eliminar el ítem 1, 2, 5, 6, 7, 11, 13, 14 y 15 .

Victimización: Se utilizó 9 ítems de la escala de victimización (CBQ-V) de Estévez, Villardón, Calvete, Padilla y Orue (2010). Adolescentes víctimas de ciberbullying: prevalencia y características. Psicología conductual. Esta escala consta de 10 ítems adaptados de la clasificación de Willard (2006) que describen 11 formas en las que se podía sufrir ciberbullying como "enviarme mensajes amenazantes o insultantes por teléfono móvil", "difundir online secretos, información comprometida o imágenes sobre mí", y "gravarme en video o sacarme fotografías con el móvil en algún tipo de comportamiento de índole sexual". El tipo de respuesta era de tipo Likert de 5 anclajes de (1) nunca, (2) poco, (3) nivel medio, (4) bastante y (5) mucho. El coeficiente alfa fue de .70, para ello se tuvo que eliminar el ítem 4 "escribir bromas, rumores, chismes o comentarios que me ponían en ridículo".

Quejas somáticas. Se midieron mediante 21 quejas de las 54 de la escala "Pennebaker Inventory of Limbic Languidness (PIL)" de Pennebaker (1982). Esta escala mide la frecuencia de aparición de un grupo de síntomas y sensaciones físicas comunes. El alfa de Cronbach es de.74. El tipo de respuesta era de tipo Likert de 5 opciones y según el tipo de pregunta las posibles respuestas eran (1) nunca o casi nunca, (2) tres o cuatro veces al año, (3) cada mes, (4) cada semana, y (5) más de una vez por semana. Algunas de las quejas somáticas son: "torpe o entumecido", "con latidos del corazón fuertes y acelerados", y "con miedo a perder el control".

\subsection{Análisis de datos}

En este trabajo se efectuaron diversos análisis de datos para obtener los resultados. En primer lugar, se han recogido las respuestas obtenidas de los cuestionarios de los estudiantes y se han plasmado en forma de tablas y figuras. Para ello se ha utilizado el programa estadístico IBM SPSS Statistics 22 y el programa Excel de Microsoft Office 2013. En segundo lugar, a través del SPSS se calcularon los índices de fiabilidad, considerando una fiabilidad adecuada a partir de un coeficiente de fiabilidad (alfa de Crombach) por encima de .70 (Nunnally, 1978), y también se 
calcularon los parámetros de centralización (medias aritméticas) y dispersión (desviación estándar). También se calcularon las correlaciones entre todas las variables usando el programa SSPS mediante el coeficiente de correlación $r$ de Pearson. Las correlaciones se han considerado significativas tomando como referencia un nivel de significación de $\mathrm{p}<.05 \mathrm{y}$ de $\mathrm{p}<.01$ Además, para examinar la correlación entre las medidas incluidas en el estudio y el sexo, debido a que son variables dicotómicas se codificaron como " 0 "chica, y " 1 " chico. A continuación, se realizó una prueba t para muestras independientes para comprobar si había diferencias significativas entre las medias de las variables según el sexo. Por último, mediante el SPSS se midieron las interacciones, es decir, cómo la relación entre la variable dependiente y la independiente podía estar modulada por una variable dependiente moduladora, en este caso el sexo. Para ello, se utilizó el método de Hayes (2013) descrito en el siguiente sitio web, http://afhayes.com/spss-sas-and-mplus-macrosand-code.html. Así, la significación menor de $\mathrm{p}<.10$ nos muestra que es significativa la interacción estudiada. En los efectos de interacción el límite convencional del nivel de $\mathrm{p}$ es de .10. Este nivel de $\mathrm{p}$ ha sido sugerido por varios investigadores (Caplan y Jones, 1975; Champoux y Peters, 1987; Rodríguez, Bravo, Peiró y Schaufeli (2001) para proteger al test de la probabilidad de cometer un error Tipo II cuando se realizan los análisis de modulación. Así pues, con el uso de estos programas estadísticos se han obtenido los resultados expuestos en el siguiente apartado.

\subsection{Resultados}

Los descriptivos (medias y desviaciones típicas) de cada una de las variables estudiadas, y las correlaciones, se muestran en la tabla 1.

Tabla 1. Correlaciones de las variables consideradas en el estudio.

\begin{tabular}{|c|c|c|c|c|c|c|c|}
\hline & $M$ & $D T$ & 1 & 2 & 3 & 4 & 5 \\
\hline 1. Ciberbullying "Agresores" & 1,03 & ,11 & 1 & & & & \\
\hline 2. Ciberbullying "Victimas" & 1,07 & , 16 & ,07 & 1 & & & \\
\hline 3. Quejas Somáticas & 1,52 & ,39 &, 10 &, 22 & 1 & & \\
\hline 4. Sexo &, 56 &, 50 & ,04 &, 14 &, 01 & 1 & \\
\hline 5. Edad & 11,71 &, 55 & ,08 &,- 11 &, 02 & 27 & 1 \\
\hline
\end{tabular}

$* * \mathrm{p}<.01$. La correlación es significativa en el nivel 0,01 ( 2 colas $) ; * \mathrm{p}<.05$ La correlación es significativa en el nivel 0,05 ( 2 colas). 
La hipótesis 1 planteaba que los chicos puntuarían más en agresión y las chicas más en victimización. Los resultados muestran que la media de Ciberbullying "Agresores" es mayor en chicos $(\mathrm{M}=1.03, \mathrm{DT}=.11)$ que en las chicas $(\mathrm{M}=1.02, \mathrm{DT}=.11)$, aunque esta diferencias es prácticamente inapreciable. Los resultados muestran que la media de Ciberbullying "Victimización" es mayor en chicos $(\mathrm{M}=1.08, \mathrm{DT}=.19)$ que en las chicas $(\mathrm{M}=1.04, \mathrm{DT}=.13)$. La media de quejas somáticas también es mayor en chicos $(\mathrm{M}=1.52$, DT $=.32)$ que en chicas $(\mathrm{M}=1.51$, $\mathrm{DT}=.47)$. No obstante, estas diferencias no son significativa. Por tanto, se rechaza la H1.

Tabla 2. Comparación de medias y prueba t para muestras independientes

\begin{tabular}{llllll}
\hline & Sexo & $M$ & DT & t & gl \\
\hline Ciberbullying "Agresores" & $0=$ Chica & 1,02 &, 11 & & \\
& $1=$ Chico & 1,03 &, 11 &,- 25 & 43 \\
Ciberbullying "Victimas" & $0=$ Chica & 1,04 &, 13 & & \\
& $1=$ Chico & 1,09 &, 19 &,- 90 & 43 \\
Quejas Somáticas & $0=$ Chica & 1,51 &, 47 & & \\
& $1=$ Chico & 1,52 &, 32 &,- 07 & 43 \\
\hline
\end{tabular}

** $p<.01$. La correlación es significativa en el nivel 0,01 (2 colas) ${ }^{*} p<.05$ La correlación es significativa en el nivel 0,05 (2 colas).

La hipótesis 2 planteaba que las personas que puntuaran por encima de la media en victimización tendían mayores niveles de quejas somáticas. Los resultados muestran que las personas que puntuaron por encima de la media en victimización mostraron una media mayor en quejas somáticas $(\mathrm{M}=1.63, \mathrm{DT}=.37)$ que las personas que puntuaron por debajo de la media en victimización $(\mathrm{M}=1.47$, $\mathrm{DT}=.39)$. No obstante, esta diferencia no alcanza el nivel de significación requerido. Es por ello que se rechaza la $\mathrm{H} 2$.

Tabla 3. Comparación de medias

\begin{tabular}{lllllll}
\hline & $\begin{array}{l}\text { Ciberbullying } \\
\text { "Victimas" }\end{array}$ & $\mathrm{N}$ & $M$ & $\mathrm{DT}$ & $\mathrm{t}$ & $\mathrm{gl}$ \\
\hline Quejas Somáticas & Alta victimización & 13 & 1,63 & .37 & & \\
& Baja victimización & 32 & 1,47 & .39 & 1,26 & 43 \\
\hline
\end{tabular}

La hipótesis 3 planteaba que las víctimas de acoso chicas tendrán mayores niveles de síntomas somáticos que los chicos. Los resultados muestran que la relación entre victimización y quejas somáticas es positiva $(\mathrm{B}=1.19, \mathrm{p}<.10)$, sin embargo, esta relación positiva es más marcada en las chicas víctimas de acoso que en los chicos. No obstante, los resultados, aunque se han graficado para observar la tendencia no 
pueden ser tenidos en consideración debido a que no alcanzan el nivel de significación requerida $(\mathrm{B}=-.89, \mathrm{~ns})$. Por tanto, se rechaza la $\mathrm{H} 3$.

Tabla 4. Resultados del análisis de regresión para quejas somáticas.

\begin{tabular}{llll}
\hline Variable & $\mathrm{B}$ & $\mathrm{R}$ & $\Delta \mathrm{R}^{2}$ \\
\hline Ciberacoso "Victimización" & $1,19 \dagger$ & & \\
Sexo &, 92 & & \\
Victimización * sexo &,- 89 & .08 & .03 \\
\hline Nota: B son los coeficientes de la regresión no estandarizados. $\dagger<.10 * \mathrm{p}<.05 * * \mathrm{p}<.01$
\end{tabular}

Figura 1. Resultados del análisis de regresión para quejas somáticas.

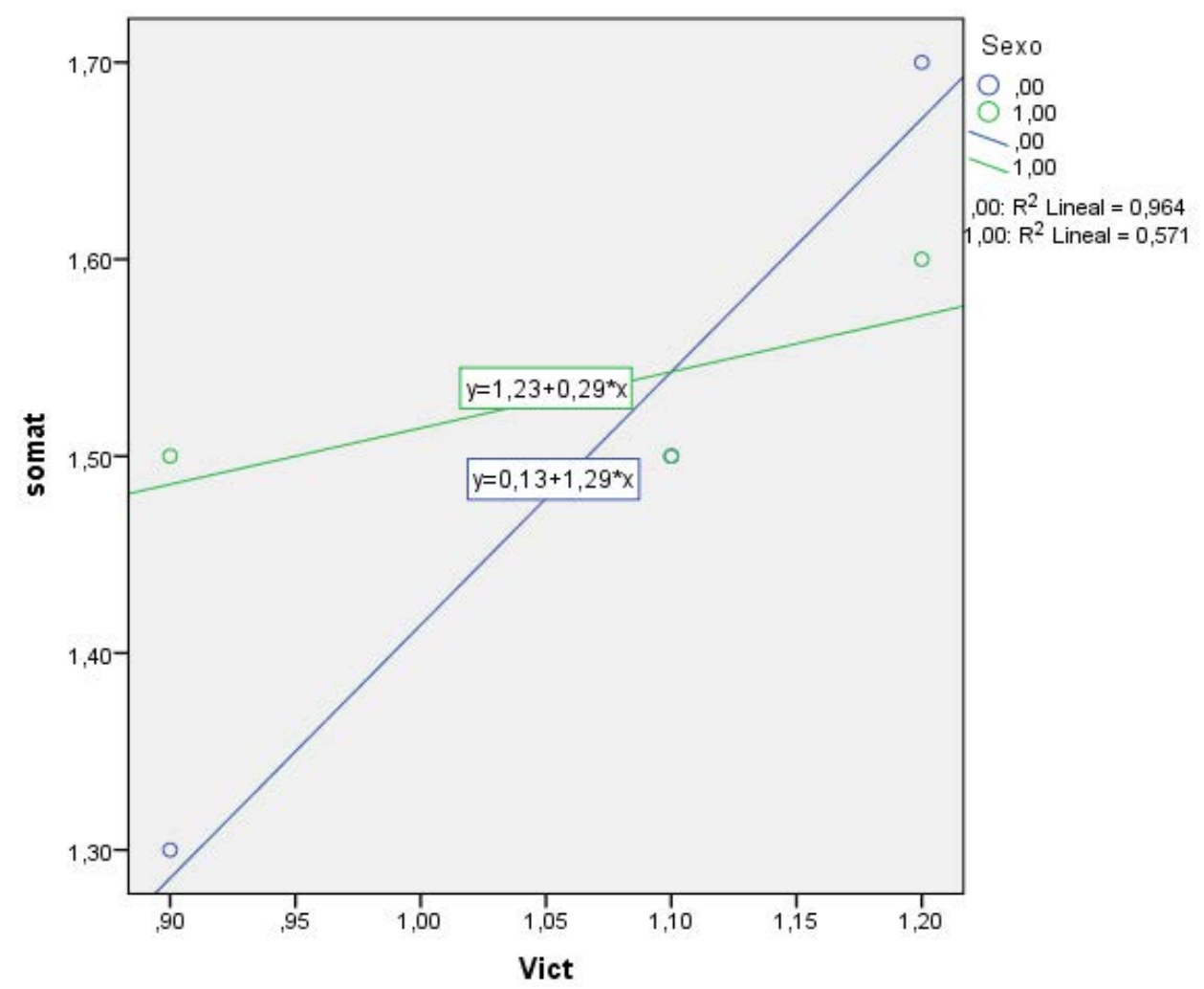

Nota. Victimización "Vict”; Quejas somáticas "somat". 
La hipótesis 4 planteaba que las agresoras chicas tendrán mayores niveles de síntomas somáticos que los chicos. Los resultados muestran que en las chicas la relación entre victimización y quejas somáticas es positiva, sin embargo, esta relación es negativa en los chicos $(B=-1.96, p<.10)$. Por tanto, se acepta la $\mathrm{H} 4$.

Tabla 5. Resultados del análisis de regresión para quejas somáticas

\begin{tabular}{|c|c|c|c|}
\hline Variable & B & $\mathrm{R}$ & $\Delta \mathrm{R}^{2}$ \\
\hline Ciberacoso "Agresores" & $1,43 \dagger$ & & \\
\hline Sexo $2,02 \dagger$ & & & \\
\hline Agresores * sexo & $-1,96 \dagger$ & .09 & $.07 \dagger$ \\
\hline
\end{tabular}

Figura 2. Resultados del análisis de regresión para quejas somáticas

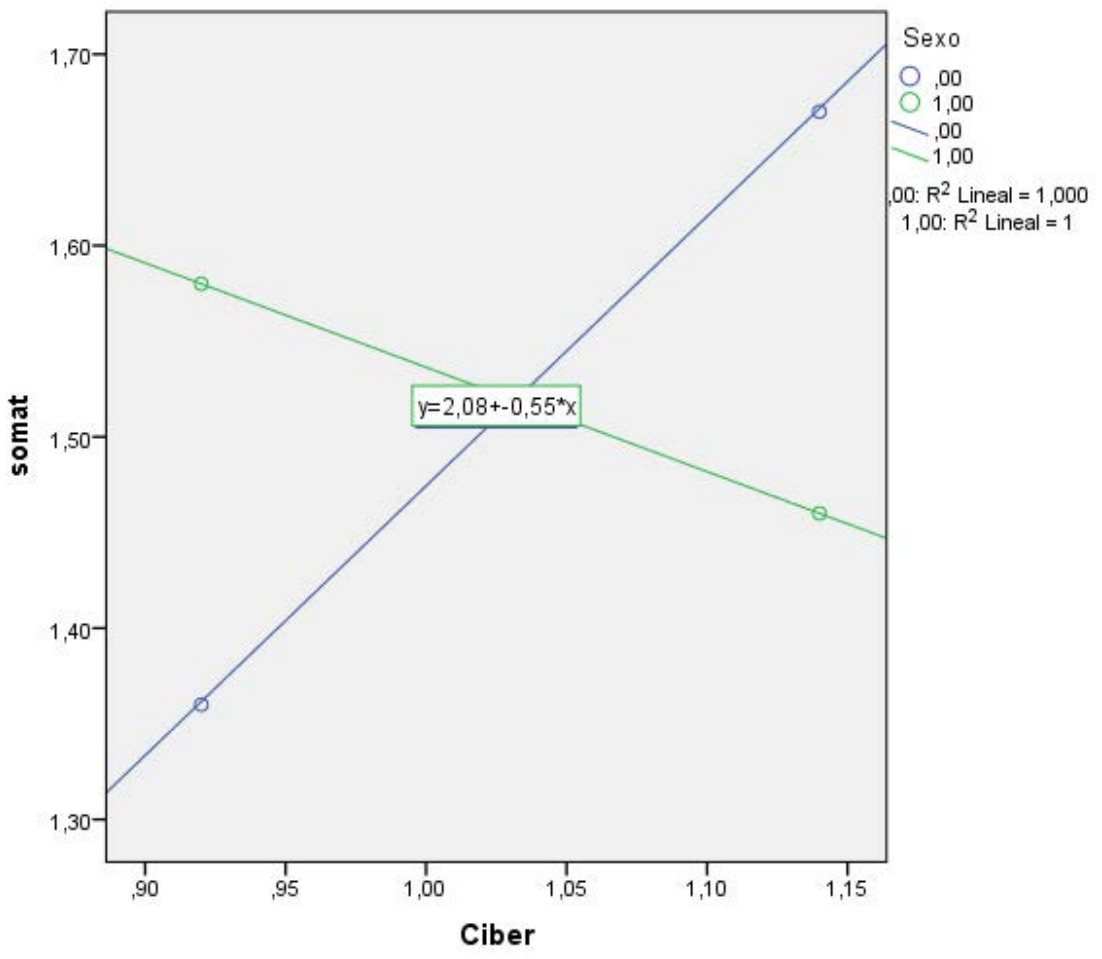

Nota. Ciberacosadores "Ciber"; Quejas somáticas "somat". 


\subsection{Discusión}

El objetivo del presente estudio era analizar la relación entre ciberbullying "agresores y victimas" y quejas somáticas en función del sexo. La hipótesis 1 planteaba que los chicos puntuarían más en agresión y las chicas más en victimización. Los resultados muestran que la media de ciberbullying "Agresores" es mayor en chicos que en las chicas aunque se podría decir que la diferencia es prácticamente nula. Los resultados muestran que la media de ciberbullying "Victimización" es mayor en chicos que en las chicas, esta diferencia es mayor que en ciberbullying "Agresores". La media de quejas somáticas también es mayor en chicos que en chicas. No obstante, estas diferencias no son significativa. Por tanto, se rechaza la H1. Por lo tanto, estos resultados están en línea con lo indicado en los estudios de Martínez (2010), Río-Pérez, Sádaba y Bringué (2010), Oliveros, Amemiya, Condorimay, Oliveros, Barrientos y Rivas (2012), Lucas López (2014), Rodas Mosquera, Vázquez Moscoso, Samaniego y Oswaldo (2014), Sabater Fernández y López-Hernáez (2015), Pérez y Vicario-Molina (2016), que indicaron que los hombres puntúan más como agresores. En cambio, no apoyan lo mostrado en el estudio de MoralesReynoso y Serrano-Barquín (2014), que indicaban que las mujeres eran más agresoras que los hombres. La hipótesis 2 planteaba que las personas que puntuaran por encima de la media en victimización tendían a tener mayores niveles de quejas somáticas. Los resultados muestran que las personas que puntuaron por encima de la media en victimización mostraron una media mayor en quejas somáticas que las personas que puntuaron por debajo de la media en victimización. No obstante, esta diferencia no alcanza el nivel de significación requerido. Es por ello que se rechaza la $\mathrm{H} 2$. Con respecto a estos resultados, se puede decir que están en línea con lo encontrado en los estudios de Monforte Fuentes (2015), Castro-Morales (2011), Novo, Seijo, Vilariño, y Vázquez (2013), Hernández (2017), Rodríguez Puentes y Fernández Parra (2014), Guardiola (2011), Clínicas (2011), Mantecón Contreras (2013), que como se ha indicado anteriormente, explicaban que cuanta más victimización más efectos somáticos tienen las personas. La hipótesis 3 planteaba que las víctimas de acoso chica tendrían mayores niveles de síntomas somáticos que los chicos. Los resultados muestran que la relación entre victimización y quejas somáticas es positiva, sin embargo, esta relación positiva es más marcada en las chicas víctimas de acoso que en los chicos. No obstante, los resultados, aunque se han graficado para observar la tendencia no pueden ser tenidos en consideración debido a que no alcanzan el nivel de significación requerida. Por tanto, se rechaza la H3. Las mujeres tienen mayores síntomas somáticos que los hombres. La hipótesis 4 planteaba que las agresoras chicas tendrían mayores niveles de síntomas somáticos 
que los chicos. Los resultados muestran que en las chicas la relación entre acoso y quejas somáticas es positiva, sin embargo, esta relación es negativa en los chicos. Por tanto, se acepta la H4. El presente estudio no está exento de limitaciones, el tamaño de la muestra es reducido y está enfocado en una edad concreta por tanto no permite examinar la relación curvilínea en forma de $U$ invertida entre ciberbullying y edad. La muestra se recopiló en un área concreta de un país, sería deseable que futuros estudios analizaran el fenómeno en diferentes países para la generalización de resultados y la especificación de problemas más graves a contextos que tal vez compartan aspectos contextuales o culturales que arrojen luz al estudio del fenómeno. Los datos se han recogido mediante un solo informador y por tanto futuros estudios deberían incluir otras fuentes y otro tipo de datos además de los recopilados mediante cuestionarios. Además, solo se han analizado las quejas somáticas como consecuencia del fenómeno. Por tanto, futuros estudios deberían analizar los antecedentes, diferentes consecuencias desde una perspectiva contingente, que permitiera identificar aquellos aspectos susceptibles de amortiguar los devastadores efectos del ciberbullying y bullying. Los resultados ponen de manifiesto que las personas que ejercen el rol de acosadores deben ser partes implicadas en los programas de prevención, especialmente las acosadoras que tal y como muestran los resultados presentan síntomas somáticos en mayor medida que los chicos. Por lo tanto, la prevención secundaria al igual que la pirmaria ha de ir dirigida a todos los agentes implicados en el fenómeno de bullying o ciberbullying. También, se deberían realizar más investigaciones para avanzar en el estudio del fenómeno tanto su prevalencia, como los antecedentes y causas de manera que estos resultados sirvan de guía y orientación a los propios investigadores. Tal y como muestran los estudios, el fenómeno de ciberbullying va en auge y las TICs han llegado para quedarse. En este sentido, las TICs son únicamente responsables de hacerlo posible como herramienta, y por lo tanto la responsabilidad de erradicarlo desde una aproximación multidisciplinar y multinivel, y en cierto modo esta tarea recae entre otros en el ámbito familiar y socioeducativo.

A modo de conclusión el presente estudio pone de manifiesto que las chicas agresoras muestran mayores síntomas somáticos cuándo ejercen ciberbullying que los chicos, esto puede ser porque empatizan en mayor nivel que los chicos con la víctima de modo que a la luz de estos resultados se dibuja un panorama esperanzador debido a que si se trabaja la empatía los agresores chicas y chicos podrían aminorar e incluso llegar a eliminar su conducta acosadora con el tiempo. En este sentido, el ApS consistiría en que el alumnado de magisterio trabajara en los colegios y analizara longitudinalmente si el ciberbullying disminuye con el tiempo tanto en chicas 
como en chicos por efecto de su intervención en mejorar los niveles de empatía del alumnado.

\section{Bibliografía recomendada}

Almenara, J. C. (2007). Las necesidades de las TIC en el ámbito educativo: oportunidades, riesgos y necesidades. Tecnología y comunicación educativas, 21(45), 5-19.

Avilés Martínez, J. M. (2013). Análisis psicosocial del ciberbullying: claves para una educación moral. Papeles del psicólogo, 34(1).

Castro-Morales, J. (2011). Acoso escolar. Revista de neuro-psiquiatría, 74(2).

Cava, M. J., Musitu, G., y Murgui, S. (2006). Familia y violencia escolar: el rol mediador de la autoestima y la actitud hacia la autoridad institucional. Psicothema, $18(3)$.

Cerezo, F. (2009). Bullying: análisis de la situación en las aulas españolas. International. Journal of psychology and psychological therapy, 9(3), 367-378.

Cervera, L. (2009). Lo que hacen tus hijos en Internet. Barcelona: Ed. Integral.

Chaux, E. (2011). Múltiples perspectivas sobre un problema complejo: comentarios sobre cinco investigaciones en violencia escolar. Psykhe, 20(2), 79-86.

Clínicas, R. (2001). Violencia Escolar I: Descripción del Problema. Adolesc Med, 155(8), 903-8.

Del Barco, B. L., Castaño, E. F., Bullón, F. F., y Carroza, T. G. (2012). Cyberbullying in a sample of secondary students: modulating variables and social networks. Electronic journal of research in Educational Psychology, 10(2), 771-788.

Domingo Coscollola, M., y Fuentes Agustí, M. (2010). Innovación educativa: experimentar con las TIC y reflexionar sobre su uso. Pixel-Bit. Revista de Medios y Educación, 36, 171-180.

Domingo, M., y Marquès, P. (2011). Aulas 2.0 y uso de las TIC en la práctica docente. Comunicar, 19(37).

Fernández, I. (2010). Prevención de la violencia y resolución de conflictos. Narcea Ediciones.

Garaigordobil, M. (2011). Prevalencia y consecuencias del cyberbullying: una revisión. International Journal of Psychology and Psychological Therapy, 11(2), 233-254.

Garaigordobil, M. (2013) Cyberbullying. Screening de Acoso entre iguales. Madrid: TEA ediciones.

Garaigordobil, M. (2015). Ciberbullying en adolescentes y jóvenes del País Vasco: Cambios con la edad. Anales de psicología, 31(3), 1069-1076. 
Gómez Nashiki, A. (2013). Bullying: el poder de la violencia. Una perspectiva cualitativa sobre acosadores y víctimas en escuelas primarias de Colima. Revista mexicana de investigación educativa, 18(58), 839-870.

Hernández, M. Á. (2017). La convivencia es cosa de todos. Padres y maestros, $369,41-45$.

Herreras, E. B. (2008). Estrategias para prevenir el bullying en las aulas. Intervención psicosocial, 17(3), 369-370.

Lacasa, C. S., y Ramírez, F. C. (2010). Variables personales y sociales relacionadas con la dinámica bullying en escolares de Educación Primaria. Electronic Journal of Research in Educational Psychology, 8(22), 1015-1032.

López, F., y Chávez, M. D. C. M. (2011). Las manifestaciones del bullying en adolescentes. Revista de Psicología, 8(17), 19-33.

Magaz, A. M., Chorot, P., Santed, M. A., Valiente, R. M., y Sandín, B. (2016). Evaluación del bullying como victimización: Estructura, fiabilidad y validez del Cuestionario de Acoso entre Iguales (CAI). Revista de Psicopatología y Psicología Clínica, 21(2), 77-95.

Martínez, J. M. A. (2010). Éxito escolar y ciberbullying. Boletín de psicología, 98, 73-85.

Novo, M., Seijo, D., Vilariño, M., y Vázquez, M. J. (2013). Frecuencia e intensidad en el acoso escolar: ¿ qué es qué en la victimización?. Revista Iberoamericana de Psicología y Salud, 4(2).

Ortega, R., Calmaestra, J., y Mora-Merchán, J. A. (2007). Cuestionario cyberbullying. Universidad de Córdoba.

Pérez, J. C., Astudillo, J., Varela, J., y Lecannelier, F. (2013). Evaluación de la efectividad del Programa Vínculos para la prevención e intervención del Bullying en Santiago de Chile. Psicologia Escolar e Educacional, 17(1).

Redondo, J., Luzardo-Briceño, M., García-Lizarazo, K. L., y Inglés, C. J. (2017). Impacto psicológico del ciberbullying en estudiantes universitarios: un estudio exploratorio. Revista Colombiana de Ciencias Sociales, 8(2), 458-478.

Rodrigo, M.J., Máiquez, M.L., García, M., Mendoza, R., Rubio, A., Martínez, A. y Martín, J.C. (2004). Relaciones padres-hijos y estilos de vida en la adolescencia. Psicothema, 16 (2), 203-210.

Sabater Fernández, C., y López-Hernáez, L. (2015). Factores de riesgo en el Ciberbullying. Frecuencia y exposición de los datos personales en Internet. Revista Internacional de Sociología de la Educación, 4(1). 


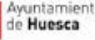

II Jornadas ApS y responsabilidad social

Facultad de Ciencias Humanas y de la Educación de la Universidad de Zaragoza 7 do nowientros 2017

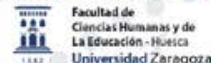

La relación entre el ciberbullying y las quejas somáticas en función del sexo Cristina Artal, Eva M. Lira, Ana Moreno y Mara Socolovski

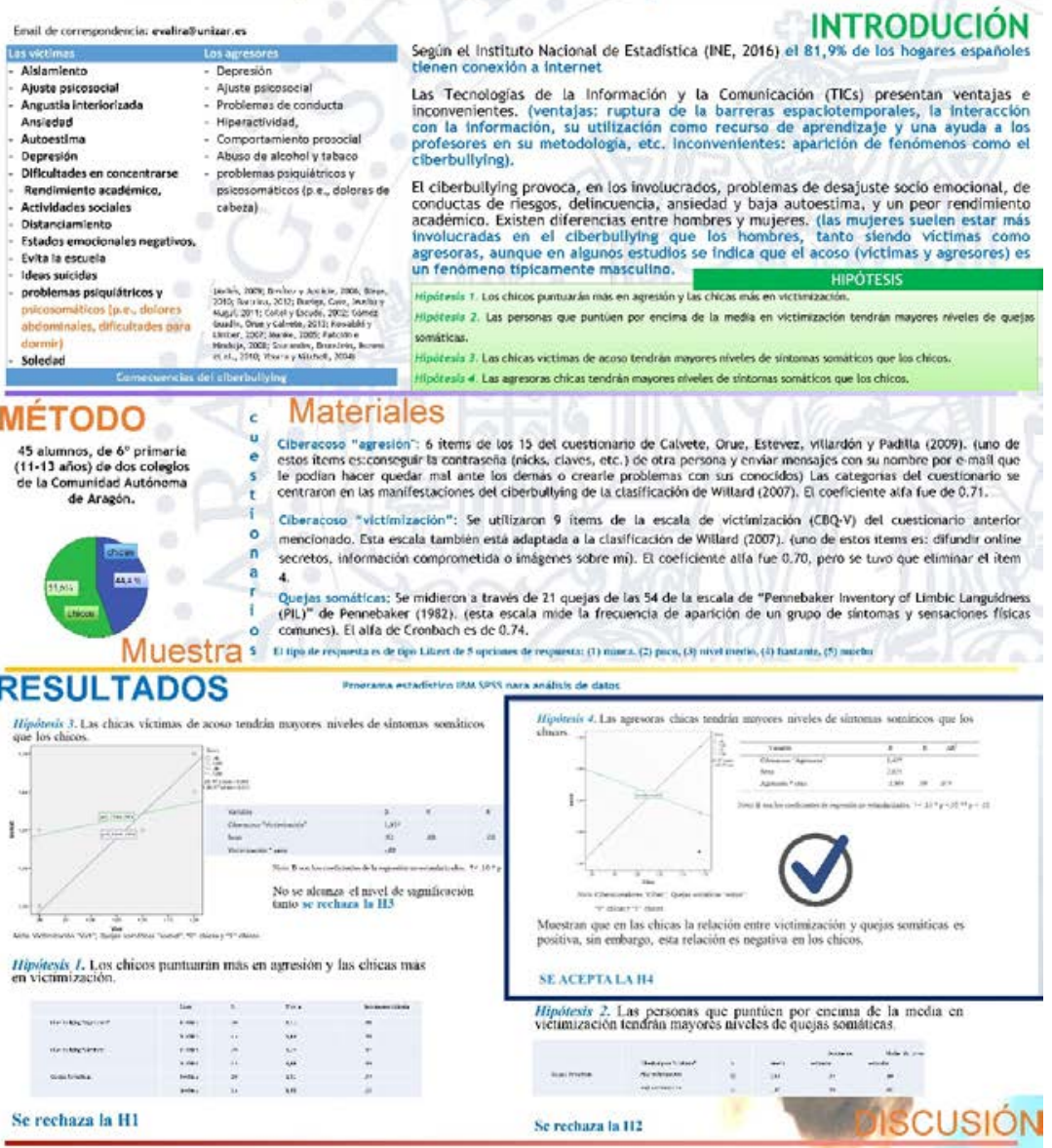

- El presente estudio no está exento de limitaciones, ya que el tamaño de la muestra es reducido y está enfocado en una edad concreta y no permite examinar las relaciones causales, la relación curvilinea en forma de $\mathrm{U}$ invertida entre ciberbullying y edad.

- Las investigaciones futuras deberían centrarse en el estudio antecedentes, consecuencias y programas de prevención primaria y secundaria tanto en Educación Primaria como en Educación Secundaria.

\section{LAS CHICAS AGRESORAS MUESTRAN MAYORES SINTOMAS SOMATICOS} CUANDO EJERCEN CIBERBULLYING QUE LOS CHICOS 


\title{
11 \\ Música, inteligencia emocional y angustia psicológica (depresión y ansiedad).
}

\author{
Eva M. Lira ${ }^{1}$ y Sara Escuer ${ }^{2}$ \\ ${ }^{1}$ Universidad de Zaragoza y ${ }^{2}$ Universidad Internacional de Valencia \\ evalira@unizar.es
}

\subsection{Introducción}

Según un estudio llevado a cabo en 282 pacientes de la Clínica Universitaria de Psicología de la Universidad Complutense de Madrid realizado por Bernaldo de Quirós et al. (2012), el porcentaje de mujeres es significativamente superior al de hombres en todos los trastornos de ansiedad excepto en el trastorno obsesivo-compulsivo. La ansiedad en las mujeres se ha asociado al riesgo de desarrollar ciertas patologías tales como la hipertensión o como factor de riesgo de la sobremortalidad cardiovascular (Hansen, 2003). Algunos estudios han relacionado la gestión emocional con la angustia psicológica (ansiedad y depresión) (Koechlin, Coakley, Schechter, Werner y Kossowsky, 2018; Rimasson, Bouvet y Hamdi, 2017). Así, Rimasson et al. (2017) analiza 449 documentos de la literatura científica sobre el manejo emocional y sus déficits en el dolor crónico desde el año 1994, los autores seleccionan este año debido a que el constructo de inteligencia emocional es introducido en el año 1990 por Salovey y Mayer. Los hallazgos sugieren que algunas estrategias de manejo emocional y sus déficits pueden mantener un círculo vicioso de estados emocionales negativos con consecuencias fisiológicas y psicopatológicas. Varios estudios muestran que la alexitimia, la ambivalencia emocional y la supresión emocional tienen un impacto perjudicial sobre el dolor, la angustia emocional (depresión, ansiedad) y la discapacidad. Por otro lado, la aceptación experiencial tiene un efecto beneficioso sobre la 
angustia psicológica (depresión, ansiedad y estrés). Del mismo modo, la expresión emocional en la vida diaria parece beneficiosa, pero cuando se distingue la expresión de los sentimientos positivos y negativos, la expresión emocional de los sentimientos negativos aumenta el dolor, la discapacidad y la angustia. Todos estos hallazgos enfatizan la necesidad de seguir investigando sobre el manejo emocional en el dolor crónico, a excepción del relacionado con el cáncer (Rimasson et al., 2017).

Por otro lado, la música puede ser beneficiosa en la reducción de la ansiedad y la depresión (Geipel, Koenig, Hillecke, Resch y Kaess, 2018). Recientes revisiones y meta análisis inciden en la importancia de la música en la depresión (Leubner y Hinterberger, 2017) y en la ansiedad (Geipel et al., 1998), incluso se le atribuyen mejoras en cognición (memoria, atención, lenguaje), emoción y comportamiento (ansiedad, depresión y agitación) de enfermos de alzhéimer (García-Casares, Moreno-Leiva y Garcia-Arnes, 2017). Así, la revisión de Leubner y Hinterberger (2017) indicó que las intervenciones musicales han mostrado ser una alternativa potencial para la terapia de la depresión, pero el número de literatura de investigación actualizada es bastante limitado y es por ello que se hace hincapié en la necesidad de más estudios que aporten luz en relación a los beneficios concretos de la misma (Geipel et al., 1998; Leubner y Hinterberger, 2017). Concretamente, Leubner y Hinterberger (2017) analizaron 28 estudios longitudinales con un total de 1.810 participantes distinguiendo entre escuchar pasivamente música (79\%) y cantar, tocar o improvisar con instrumentos activos (46\%). Los parámetros críticos fueron, por ejemplo, la duración de la prueba, el número de sesiones, la edad de los participantes, el tipo de música, la participación activa o pasiva y la configuración individual o grupal. En 26 estudios se encontró una reducción estadísticamente significativa en los niveles de depresión a lo largo del tiempo en el grupo experimental (intervención musical) en comparación con un control. En particular, los participantes de mayor edad mostraron mejoras impresionantes, en palabras de los autores, cuando escucharon música o participaron en proyectos de musicoterapia. Además, se encontró un mayor efecto en las configuraciones grupales que en las individuales. Asimismo, la confianza, la autoestima y la motivación de los participantes también presentaron mejoras. Por lo tanto, la música en grupo y en mayores podría representar una valiosa ayuda para los síntomas de la depresión. Por otro lado, la inteligencia musical fue considerada como una de las siete inteligencias múltiples de Gardner (1983) divulgadas en su obra "Multiple intelligences. The theory in practice" (Gardner, 1993) en la cual explica y justifica su teoría sobre las inteligencias múltiples, reformulando así el concepto de inteligencia establecido hasta entonces. Este autor defiende en su teoría que los seres humanos poseen siete inteligencias diferentes e independientes las cuales se concretan en: mu- 
sical, cinético-corporal, lógico-matemática, lingüística, espacial, interpersonal e intrapersonal, siendo estas dos últimas (intra e interpersonal) las inteligencias precursoras y que sentaron las bases de los que posteriormente se denominó IE, constructo artículado y acuñado por Salovey y Mayer (1990).

La investigación en torno a la inteligencia emocional (IE) encuentra habilidades de IE más desarrolladas en función del género (Caballero, 2004; Extremera, FernándezBerrocal y Salovey, 2006; Mestre, Guil y Lim, 2004; Pena, Rey y Extremera, 2012; Valadez-Sierra, Pérez-Sánchez y Beltrán-Llera, 2010; Valadez-Sierra, Borges, Ruvalcaba-Romero, Villegas y Lorenzo, 2013) mostrando mayores niveles de atención emocional en mujeres y de reparación en hombres (Molero, Ortega-Álvarez y Moreno, 2010; Pena, Extremera y Rey, 2011), otros autores, en cambio, no encuentran estas diferencias en función de ser hombre o mujer (Cazalla-Luna y Molero, 2014; Chan, 2005; Prieto-Rincón, Inciarte-Mundo, Rincón-Prieto y Bonilla, 2008).

El metaanálisis de Martins, Ramalho y Morin (2010) muestra una relación positiva entre la IE y la salud mental y física. En este sentido Ruiz-Aranda, Salguero y Fernández-Berrocal (2012) mostraron que en los que los sujetos que participaron de un programa para la mejora de la IE disminuyeron sus niveles de depresión y estrés social. Kotsou, Nelis, Grégoire y Mikolajczak (2011) realizaron un estudio en 132 adultos que participaron en una intervención de 15 horas diseñada específicamente para las 5 competencias emocionales principales, complementada con un seguimiento por correo electrónico de 4 semanas, encontraron un aumento de IE tras el programa que resultó en una menor secreción de cortisol, (hormona del estrés), un mayor bienestar subjetivo y físico, así como una mejor calidad de las relaciones sociales y matrimoniales. Extremera y Fernández Berrocal (2006) analizaron la influencia de la atención (AE), claridad y reparación (ER) emocional sobre los niveles de ansiedad y depresión de184 universitarios mayoritariamente mujeres (38 hombres y 146 mujeres). Específicamente, observaron que una puntuación alta en AE se relacionaba significativa y positivamente con una mayor sintomatología ansiosa y depresiva. Por lo tanto, estos resultados ponen de manifiesto que atender demasiado a las propias emociones, sobre todo las negativas, puede no ser beneficioso. En este sentido, las personas que prestan demasiada atención a sus emociones y que tienen puntuaciones bajas en claridad y reparación emocional, tiende a entrar en un ciclo rumiativo que puede perjudicar su bienestar emocional y su funcionamiento interpersonal. Por el contrario, mayores niveles de claridad y reparación emocional se relacionaron con menores niveles de ansiedad y depresión y mayor puntuación en rol físico, funcionamiento social, salud mental, vitalidad y percepción de salud, es decir, niveles altos en CE y RE predicen un mejor ajuste psicológico y físico. Teniendo en cuenta, que las dimensiones de IE 
(percepción o atención emocional, comprensión o claridad de las emociones y regulación o reparación emocional) no operan en la misma dirección, Cejudo, GarciaMaroto y Lopez-Delgado (2017) analizaron los efectos de un programa de mejora de la inteligencia emocional (IE) en las mujeres con cáncer de mama con cirugía. Los resultados mostraron que la intervención en IE tuvo efectos positivos en la claridad y la reparación de las mujeres con cáncer de mama que participaron en el programa, aunque no en la atención emocional. Asimismo, el estudio de Cejudo et al. (2017) mostró un descenso de la ansiedad estado por efecto del programa de IE. También, evidenciando resultados en líneas diferentes para as distintas dimensiones de IE, Cejudo, López-Delgado y Rubio (2016) analiza la relación entre IE, resiliencia y bienestar en 432 estudiantes universitarios de entre 17 y 59 años. En este estudio la satisfacción con la vida se relacionó de manera estadísticamente significativa y positiva con claridad emocional y con reparación emocional. Por el contrario, se confirmaron asociaciones negativas de resiliencia y satisfacción con la vida y la dimensión de atención emocional. En este sentido, Nelis, Kotsou, Quoidbach, Hansenne, Weytens, Dupuis y Mikolajczak (2011) encontraron que 18 horas de entrenamiento con seguimiento por correo electrónico mejoraron significativamente la reparación y claridad emocional y la competencia emocional en general. Además, los resultados mostraron que el desarrollo de la competencia emocional produjo cambios positivos en el bienestar psicológico, la salud subjetiva, la calidad de las relaciones sociales y la empleabilidad. En base a los resultados previamente expuestos se plantean las siguientes hipótesis:

Hipótesis 1. La relación entre IE y la ansiedad psicológica (ANS y DEPRE) estará modulada por el tipo de coro

Hipótesis 1a. La relación entre IE y ANS estará modulada por el tipo de coro

Hipótesis $1 b$. La relación entre IE y DEPRE estará modulada por el tipo de coro

Hipótesis 2. La relación entre AE y la ansiedad psicológica (ANS y DEPRE) estará modulada por el tipo de coro

Hipótesis $2 a$. La relación entre AE y ANS estará modulada por el tipo de coro

Hipótesis $2 b$. La relación entre AE y DEPRE estará modulada por el tipo de coro

Hipótesis 3. La relación entre las dimensiones de IE (RE y CE) y la ansiedad psicológica (ANS y DEPRE) estará modulada por el tipo de coro

Hipótesis 3a. La relación entre las dimensiones de IE (RE y CE) y ANS estará modulada por el tipo de coro 
Hipótesis $3 b$. La relación entre las dimensiones de IE (RE y CE) y DEPRE estará modulada por el tipo de coro

\subsection{Participantes}

La muestra ha sido constituida por un total de 28 mujeres pertenecientes a dos coros de la provincia de Huesca. Ambos coros son amateur, dado que sus integrantes (a excepción de su directora) no poseen formación musical ni vocal específica, por lo que la diferencia entre ellos es el tipo de repertorio que interpretan ("música culta" vs. "música ligera"). El primero de estos coros, al que denominaremos "coro especializado' ( $\mathrm{n}=14)$, interpreta música culta o música académica, es decir, repertorio coral de diferentes períodos histórico musicales (desde el Renacimiento hasta la actualidad) compuesto para tres voces femeninas con o sin acompañamiento instrumental (piano, órgano u orquesta de cámara). El segundo de los coros incluidos en este estudio, al que denominaremos 'coro no especializado' $(\mathrm{n}=12)$, interpreta repertorio a una voz, de tradición popular de los últimos ochenta años, acompañado por una guitarra acústica (denominada "música ligera", de mayor sencillez musical/armónica/melódica, y por tanto de más fácil ejecución para un intérprete no profesional). El rango de edad va desde los 44 a los 80 años siendo la media de 67.42 años $(\mathrm{DT}=7.61)$. La media de edad en el coro no especializado es de $70.50(\mathrm{DT}=5.23)$ y en el especializado es de $64.79(\mathrm{DT}=8.49)$.

\subsection{Medidas}

Las participantes en el estudio cumplimentaron un cuestionario compuesto por diferentes medidas que a continuación se detallan:

Inteligencia emocional. La IE se midió con 24 ítems ( 8 por dimensión) procedentes de la escala TMMS-24 (Trait Meta-Mood Scale) versión reducida y adaptada a la población española por Fernández-Berrocal, Extremera y Ramos (2004). Esta escala está basada en la escala Trait Meta-Mood Scale (TMMS-48) del grupo de Salovey, Mayer, Goldman, Turvey, y Palfai (1995). La TMMS-24 incluye tres dimensiones claves de la inteligencia emocional: atención emocional, claridad emocional y reparación emocional. Cada dimensión consta de 8 ítems. Así, los ítems del 1 al 8 se corresponden con la atención emocional, los ítems del 9 al 16 con la claridad emocional y del 17 al 24 con la reparación emocional. La atención emocional se define como la capacidad para percibir y expresar los sentimientos de forma adecuada, la claridad emocional sería la comprensión de los estados emocionales y la reparación emocional es la capacidad de regular los estados emocionales correctamente. Un 
ejemplo de ítem de atención emocional es: "Presto mucha atención a los sentimientos.", de claridad emocional: "Tengo claros mis sentimientos" y de reparación emocional: "Aunque a veces me siento triste, suelo tener una visión optimista". El coeficiente alfa fue de .90 en la atención emocional, .79 en la claridad emocional y .76 en la reparación emocional. El coeficiente de fiabilidad alfa en inteligencia emocional total fue de .81 .

Ansiedad y Depresión. Fueron evaluadas mediante 9 ítems dirigidos a sintomatología de tipo ansioso y 9 ítems de síntomas depresivos a partir de la escala de ansiedad y depresión de Goldberg. Escala E.A.D.G. (Goldberg et al., 1998, versión española GZEMPP, 1993) (versión modificada de la Psychiatric Asséssment Schedule) tiene como objetivo valorar la intensidad de los síntomas de ansiedad y depresión. La versión en castellano ha sido validada por Montón et al. (1993) consta de dos escalas, una de ansiedad y otra de depresión, con 9 ítems cada una con preguntas tales como: ¿Se ha sentido muy irritable?, ¿Ha tenido dificultad para relajarse?, ¿Ha perdido usted el interés por las cosas? o ¿Se ha sentido usted desesperanzado, sin esperanzas?. Los índices de consistencia interna alcanzados en esta prueba han sido adecuados, habiendo obtenido un coeficiente de fiabilidad alfa en ansiedad de .89 y de .90 en depresión.

\subsection{Análisis de datos}

Una vez recopilados los cuestionarios, se llevó a cabo el análisis de datos utilizando para ello la versión 22 del programa estadístico IBM SPSS (Statistical Process for Social Science). Con el SPSS se llevaron a cabo los índices de fiabilidad [considerando una fiabilidad adecuada a partir de un coeficiente de fiabilidad (alfa de Cronbach) por encima de .70 (Nunnally, 1978)] así como parámetros de centralización (medias aritméticas) y dispersión (desviación estándar). Posteriormente, también con el programa SPSS se calcularon las correlaciones, mediante el coeficiente de correlación $r$ de Pearson. Por último, mediante el SPSS se midieron las interacciones, como la relación entre la variable dependiente y la independiente podía estar modulada por una variable dependiente moduladora, en este caso el sexo. Para ello, se utilizó el método de Hayes (2013) descrito en el siguiente sitio web, http://afhayes.com/spss-sas-and-mplus-macros-and-code.html. La variable coro debido a que es una variable dicotómica se ha codificado como " 0 " coro no especializado y "1" coro especializado para ser introducida en el análisis de regresión. En este caso, la significación menor de $\mathrm{p}<.10$ nos muestra que es significativa la interacción estudiada. En los efectos de interacción el límite convencional del nivel de $\mathrm{p}$ es de .10. Este nivel de $\mathrm{p}$ ha sido sugerido por varios investigadores 
(Champoux y Peters, 1987) para proteger al test de la probabilidad de cometer un error Tipo II cuando se realizan los análisis de modulación. De este modo, con el uso de estos programas estadísticos se han obtenido los resultados expuestos en el siguiente apartado.

\subsection{Resultados}

Los descriptivos (medias y desviaciones típicas) de cada una de las variables estudiadas así como las correlaciones fueron calculados tal y como se muestra en la tabla 1.

Tabla 1. Estadísticos descriptivos y análisis de correlaciones

\begin{tabular}{|c|c|c|c|c|c|c|c|c|c|c|c|}
\hline & & $M$ & $D T$ & 1 & 2 & 3 & 4 & 5 & 6 & 7 & 8 \\
\hline 1. & $I E$ & 3,50 & 0,39 & 1 & & & & & & & \\
\hline 2. & $A E$ & 3,01 & 0,82 &, $68^{* *}$ & 1 & & & & & & \\
\hline 3. & $C E$ & 3,66 & 0,52 &, $47^{*}$ &,- 17 & 1 & & & & & \\
\hline 4. & $R E$ & 3,85 & 0,53 &, $69 * *$ & ,06 & ,32 & 1 & & & & \\
\hline 5. & $A N S$ & 2,69 & 0,86 &, 02 & ,32 &,- 11 &,- 32 & 1 & & & \\
\hline 6. & DEPRE & 1,97 & 0,76 &,- 31 &, 07 &,- 15 &,- 42 &, $73 * *$ & 1 & & \\
\hline 7. & CORO & 0,5 & 0,51 &,- 27 &,- 20 &, 10 &,$- 39 *$ &,- 08 &, 15 & 1 & \\
\hline 8. & $E D A D$ & 67,42 & 7,61 & ,06 &, 14 &,- 07 &, 07 &,- 20 &,- 02 &,- 38 & 1 \\
\hline
\end{tabular}

Tal y como muestran los resultados las mujeres que conformaban el coro del hogar de mayores, es decir que no cantaban a nivel especializado mostraron menos ansiedad cuándo sus niveles de IE fueron altos. No obstante, la relación entre IE y ansiedad fue positiva en las mujeres del coro especializado, es decir, presentaron mayores niveles de ansiedad cuándo su IE fue alta en comparación con el otro coro $(\mathrm{B}=.54, n s)$. Sin embargo, aunque se han graficado los resultados para ver el patrón de la relación, estos no son significativos. Por tanto, se rechaza la H1a. 
Tabla 2. Resultados del análisis de regresión para ansiedad (ANS)

\begin{tabular}{llll}
\hline Variable & $\mathrm{B}$ & $\mathrm{R}$ & $\Delta \mathrm{R}^{2}$ \\
\hline Coro & -2.19 & & \\
Inteligencia emocional (IE) & -.41 & & \\
Coro*IE & .54 & 03 & .01 \\
\hline Nota: B son los coeficientes de regresión no estandarizados. $\uparrow<.10 * p<.05 * * p<.01$
\end{tabular}

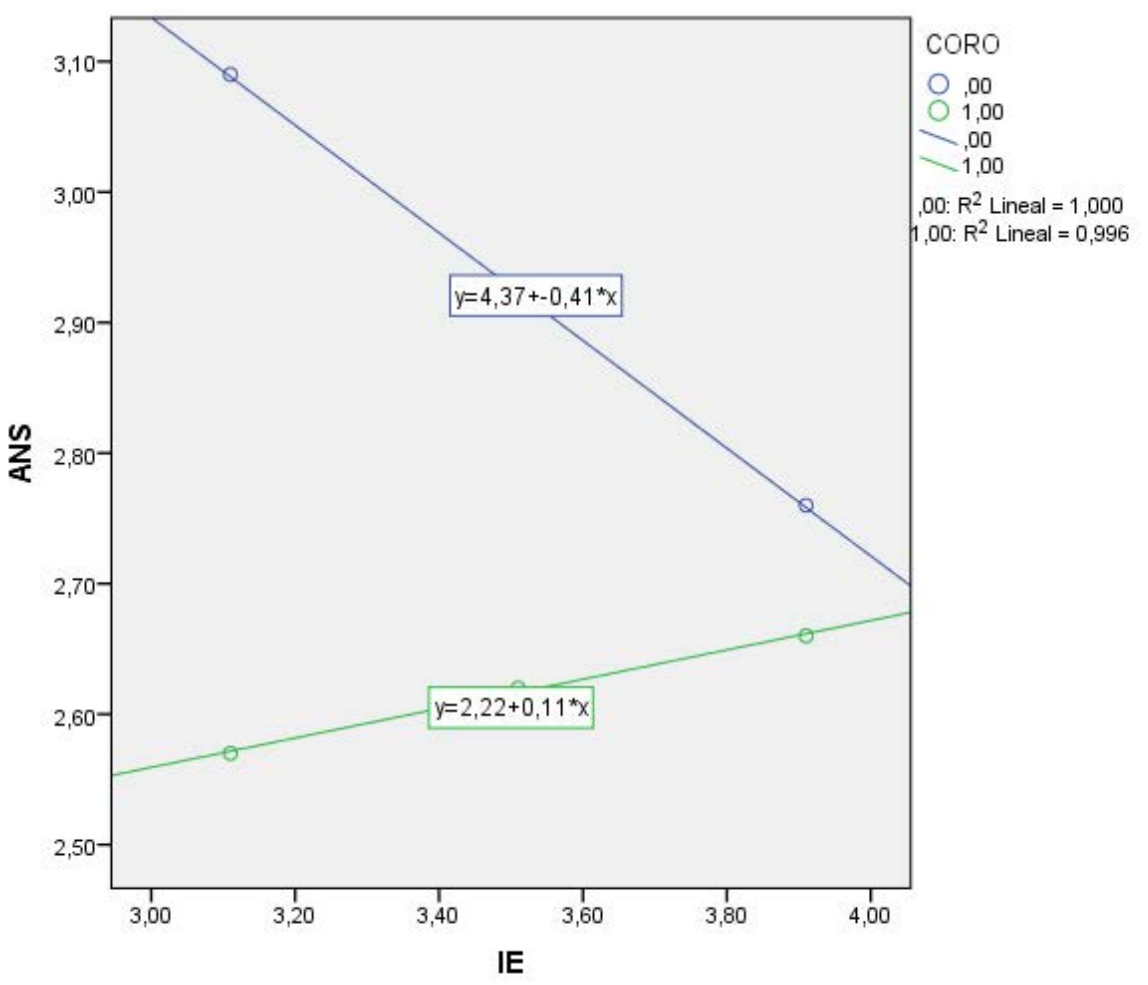

Figura 1. Resultados del análisis de regresión para ansiedad (ANS)

Tal y como muestran los resultados las mujeres cuyos niveles de IE fueron altos mostraron menores niveles de depresión, siendo esta relación más intensa en el coro no especializado. Sin embargo, aunque se han graficado los resultados para ver el patrón de la relación, estos no son significativos $(\mathrm{B}=.18, n s)$. Por tanto, se rechaza la $\mathrm{H} 1 \mathrm{~b}$. 
Tabla 3. Resultados del análisis de regresión para depresión (DEPRE)

\begin{tabular}{llll}
\hline \multicolumn{1}{c}{ Variable } & $\mathrm{B}$ & $\mathrm{R}$ & $\Delta \mathrm{R}^{2}$ \\
\hline Coro & -.80 & & \\
Inteligencia emocional (IE) & -.68 & .12 & .01 \\
Coro*AE & .18 & $.12 * p<.05 * *<.01$
\end{tabular}

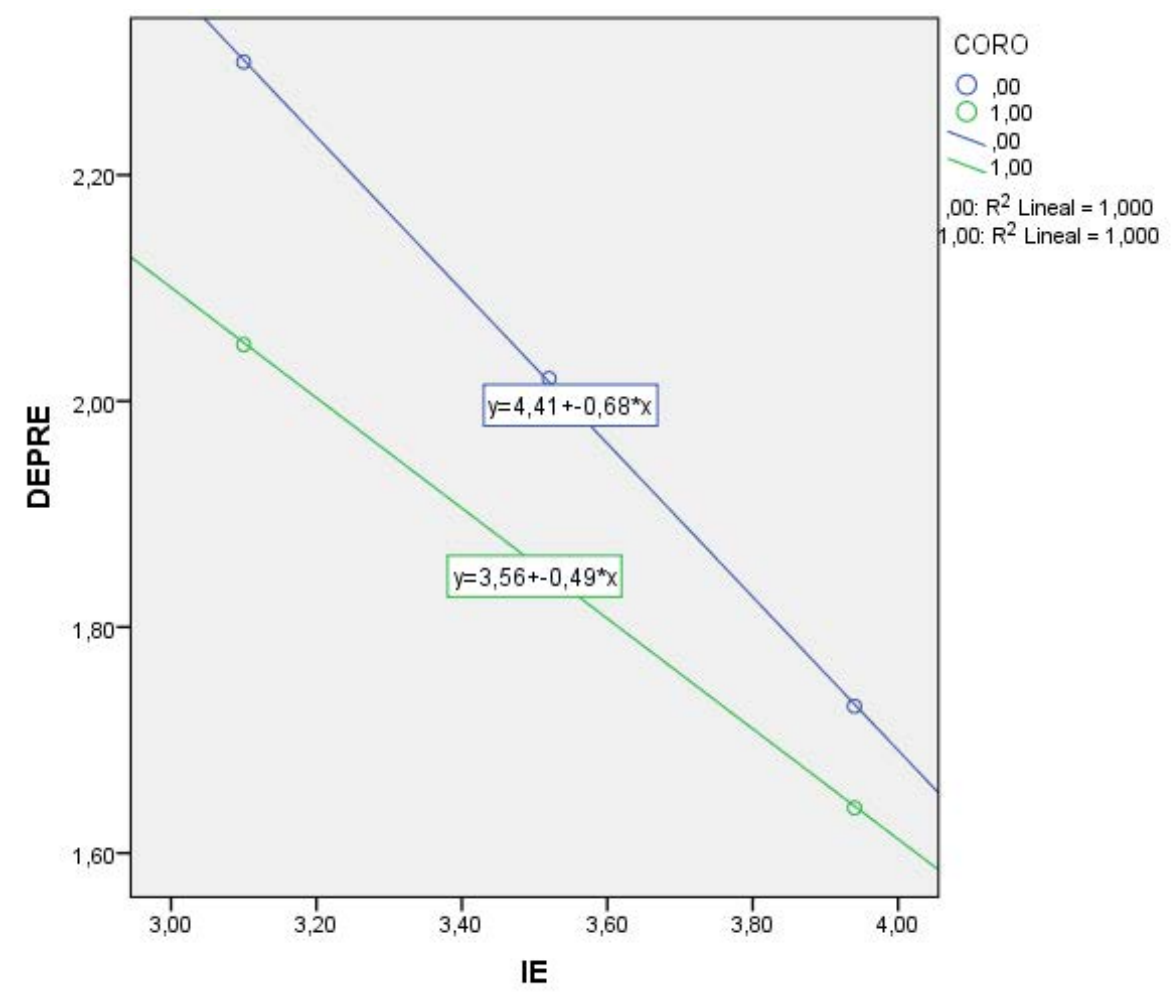

Figura 2. Resultados del análisis de regresión para depresión (DEPRE)

Tal y como muestran los resultados las mujeres cuyos niveles de atención emocional (AE) fueron altos mostraron mayores niveles de ansiedad, siendo esta relación más intensa en el coro no especializado. Sin embargo, aunque se han graficado los resultados para ver el patrón de la relación, estos no son significativos $(\mathrm{B}=-.12, n s)$. Por tanto, se rechaza la $\mathrm{H} 2 \mathrm{a}$. 
Tabla 4. Resultados del análisis de regresión para ansiedad (ANS)

\begin{tabular}{llll}
\hline Variable & $\mathrm{B}$ & $\mathrm{R}$ & $\Delta \mathrm{R}^{2}$ \\
\hline Coro & .29 & & \\
Atención emocional (AE) & .41 & & \\
Coro*AE & -.12 & .11 & .01 \\
\hline Nota: B son los coeficientes de regresión no estandarizados. $\dagger<.10^{*} p<.05^{* *} p<.01$
\end{tabular}

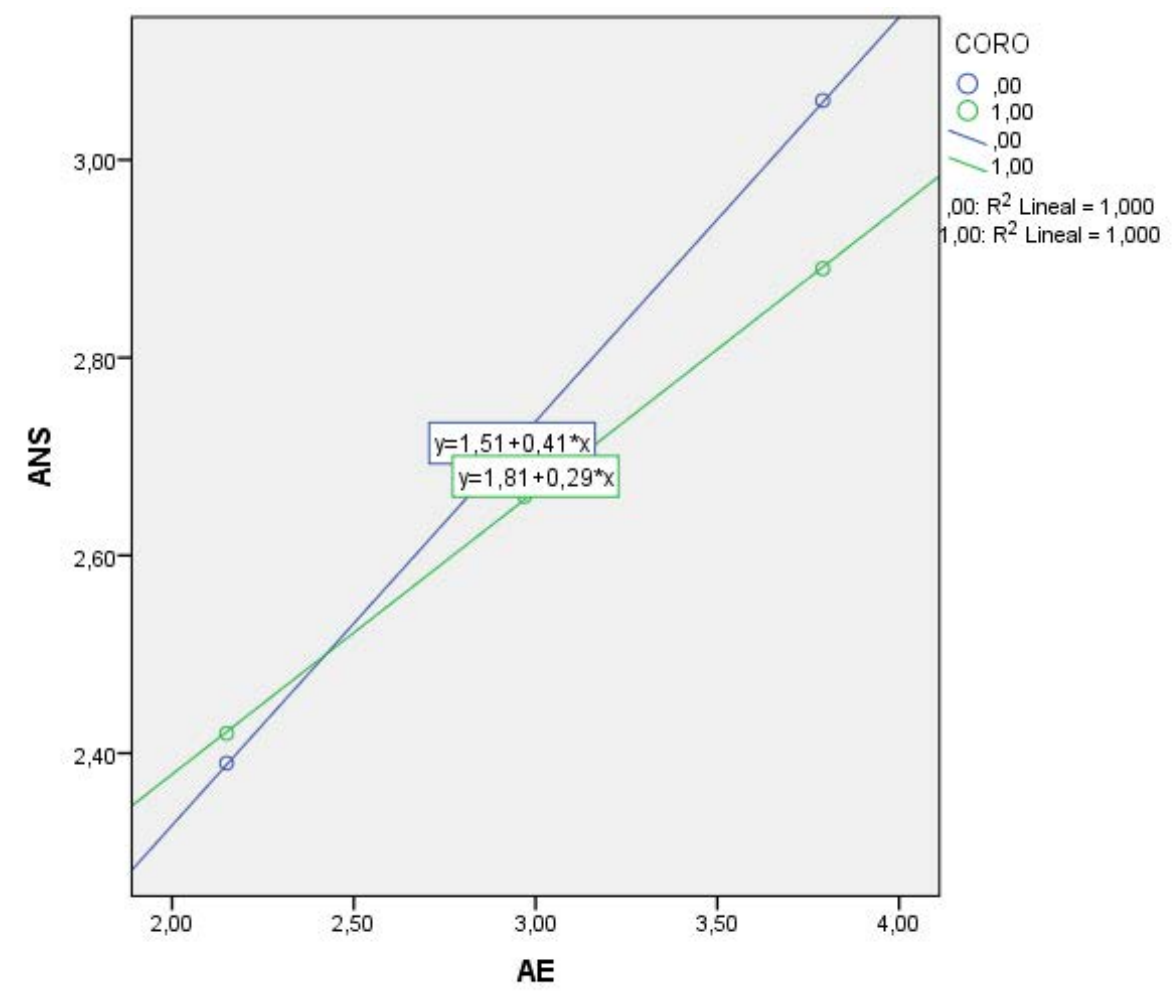

Figura 3. Resultados del análisis de regresión para ansiedad (ANS)

Tal y como muestran los resultados las mujeres del coro no especializado cuyos niveles de atención emocional (AE) fueron altos mostraron mayores niveles de depresión, siendo esta relación (AE-DEPRE) prácticamente nula en el coro especializado. Sin embargo, aunque se han graficado los resultados para ver el patrón de la relación, estos no son significativos $(\mathrm{B}=-.11, n s)$. Por tanto, se rechaza la $\mathrm{H} 2 \mathrm{~b}$. 
Tabla 5. Resultados del análisis de regresión para depresión (DEPRE)

\begin{tabular}{llll}
\hline Variable & $\mathrm{B}$ & $\mathrm{R}$ & $\Delta \mathrm{R}^{2}$ \\
\hline Coro & .40 & & \\
Atención emocional (AE) & .12 & & \\
Coro*AE & -.11 & .01 & .01 \\
\hline Nota: B son los coeficientes de regresión no estandarizados. $\uparrow<.10^{*} p<.05 * *<<.01$
\end{tabular}

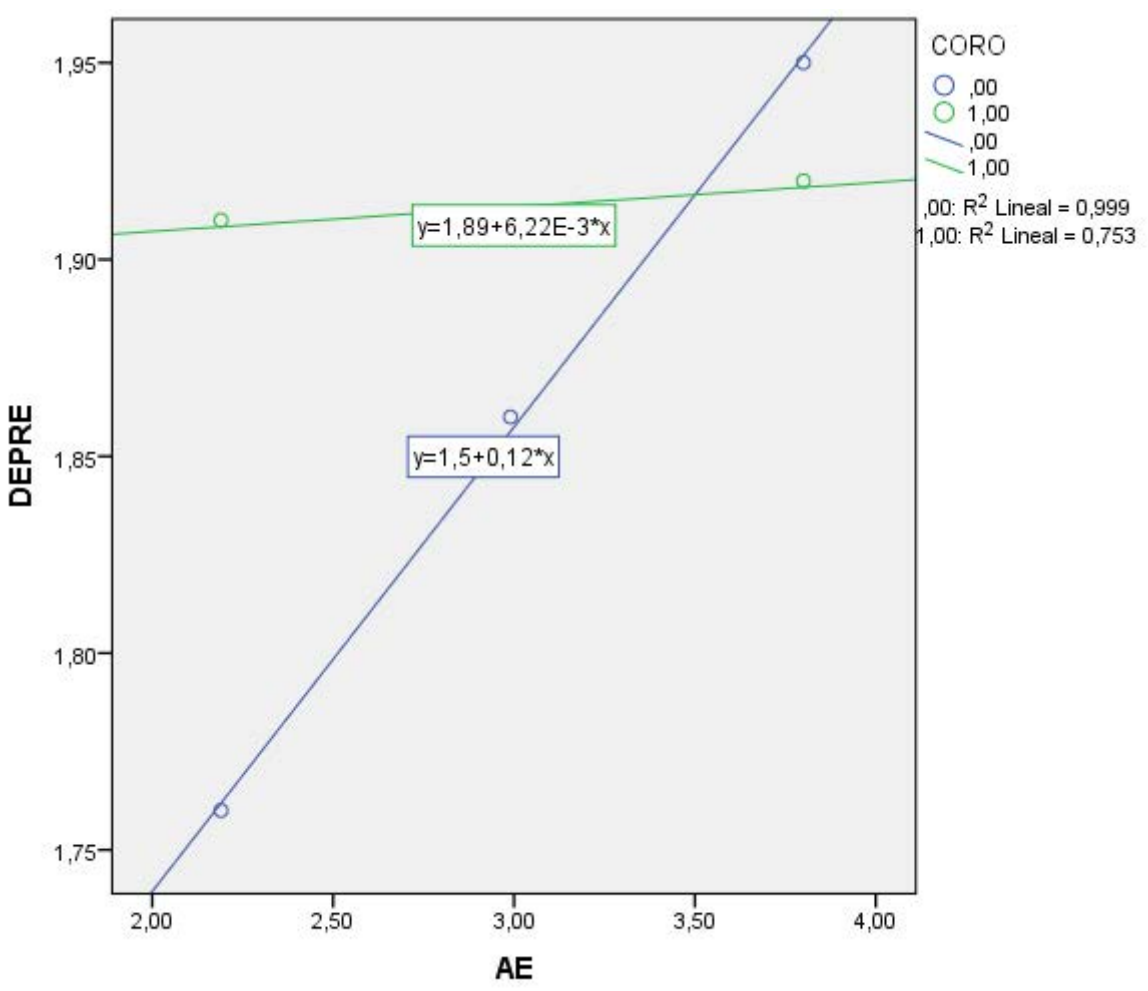

Figura 4. Resultados del análisis de regresión para depresión (DEPRE)

La claridad emocional $(B=-10.45, \mathrm{p}<.09)$ y la reparación $(\mathrm{B}=-9.87, \mathrm{p}<.07)$ tuvieron una influencia negativa y directa sobre la ansiedad de las mujeres de ambos coros. Cuándo se compararon ambos coros con altos niveles de RE las mujeres del coro no especializado mostraron una disminución de sus niveles de ansiedad mayor que las mujeres del coro especializado cuando sus niveles de CE fueron bajos, esta diferencia en la relación entre RE y ansiedad fue disminuyendo a aumentar los niveles de CE. De tal modo que en los casos de altos niveles de CE y RE $(B=2.37, p<.09)$ 
no hubo diferencias en ansiedad en función del coro. Sin embargo, aunque se han graficado los resultados para ver el patrón de la relación, estos no son significativos. Por tanto, se rechaza la $\mathrm{H} 3 \mathrm{a}$.

Tabla 6. Resultados del análisis de regresión para ansiedad (ANS)

\begin{tabular}{llll}
\hline Variable & $\mathrm{B}$ & $\mathrm{R}$ & $\Delta \mathrm{R}^{2}$ \\
\hline Coro & -24 & & \\
Claridad emocional (CE) & -10.45 & & \\
Reparación emocional (RE) & -9.87 & & \\
$\mathrm{RE}^{*} \mathrm{CORO}$ & 4.39 & & \\
$\mathrm{RE}^{*} \mathrm{CE}$ & $2.37 \dagger$ & & \\
CORO* CE & 6.21 & .39 & .01 \\
RE*CORO*CE & -1.17 &
\end{tabular}

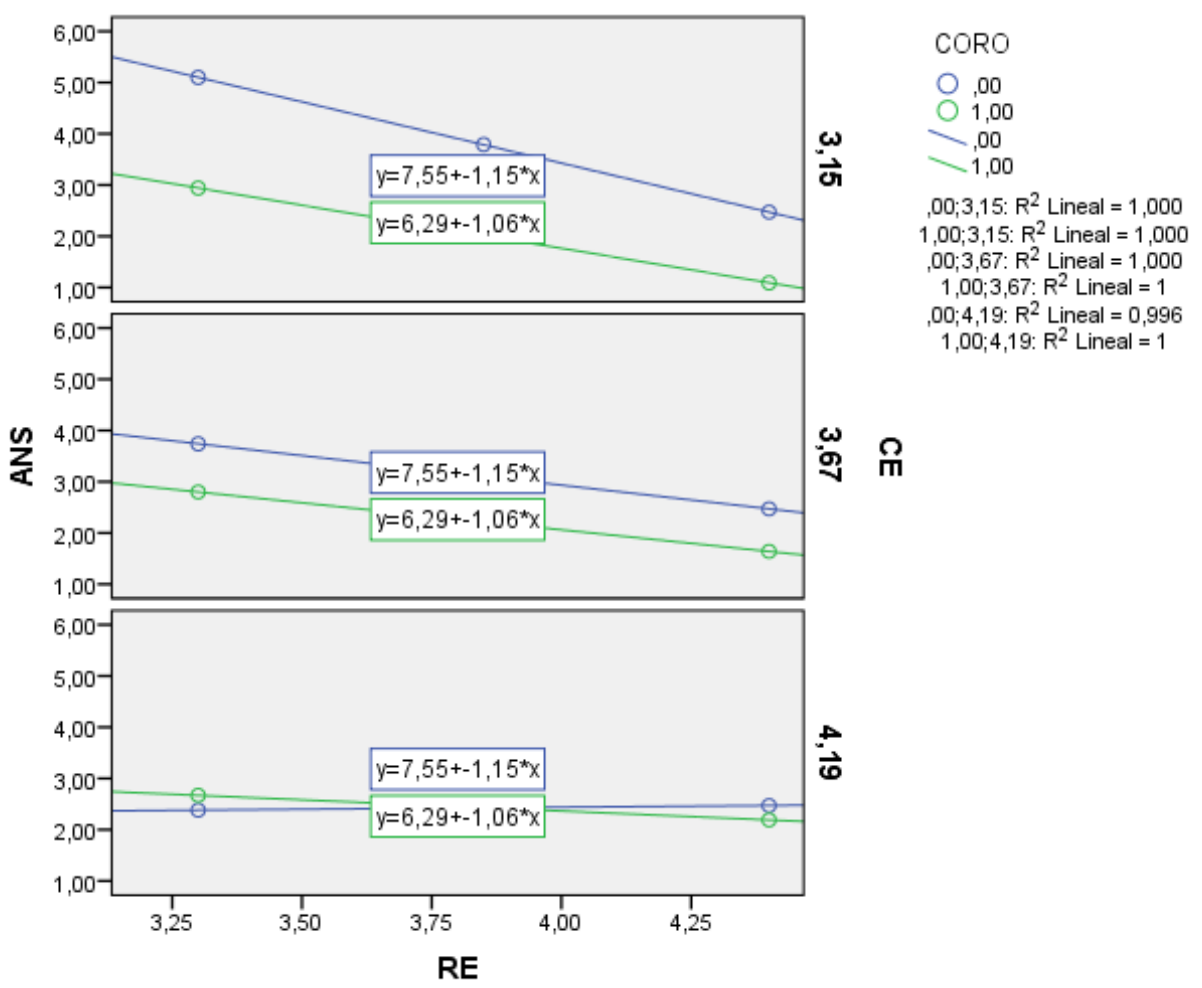

Figura 5. Resultados del análisis de regresión para ansiedad (ANS) 
En el caso de las mujeres del coro no especializado a mayores niveles de reparación emocional (RE) menores niveles de depresión, sin embargo, no hubo variaciones en función de los niveles de claridad emocional (CE). Por otro lado, los niveles de CE y RE no mostró ninguna influencia en las mujeres del coro especializado en comparación con las del coro no especializado $(\mathrm{B}=-.57, n s)$. Por tanto, se rechaza la $\mathrm{H} 3 \mathrm{~b}$.

Tabla 7. Resultados del análisis de regresión para depresión (DEPRE)

\begin{tabular}{llll}
\hline Variable & $\mathrm{B}$ & $\mathrm{R}$ & $\Delta \mathrm{R}^{2}$ \\
\hline Coro & -12.13 & & \\
Claridad emocional (CE) & -2.32 & & \\
Reparación emocional (RE) & -3.19 & & \\
RE*CORO & 3.31 & & \\
RE*CE & .55 & & \\
CORO* CE & 2 & .28 & .01 \\
RE*CORO*CE & -.57 & . & \\
\hline Nota B son los coeficientes de regresión no estandarizados. $\dagger<.10^{*} p<.05^{* *} p<.01$
\end{tabular}

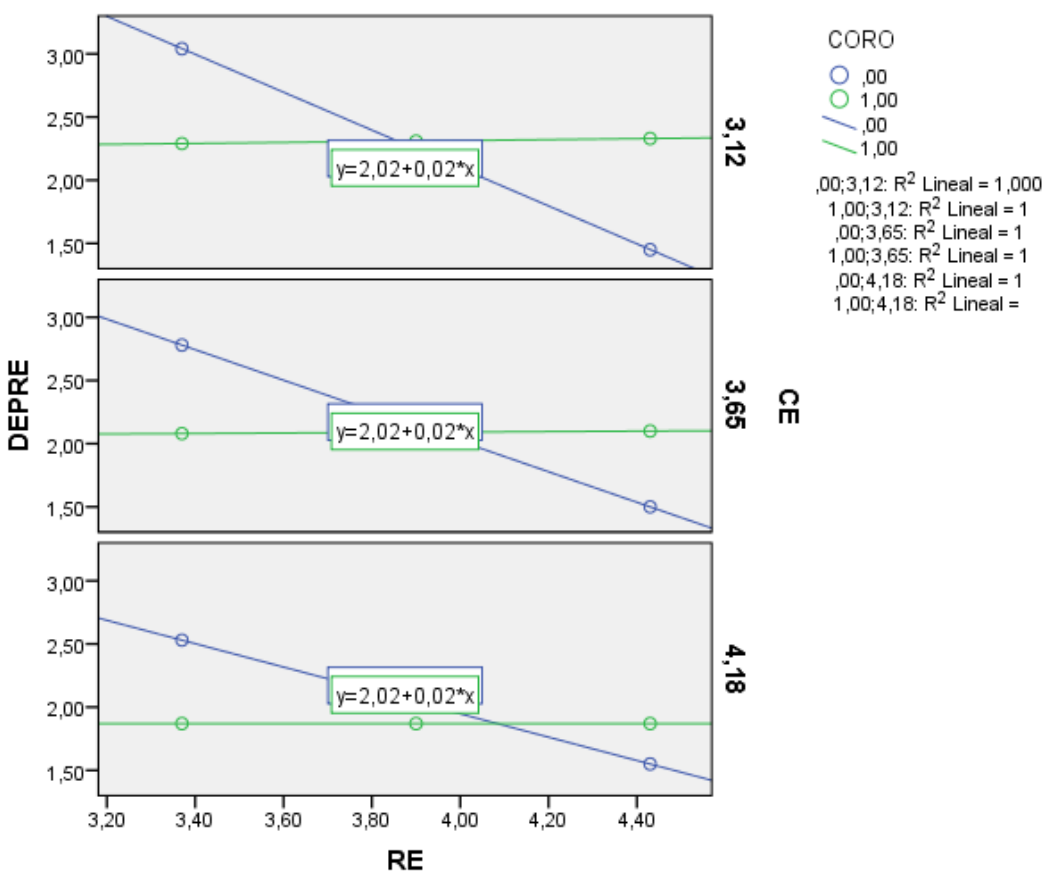

Figura 6. Resultados del análisis de regresión para depresión (DEPRE) 


\subsection{Conclusiones}

El objetivo del presente trabajo era analizar la relación entre la inteligencia emocional global y por subdimensiones (atención, claridad y reparación) y la angustia psicológica (ansiedad y depresión) en mujeres pertenecientes a un coro especializado y no especializado. Los resultados sugieren que la claridad y la reparación emocional tienen una influencia negativa y directa sobre la ansiedad de las mujeres de ambos coros. Por tanto, estos resultados apuntan a que niveles altos de IE en las dimensiones de CE y RE se relacionan con niveles más bajos de ansiedad en línea con lo apuntado en diversos estudios (Extremera y Fernández Berrocal, 2006; Cejudo et al., 2016; Cejudo et al., 2017; Kotsou et al., 2011; Martins et al., 2010; Nelis et al., 2011Ruiz-Aranda et al., 2012).

No obstante, son necesarios estudios longitudinales para analizar si la música mejora los niveles de ansiedad y depresión debido a que literatura disponible es limitada y es por ello que se hace hincapié en la necesidad de realizar más estudios para aunar masa crítica en torno a esta temática (Geipel et al., 1998; Leubner y Hinterberger, 2017). Asimismo, sería interesante analizar si los participantes de mayor edad muestran mejoras más significativas, cuando escuchan música de forma pasiva y si hay diferencias a cuándo participan de forma activa. Además, sería interesante analizar si la configuración grupal muestra mejoras más relevantes en angustia psicológica y otras variables de interés (p.e., autoeficacia), que las configuraciones individuales, tal y como apuntan Leubner y Hinterberger (2017). Por otro lado, futuros estudios deberían combinar grupos de música tales como coros de mujeres en edad de jubilación [p.e., vinculados a Hogares de Mayores (IASS)], jóvenes con discapacidad intelectual [p.e. coros de entidades pertenecientes a CADIS Huesca] así como coros infantiles o alumnos de música en educación infantil y primaria de manera que el profesorado de magisterio pudiera poner en práctica la metodología aprendizaje-servicio (ApS) crucial para la formación de los estudiantes universitarios.

\section{Bibliografía recomendada}

Bernaldo-de-Quirós, M., Estupiña, F. J., Labrador, F. J., Fernández-Arias, I., Gómez, L., Blanco, C. y Alonso, P. (2012). Diferencias sociodemográficas, clínicas y de resultados del tratamiento entre los trastornos de ansiedad. Psicothema, 24 (3), 393-401. 
Caballero, A. (2004). Cómo enfocar la educación emocional dentro del aula desde la perspectiva de género. En AEOP, Actas de la Conferencia Internacional de Orientación, Inclusión Social y Desarrollo de la Carrera

Cazalla-Luna, N. y Molero, D. (2014). Inteligencia emocional percibida, ansiedad y afectos en estudiantes universitarios. Revista Española de Orientación y Psicopedagogía, 25(3).

Cejudo, J., Garcia-Maroto, S. y Lopez-Delgado, M. L. (2017). Effects of an emotional intelligence program in anxiety and self-concept in women with breast cancer. Terapia Psicológica, 35(3), 239-246.

Cejudo, J., López-Delgado, M. L. y Rubio, M. J. (2016). Inteligencia emocional y resiliencia: Su influencia en la satisfacción con la vida en estudiantes universitarios. Anuario de Psicología, 46(2), 51-57.

Chan, D. W. (2005). Self-perceived creativity, family hardiness, and emotional intelligence of Chinese gifted students in Hong Kong. The Journal of Secundary Gifted Education, 16 (2-3), 47-56.

Extremera Pacheco, N. y Fernández Berrocal, P. (2004). Inteligencia emocional, calidad de las relaciones interpersonales y empatía en estudiantes universitarios. Clínica y salud, 15(2).

Extremera, N. y Fernández-Berrocal, P. (2006). Emotional Intelligence as Predictor of Mental, Social and Physical Health in University Students. The Spanish Journal of Psychology, 9 (1), 45-51.

Extremera, N., Fernádez-Berrocal, P. y Salovey, P. (2006). Spanish version of the Mayer-Salovey-Caruso Emotional Intelligence Test (MSCEIT). Version 2.0: Reliabilities, Age and Gender differences. Psicothema, 18 (Supl.1), 42-48 (p. 546). Universidad de Coruña.

Garcia-Casares, N., Moreno-Leiva, R. M. y Garcia-Arnes, J. A. (2017). Music therapy as a non-pharmacological treatment in Alzheimer's disease. A systematic review. Revista de neurologia, 65(12), 529-538.

Geipel, J., Koenig, J., Hillecke, T. K., Resch, F. y Kaess, M. (2018). Musicbased interventions to reduce internalizing symptoms in children and adolescents: A meta-analysis. Journal of affective disorders, 225, 647-656.

Koechlin, H., Coakley, R., Schechter, N., Werner, C. y Kossowsky, J. (2018). The role of emotion regulation in chronic pain: A systematic literature review. Journal of psychosomatic research, 107, 38-45.

Kotsou, I., Nelis, D., Grégoire, J. y Mikolajczak, M. (2011). Emotional plasticity: Conditions and effects of improving emotional competence in adulthood. Journal of Applied Psychology, 96, 827-839.

Leubner, D. y Hinterberger, T. (2017). Reviewing the Effectiveness of Music Interventions in Treating Depression. Frontiers in psychology, 8, 1109. 
Mestre, J. M., Guil, R. y Lim, N. (2004). Inteligencia emocional: ¿a qué pueden deberse las diferencias respecto a la variable género? En E. Barberá, L. Mayor, M. Chóliz, E. Cantón, E. Carbonell, C. Candela y C. Gómez (Eds.), Motivos, emociones y procesos representacionales: de la teoría a la práctica (pp. 313-324). Valencia. Fundación Universidad-Empresa de Valencia (ADEIT).

Molero, D., Ortega-álvarez, F. y Moreno, M. R. (2010). Diferencias en la adquisición de competencias emocionales en función del género. Revista Electrónica de Investigación y Docencia, 3, 165-172.

Nelis, D., Kotsou, I., Quoidbach, J., Hansenne, M., Weytens, F., Dupuis, P. y Mikolajczak, M. (2011). Increasing emotional competence improves psychological and physical well-being, social relationships, and employability. Emotion, 11(2), 354.

Pena, M., Extremera, N. y Rey, L. (2011). El papel de la inteligencia emocional percibida en la resolución de problemas sociales en estudiantes adolescentes. Revista Española de Orientación y Psicopedagogía, 22 (1), 69-79.

Prieto-Rincón, D., Inciarte-Mundo, J., Rincón-Prieto, C. y Bonilla, E. (2008). Estudio del coeficiente emocional en estudiantes de medicina. Revista Chilena de Neuro-Psiquiatría, 46 (1), 10-15.

Rimasson, D., Bouvet, C. y Hamdi, H. (2017). La gestion des émotions et ses déficits, chez les personnes atteintes de douleur chronique: une revue systématisée des études relatives à l'alexithymie, à l'intelligence émotionnelle, à la régulation émotionnelle et au coping. Psychologie Française.

Ruiz-Aranda, D., Castillo, R., Salquero, J. M., Cabello, R., Fernandez-Berrocal, P. y Balluerka, N. (2012). Short and midterm effects of emotional intelligence training on adolescent mental health. Journal of Adolescent Health, 51, 462-467.

Ruiz-Aranda, D., Salguero, J. M. y Fernández-Berrocal, P. (2011). Emotional Intelligence and Acute Pain: The Mediating Effect of Negative Affect. The Journal of pain, 12 (11), 1190-1196.

Valadez-Sierra, M. D., Borges, M. A., Ruvalcaba-Romero, N., Villegas, K. y Lorenzo, M. (2013). Emotional intelligence and its relationship with gender, academic performance and intellectual abilities of undergraduates. Electronic Journal of Reseach in Educational Psycholoy, 11 (2), 395-412.

Valadez-Sierra, M. D., Pérez-Sánchez. L. y Beltrán-Llera, J. (2010). La inteligencia emocional de los adolescentes talentosos. Faísca, 15 (17), 2-17. 


\title{
El videoartivismo como contexto para el desarrollo de actividades de Aprendizaje y Servicio (ApS).
}

\author{
Miguel Ángel Alvira Juan. \\ Universidad de Zaragoza \\ maalvira@unizar.es
}

El siguiente texto analiza algunas de las experiencias de los trabajos en vídeo arte que destacaron por un marcado carácter activista en las décadas desde los años 60 hasta la actualidad como posible fuente de inspiración para proyectos de APS. Especialmente destacable con sus luces y sombras son los movimientos entorno a Mayo del 69, efervescencia idealizada por unos y denostada por otros pero que más allá de toda crítica a dicho movimiento sirvió y sirve de inspiración para el posicionamiento crítico frente a diversos modelos de poder, que a su vez, implican modelos de educación, consumo y economía. Estas experiencias lejos de poseer un carácter reglado respondieron más a una suerte de sinergias que acompañaban a los movimientos utópicos del momento y deberían servir de muestra, en el caso concreto del uso del vídeo, para transmitir conciencia y visión crítica tanto hacia el propio medio como a diversos aspectos sociales.

Debemos tener en cuenta que no todo gira alrededor de los grandes discursos ya que algunas de las estrategias han pretendido éxitos a muy pequeña escala con un carácter fundamentalmente local. Algunos de los proyectos de vídeo comunitario no tenían mayor pretensión que poner al alcance una cultura que en determinados momentos parecía estar al alcance de unos pocos. Es está seguramente la función más destacada de estos grupos que al sentir que no estaban representados por los discursos hegemónicos generaban sus propios canales de comunicación para tratar 
sus problemáticas e intereses concretos y que en ocasiones se sirvieron de la tradición contestataria heredada de los orígenes del videoarte y su desarrollo hasta llegar a la era internet.

Se diferencian dos modos fundamentales de trabajo crítico en la red que siguen: los que desarrollan una voluntad conciliadora y los basados en las tácticas de sabotaje. El primero es constructivo y fundamentado en la crítica manteniendo un alto grado de escepticismo. Su vertiente artística genera proyectos creativos utilizando el potencial específico de la red como The File Room, Potatoland, Refugee Republic o The Technologies To The People. Su carácter documental y comunicativo cubriría los huecos que la información espectacular anula o distorsiona participando del debate crítico de ideas y proyectos mediante el uso de grupos de discusión y de la planificación colectiva. La duda se constituye en herramienta de la inteligencia. (Baigorri, 2012) El segundo modelo por su estrategia basada en el sabotaje no encajaría dentro de un contexto normalizado de educación dado que no fomenta aspectos como la empatía por lo que resulta mucho más cuestionable.

Podemos, a partir del pequeño análisis que realizaremos, llegar a la conclusión errónea de que la vídeo creación y especialmente su faceta plástico artística no constituye un modelo viable de estrategia crítica. Sin embargo poner en conocimiento de los estudiantes estas estrategias así como sus virtudes y defectos será un aliciente para implementarlas y construir espacios alternativos de discurso donde entren todos aquellos ámbitos que la comunicación dominante margina o ignora. El fracaso o poca efectividad demostrados en el pasado no debe servir más que para insistir en el intento y formar a los estudiantes en un uso pragmático de estos recursos. Usar como metodología de enseñanza/aprendizaje los modelos de comunidades de vídeo puede resultar una actividad compatible con varios de los motivos que fundamentan el aprendizaje y servicio.

La profesora Roser Batlle enumera 10 razones que justifican el APS que van desde el sentido social de la educación, la integración de los aspectos cognitivos con aspectos actitudinales y morales hasta mejorar la percepción social de los adolescente entre otras. (Batlle, 2012) Todas ellas parecen encajar a la perfección en una propuesta de formar y practicar la construcción de canales de difusión alternativos que hablen de las personas y lugares desde el punto de vista de los verdarderos protagonistas a la par que centrada en su casuística particular.

Nuestro objetivo debería ser formar estudiantes capaces de conocer un código y un lenguaje de la imagen que les permita tomar distancia de los mensajes mass 
mediáticos y comprender en profundidad cuando estos están siendo manipulados o parcializados a la par que son capaces de contestarlos en un lenguaje tan efectivo como el de los propios medios. Hacerles comprender que la información y la imagen debe ser atractiva pero que no debería dominar dicho atractivo por encima de un mensaje sincero y constructivo. La función de la imagen y su consumo no debería ser un acto pasivo y narcótico sino algo cargado de significación y provecho.

\section{Algunos apuntes sobre el contexto artístico de los usos del vídeo como herramienta de crítica de las doctrinas visuales hegemónicas.}

Durante sus primeros años se esperó del vídeo como herramienta una capacidad de respuesta ante los excesos de los mass media trabajando con sus propios instrumentos. Serviría para la generación de canales alternativos de comunicación tratando de materializar así las teorías de Marshall McLuhan de aldea global, que dominaban muchos de los simposios en universidades y foros de discusión. Pero la utopía tecnológica no duró demasiado; la política y la industria terminaron por asimilar la tecnología para sus fines tradicionales reduciendo o desvirtuando las acciones de quienes trataban de usarlos contra los sistemas establecidos, convirtiendo a la industria mass mediática en un conjunto de actividades lúdicas e información manipulada dirigida con determinados intereses.

No pocos de los artistas que esgrimieron el vídeo como arma social terminaron por ser absorbidos por los canales hegemónicos y de ese modo participando de aquello que habían originalmente cuestionado. A lo largo de la segunda mitad del s.XX, artistas de toda índole se mantiene en posiciones más o menos ambiguas. Fluxus trabajó de forma independiente al mercado y las instituciones durante buena parte de su existencia pero finalmente desapareció, precisamente, con la incorporación al mercado de sus autores. George Maciunas considerado como uno de los organizadores y fundadores del movimiento de Fluxus, tras un incidente en el que participaron varios componentes del movimiento, optó por eliminar las cuestiones políticas de la agenda del movimiento limitándolo a cuestiones puramente plásticas. Al igual que en el caso de la Internacional Situacionista no fueron capaces de establecer un movimiento artístico y político a la vez que poseyera cierto grado de continuidad efectiva.

Independientemente de las pretensiones del videoarte en sus inicios cuyo objetivo era generar una visión alternativa a los discursos hegemónicos y establecer una fuerte oposición a los mismos no pareció germinar, aunque si estableció toda una 
serie de recursos y estrategias que se han ido recuperando una y otra vez con idénticas pretensiones.

La relación ambigua entre medios televisivos y videoarte no impidió su conexión lógica generando un entorno del que se alimentaron a ambos. Tanto uno como otro medio colaboraron directa e indirectamente en sus respectivos desarrollos. Esta relación se produce en base a la conexión directa del realizador con el público ya que es para éste último para quien es creada la obra. La voluntad de poseer un público amplio de algunos videoartistas supuso que parte del videoarte mirase de nuevo hacia sus orígenes retomando la televisión como soporte de distribución de sus trabajos. La oposición del videoarte a los mass media pudo ser resultado solo de la coincidencia de su aparición con las tendencias revolucionarias del momento. Pero dado que no deja de resultar paradójico luchar en contra de aquello que es responsable directo de tu existencia la solución era la creación de canales alternativos. La televisión fue tributaria, aunque pueda querer no admitirlo, de la labor de los artistas pioneros que investigaron, experimentalmente, las posibilidades creativas y comunicativas del medio tanto de modo formal como expresivo y conceptual.

Cuanto más se afianza la institución televisiva, más se opone a la entrada del videoarte abriéndose cada vez más a la publicidad. Y curiosamente es esta publicidad la que más asimila los logros formales del vídeo independiente incluyéndolos como estrategia comercial. Por lo tanto la experimentación que realizaron los artistas con los medios expresivos del video fue transportada a los usos del mundo de la televisión. Por otro lado el poder económico de los medios televisivos ha permitido el perfeccionamiento de los instrumentos de vídeo permitiendo que sean más versátiles y den mejores y más rápidos resultados. Zunzunegui habla de "fascinación de la televisión por el vídeo" (Zunzunegui, 1985) que ha contribuido a ampliar "sus posibilidades sintácticas y liberándolo de la escasez de semas de que es producto por las limitaciones temporales" (Cabero, 1989)

Rosales Mateos describe de la siguiente forma uno de los motivos por los que el mundo de la televisión (y los mass media en general) se imponen a los sistemas tradicionales del arte. Las propias categorizaciones dentro del mundo artístico determinan la capacidad y calidad de cada autor. Por el contrario en los medios de comunicación esta figura de autor se pierde en un cúmulo de fases en las que intervienen de forma directa muchas personas y departamentos. El distanciamiento que supone la ausencia física del artista tradicional se suma a una ausencia real de 
un autor en los mass media dado lo difícil que resulta localizar un "sujeto emisor en el origen del mensaje". "...el modo en que algunos medios de masas diseñan sus actos comunicativos los convierte en algo mucho más próximo y directo que la comunicación artística tradicional" (Rosales, 2002).

Esta falta de eficacia por parte del arte puede situarse en su carencia de estrategia en pro de desarrollar cuestiones que parecen no interesar a nadie más que los propios artistas o a pequeños grupos minoritarios. Por otra parte los estándares y la homogenización de la cultura, los productos consumo, la política que promuevan los mass media implican una homogenización de los seres humanos. Con un solo modelo se pierde la variedad en su totalidad, variedad de opiniones, variedad de puntos de vista, variedad de soluciones, etc. La creación de masa es, según Baudrillard, la culpable de la regresión cultural, el retorno a la no-cultura. "La masa es la esfera, cada vez más densa, donde implosiona todo lo social y es devorado en un proceso de simulación ininterrumpido" (Baudrillad, 2005)

Como venimos analizando los sistemas hegemónicos de comunicación de la imagen iconocinética se nutrieron de las investigaciones discursivas y plásticas del video arte. Pero existe una clara retroalimentación ya que el desarrollo de mejores recursos tecnológicos y sistemas de distribución son posibles gracias a la gran cantidad de recursos económicos de los medios de comunicación convencionales. Sin embargo no existe un equilibrio entre lo que cada uno de los ámbitos a realizado por el otro dado que por su carácter minoritario y las bajas audiencias fueron desplazando al vídeo como práctica artística de los espacios mayoritarios en las cadenas de televisión y los circuitos de proyección comercial.

Dilucidar si esto se corresponde con un verdadero desinterés por la audiencia o a una manipulación del discurso a favor de mensajes menos comprometidos, más banales y con un claro fondo comercial no está del todo claro. Sin embargo esto podría funcionar como un modelo encubierto de censura que funciona precisamente no censurando. Hoy día ya no es necesario censurar directamente dado que la información se desintegra precisamente en el exceso de información.

La censura funciona mediante el ocultamiento expreso de un hecho, sino por su inmersión en un océano vastísimo de flujos de información. No se censura prácticamente nada. Nos muestran abiertamente la guerra el hambre, que hay precariedad y muerte laboral, que hay especulación, que los inmigrantes mueren ahogados en las pateras, que el régimen de partidos es un carnaval, que los gobiernos mienten sin impunidad. Los medios oficiales no ocultan estos hechos, 
nos los cuentan cada día, no necesitan censurarlos porque aparentemente no pasa nada.

Todo esto viene a destacar la importancia de sistemas de comunicación alternativos que ofrezcan una visión más cercana y concreta de las inquietudes y problemáticas locales como alternativa a los discursos generales mediáticos. Tanto por la aparente falta de honestidad de estos como por la necesidad de abordar discursos más concretos enfocados a las necesidades de lo local y lo cercano.

En los años 70 surgirá el movimiento Guerrilla Televisión formado por algunos grupos radicales que centraron sus intereses en la confrontación con la televisión como instrumento destinado a revolucionar el mundo. Raindance, Ant Farm, Telethon, Video Freex, o TVTV en EEUU; Videoheads en Ámsterdam; Telewissen en Alemania; TVX en Inglaterra, y Video-Nou en España son algunoes ejemplos. Estos grupos se propusieron crear redes realmente alternativas de televisión mediante la creación de nuevas cadenas o con colaboraciones en otros canales.

Estas alternativas se estructuraron en forma de pequeñas cadenas a nivel local que perseguían ser una comunicación alternativa a los grandes comunicadores mediáticos. También en forma de comunidades de vídeo o "vídeo comunitario", a una escala incluso menor que la anterior, como es el caso de Video-Nou que inicia sus actividades en 1977.

En el caso de américa latina la complejidad de estos grupos es casi tan extensa como los diferentes modelos y asociaciones que han llegado a generarse. Pero en términos generales tienen en común una extensa tradición de relación con los estamentos oficiales que ha pasado desde intentos de prohibición bajo algunos regímenes totalitarios (de los muchos que han existido en Sudamérica) y los más recientes intentos encaminados a su legislación. No pretendemos aquí hacer un análisis extenso de estos casos pero sirva de ejemplo los puntos comunes de varias investigaciones donde se repite una y otra vez la participación en estos canales alternativos de profesionales llegados desde el cine experimental y el videoarte; la necesidad de estos espacios como contrapunto tanto a los canales oficiales estatales como a la irrupción de la televisión privada; su necesario carácter social que se enfrenta tanto a la estandarización cultural o invasión cultural dando visibilidad a sectores sociales concretos como los pueblos indígenas por poner uno de múltiples ejemplos. 
Son muchos más los casos de estas comunidades en el mundo pero con el matiz de enfrentarse a diferentes problemáticas concretas todos tienen en común un cuestionamiento del modelo hegemónico de la comunicación a través del vídeo y su distribución y un marcado carácter de compromiso social. (Gumucio, 2003)

En definitiva ya a pesar de la diversidad de los formatos y objetivos de unos y otros modelos del vídeo y sus desarrollo son las comunidades de vídeo y sus derivaciones los que plantean un enfoque constructivo acorde con las pretensiones básicas de una educación para el servicio; un enfoque humanista en pro de la enseñanza y la práctica de estrategias que tienen como fin la búsqueda de un bien común para a la sociedad.

\section{Un caso de análisis: You Tube}

Es primordial que la enseñanza se enfoque desde una formación que permita a los estudiantes un contacto real con estos recursos llegando mucho más allá de la mera fundamentación teórica dado que lo que sí han demostrado los productos mass mediáticos es una extrema eficacia en resultar considerablemente más atractivos que la mayoría de recursos docentes. Enfrentarse a la los atractivos de la televisión o la red es tremendamente complicado pero quizá servirse de sus propios recursos pueda suponer una estrategia viable y efectiva sin omitir que existen ciertos peligros o inconvenientes.

Con el perfeccionamiento de Internet y a partir del momento en el que su banda permitió la transmisión fluida de vídeo contenidos no tardaron en aparecer diversos canales de vídeo como el omnipresente Youtube. Plataforma que permite una distribución al mismo nivel que cualquier canal de televisión o incluso uno mayor dado que la red es global. Por otro lado un ordenador de gama media es un aparato capaz de concentrar toda la tecnología y recursos suficientes de los que antes solo disponían los grandes canales.

Esta nueva situación permite salvar de forma más o menos eficiente las carencias logísticas y el enfrentamiento institucional al que algunas de las comunidades de vídeo fueron sometidas en el pasado. No se debe obviar por otro lado que estas plataformas pertenecen a los medios hegemónicos y que siempre estarán sometidos a cierto grado de control con el consecuente peligro de censura y manipulación.

Un análisis de la propia web Youtube Creators espacio generado desde la propia web Youtube con recomendaciones y consejos para la creación de una comunidad 
de vídeo puede aportarnos algunas pistas sobre esta posibilidad de manipulación. Se puede empezar por comentar que el valor de éxito que fomenta la compañía ya chocaría con un planteamiento desde la educación social. Las estrategias de éxito en youtube se fundamentan como en casi todas estas plataformas en el número de seguidores y las visitas que estos realizan a tus contenidos. Esto responde a su planteamiento comercial dado que sus ingresos dependen tanto de la venta de publicidad como de datos de sus usuarios. A más usuarios más publicidad y datos que se corresponde lógicamente con más ingresos.

Aquí encontramos uno de los primeros escollos a salvar dado que un enfoque pedagógico desde la visión del servicio no concordaría con este modelo de comercio agresivo donde se priman las ganancias por encima del bien social. Sin embargo es uno de los aspectos en los que se centra la compañía en cuestión amparándose en una mal entendida defensa de la libertad de expresión. La finalidad de una propuesta educativa por lo tanto debería alejarse de las estrategias en las que la cantidad de seguidores se obtenga a cualquier precio para no repetir los vicios de la comunicación mayoritaria. Hay que alejarse por tanto de lo que Guy Debord definió como lo espectacular integrado donde bajo el amparo de un aparente altruismo se esconde la peor cara del capitalismo descontrolado (Debord, 1979)

La finalidad de una comunidad de vídeo desde una visón de APS no debería ser la "monetización" y sin embargo una búsqueda rápida en la propia web que de información sobre espacios donde no se "monetice" la información da resultados precisamente en sentido contrario. La búsqueda en google de "alternativas a youtube" muestra en sus 10 primeras entradas precisamente información relacionada con la posibilidad de ganar dinero a través de estos canales u otros alternativos.

Continuando con las recomendaciones que se muestran en You Tube Creators y de nuevo adornada por el uso de alusiones a la responsabilidad y el respeto la web recomienda el uso de las estrategias tradicionales de la publicidad, como el uso de frases pegadizas y los recursos de creación de imagen de marca. No es que estos recursos sean negativos per se pero pueden generar una densa niebla que implique que el consumo de lo que es realmente importante en nuestra comunicación se pierda en el efectismo donde el consumo de imágenes pase de una actividad activa a una pasiva.

En ese sentido Joan Ferrès es bastante claro "El desconocimiento de los mecanismos por los que se rige el cerebro emocional impide la autonomía del 
ciudadano en ambos registros. (Recibir y enviar mensajes) Como consecuencia de estas carencias se ensancha cada vez más la brecha entre unos mensajes mediáticos fascinantes que recurren a la emoción y al inconsciente sin activar la racionalidad y unos mensajes con voluntad educativa y cultural que creen posible activar la racionalidad sin recurrir a la emoción." Por lo tanto siempre se debería tener presente que la pantalla es un instrumento que puede ampliar o potenciar la visión o por el contrario limitarla o impedirla. (Ferrès, 2014).

Ante una propuesta para usar el concepto de comunidad vídeo desde los proyectos educativos es necesaria una toma de distancia que impida que estas estrategias actúen en contra de los intereses de la educación y la formación en valores. Para ello es imprescindible, como ya hemos comentado anteriormente, un alumnado que reciba unos buenos conocimientos no solo de los recursos técnicos del propio medio sino igualmente conocimientos del léxico y la gramática propios de la imagen.

\section{Bibliografía recomendada}

Baudrillard, J. (2005). Cultura y simulacro, Barcelona, España: Kairos.

Cabero Allmenara, J., (1989). Tecnología educativa: Utilización didactica del vídeo, Barcelona, España: PPU. Gedisa.

Ferrés, J., (2014). Las pantallas y el cerebro emocional, Barcelona, España:

Debord, G.,(1999). Comentarios sobre la sociedad del espectáculo, Barcelona, España: Anagrama

Rosales Mateos, E., (2002). Estética de los medios de comunicación, sueños que el dinero puede compra. Madrid, España: TECNOS.

VVAA, (2006) NET. ART. Prácticas estéticas y políticas en la red, Barcelona, España: Brumaria/Universidad de Barcelona. Vasco.

Zunzunegui, S., (1985). Mirar la imagen, Vizcaya: Universidad del País

\section{Webgrafia}

Gumucio Dragon, A., (2003). La televisión comunitaria. Ni pulpo, ni púlpito: pálpito, Recuperado de: https://es.scribd.com/document/137908302/LA-TELEVISION-COMUNITARIA-NI-PULPO-NI-PULPITO-PALPITO-Alfonso-GumucioDagron-pdf

YouTube Creators Consultado en: https://creatoracademy.youtube.com/ 


\title{
13 \\ Fotografía y conocimiento; aprender a ver, aprender a comprometerse.
}

\author{
Alfonso Revilla Carrasco ${ }^{1}$ y Fernando J. Sadio-Ramos ${ }^{2}$ \\ ${ }^{1}$ Universidad de Zaragoza \\ ${ }^{2}$ Escola Superior de Educação do Instituto Politécnico de Coimbra \\ alfonsor@unizar.es
}

\subsection{Introducción}

La Educación Artística no está exenta de una cierta responsabilidad social (G. Grosz, Delacroix, Goya, Siquerios, etcétera), que permite a los artistas un diálogo comprometido y crítico con la realidad (Tolstoy 1978, Morris 1977). En ese sentido, la Educación Artística contiene en sí misma un enorme potencial para dar seguimiento a la idea de sostenibilidad curricular (CRUE, 2005), y así ir al encuentro de la Agenda para el desarrollo sostenible 2030 y sus objetivos. En esta, efectivamente, se atribuye a la educación (entendida como inclusiva, igualitaria y permanente) la promoción de los siguientes objetivos: «By 2030, ensure that all learners acquire the knowledge and skills needed to promote sustainable development, including, among others, through education for sustainable development and sustainable lifestyles, human rights, gender equality, promotion of a culture of peace and non-violence, global citizenship and appreciation of cultural diversity and of culture's contribution to sustainable development» (GA, 2015, p. 17). En Portugal, la Agenda 2030 es una referencia fundamental para el desarrollo holístico de las instituciones de enseñanza superior y de investigación a cargo de las mismas (Marques, 2018). 
Nuestra propuesta es una reflexión, a partir de un proyecto fotográfico, sobre la mirada mercantilizada que se proyecta desde Occidente sobre el ser humano de los países del África subsahariana. La fotografía genera conocimiento desde la mirada; es desde esta perspectiva que presentamos nuestra propuesta, que pretende ser un acercamiento al ser humano lejos de paradigmas paternalistas coloniales, a partir de un proyecto fotográfico, que el primero autor de la propuesta realizó en Costa de Marfil.

\subsection{Fotografía, compromiso y diálogo intercultural}

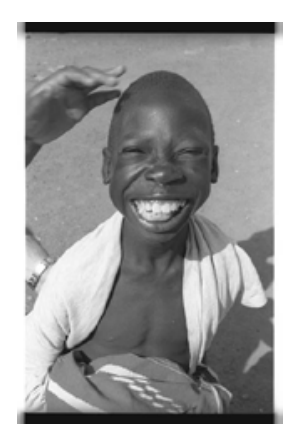

Ilustración 1. Fotografía de la serie La Mirada Imperfecta, realizada en la Santé Mentale. Alfonso Revilla

Este proyecto fotográfico pretende ser una reflexión sobre la mercantilización del ser humano, así como de la cultura a la que pertenece y con ello todo su contexto cultural.

Las fotografías se han realizado en la ciudad de Bouaké que se halla en el centro del país, en una zona de sabana. Se trata de una población de aproximadamente medio millón de habitantes, la cual si contamos la zona rural del entorno se eleva hasta los tres millones y medio de habitantes. Se trata de fotografiar el sector humano probablemente más menospreciado y abandonado de África, que es el de los enfermos mentales, considerados malditos poseídos por los malos espíritus. Ello hace que ni la sociedad, ni sus mismas familias los atiendan. Los mínimos ensayos hechos, viven en unas condiciones de abandono increíble, como es el caso de Hospital Psiquiátrico de Bouaké.

En Costa de Marfil, las enfermedades psiquiátricas no se reconocen como tales entre la población con una cultura basada en la tradición y la religión animista. Desde 
la epilepsia a la esquizofrenia, pasando por cualquier tipo de enfermedad que afecte al comportamiento, se leen desde las dos claves antes referidas; cualquier enfermo psiquiátrico es un "poseído por los espíritus" al que hay que expulsar del poblado, de la familia, de la sociedad o bien encerrarlo en un lugar aislado hasta que muera de hambre, sed o cualquier otra cosa; ni siquiera tienen derecho a un entierro o al luto familiar, y se ven despojados de identidad y de su dignidad como personas.

Sin embargo, poco a poco, esta concepción va cambiando y están apareciendo algunos centros psiquiátricos. En Bouaké se encuentra la "Santé Mental", un centro psiquiátrico donde se atiende, como se puede, a parte de estos enfermos. Esta atención se ve limitada por una serie de condiciones que afectan a la institución de igual manera que a la población marfileña; así el altísimo precio y la escasez, tanto en cantidad como en variedad de medicamentos, dificultan los tratamientos. La alimentación, los medios sanitarios, el equipamiento e instalaciones que ofrece el propio centro, están mermados por falta de financiación pública o privada. Este centro acoge a una media de unos cincuenta enfermos, muchos de ellos abandonados allí por sus familias. Además del personal, en el centro trabaja una asociación "Les amis des malades" (los amigos de los enfermos), que voluntariamente apoyan el trabajo del centro, con ayudas económicas, medicinas, material de aseo y compañía a los enfermos.

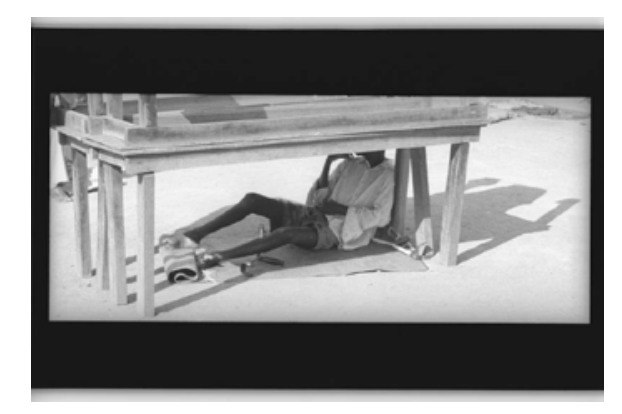

Ilustración 1. Fotografía de la serie La Mirada Imperfecta, realizada en Ferke. Alfonso Revilla

El progresivo aumento de la diversidad cultural en nuestra sociedad debido a movimientos migratorios hace inevitable una corrección de nuestros planteamientos sociopolíticos, educativos y económicos. "Los problemas suscitados por la llegada a las ciudades españolas de inmigrantes de diversos orígenes culturales está siendo objeto de examen en aproximaciones interdisciplinarias." (Capel, 1999, p.78). 
Asistimos en los últimos años a diferentes acontecimientos políticos y sociales que generan conflictos preocupantes en el seno de las sociedades occidentales que muestran un claro tinte racista, bien explícito, que suele aparecer en medios de comunicación y que degenera en muchos casos en determinados tipos de violencia, o bien implícito, más sutil e intelectualizado que sostiene y alimenta las manifestaciones del racismo explícito. Una de las manifestaciones del racismo implícito es la desestimación de las propuestas de otras culturas, presentadas carentes de planteamientos y desarrollos.

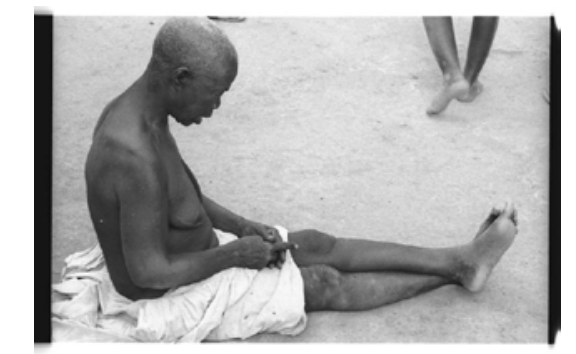

Ilustración 2. Fotografía de la serie La Mirada Imperfecta, realizada en Bouake. Resulta, a parte de su propia realidad, una visión muy simbólica que Occidente le otorga a África; la pasividad ante la Historia. Alfonso Revilla

\subsection{Dirección del poder en las organizaciones}

Nuestra propuesta es una reflexión fotográfica de cómo se produce el sometimiento la cultura dominada por el concepto de mercantilización de la cultura dominante. Se ejerce así un dominio cultural, ético, histórico, etcétera, que mantiene los mismos parámetros coloniales bajo los conceptos neocoloniales. Para ellos utilizamos la fotografia que el autor ha realizado en la Santé Mentale de Costa de Marfil.

Las opciones tomadas por occidente, que ha basado nuestro desarrollo en los pilares de la economía y la tecnología, han influido negativamente en el respeto hacia otras culturas, a las que occidente ha sometido a fin de mantener y elevar el concepto del estado de bienestar propio. Los valores de libertad e igualdad consignados en las democracias occidentales parecen haber sido aplicados únicamente entre unos iguales, y esto, ni tan siquiera. Entre los términos acuñados bajo este planteamiento está Los Otros. 
El hecho de que por que otras culturas opten por otros tipos de desarrollo, no podemos inferir que éstas sean subdesarrolladas, y mucho menos podemos reafirmar nuestro propio modelo, utilizando como herramienta la desestimación y deslegitimación de ámbitos parciales de otras culturas.

El trabajo presentado ha sido expuesto con determinadas variaciones en:

- Sala de exposiciones Fundación CAI, Centro Joaquín Roncal, Zaragoza del 3 al 27 de septiembre de 2014.

- Museo Orús. Lugar: Museo Orús, Utebo, Zaragoza del 6 al 31 de mayo del 2015.

- Palacio de Villahermosa, Ibercaja, Sala de los Duques de Guara del 26 de octubre al 21 de noviembre de 2015.

El trabajo, al mismo tiempo, ha sido presentado en dos clases de Educación NoFormal con Poblaciones Específicas, en las titulaciones de Música/ Estudios Musicales Aplicados y de Teatro y Educación de la Escola Superior de Educação do Instituto Politécnico de Coimbra el 24 de Abril de 2018.

\section{Bibliografia recomendada}

Bernal, J. L. (1999). Elección de la escuela, clase social y fuerzas del mercado. Anuario de Pedagogía, 1, 217-248.

CRUE (2005). Directrices para la introducción de la Sostenibilidad en el Currículum. Disponible en: http://www.crue.org/Sostenibilidad/CADEP/Documents/DIRECTRICES\%20SOSTENIBILIDAD\%20CRUE\%202012.pdf

GA - General Assembly of the United Nations (2015). Resolution adopted by the General Assembly on 25 September 2015. 70/1. Transforming our world: the 2030 Agenda for Sustainable Development. Disponible en: http://www.un.org/ga/search/view_doc.asp?symbol=A/RES/70/1\&Lang=E

Juliano, D. (1993). Educación intercultural: escuelas y minorías étnicas. Madrid: Eudema.

Lovelace, M. (1995). Educación multicultural. Madrid: Escuela Española.

Llevot, N. (2005). La mediación intercultural en la educación secundaria obligatoria posibilidades y dificultades, Bordón, 57(1), 129-139.

Llevot, N. (2006). La educación intercultural: Discursos y prácticas. Lleida: Universidad de Lleida. 
Capitulo 13. Fotografía y conocimiento; aprender a ver, aprender a comprometerse.

Marques, R. (Coord.) (2018). Livro Verde sobre Responsabilidade Social e Instituições de Ensino Superior. S. 1.: PRESS FORUM - Comunicação Social.

Mélich, J. C. y Boixader, A. (Coords.). (2010). Los márgenes de la moral. Una mirada ética a la educación. Barcelona: Graó.

Ruíz Román, C. (2003). Educación intercultural. Una visión crítica de la cultura. Barcelona: Octaedro.

Sabariego, M. (2002). La educación intercultural ante los retos del siglo XXI. Bilbao: Descleé.

Sáez, P. (2002). Educar en la escuela multicultural. Madrid: CCS-ICCE.

Terrén, E. (2004). Incorporación o asimilación. La escuela como espacio de inclusión social.Madrid: Catarata.

Torres, J. (2008). Diversidad cultural y contenidos escolares. Revista de Educación, 345, 83-110.

Valverde, A; Begley, A. y Piedra, M. J. (2005). Integración de minorías étnicas. Málaga: Aljibe.

Vlachou, A. D. (1999). Caminos hacia una educación inclusiva. Madrid: La Muralla.. 


\title{
14 \\ Exposición MIRADAS
}

\author{
Alfonso Revilla Carrasco \\ ${ }^{1}$ Universidad de Zaragoza \\ alfonsor@unizar.es
}

\subsection{Introducción}

En las jornadas se inauguró la segunda edición de la exposición Miradas que tuvo lugar en Sala Roja del Casino de Huesca y estuvo abierta hasta el 24 de noviembre de 2017.

"Miradas" es un proyecto coordinado por el profesor Alfonso Revilla Carrasco y Elias Vived, y realizado con un grupo de jóvenes de la Asociación Down de Huesca, en el que pretendemos desarrollar un proyecto fotográfico, que nos permita un acercamiento a su realidad desde la mirada de alumnas del Grado de Infantil y Primaria de la Facultad de Ciencias Humanas y de la Educación de la Universidad de Zaragoza. Las fotografías han sido realizadas por Alfonso Revilla Carrasco, María Algueró Royo, Yolanda Domper Sin y Belén Gimeno Elipe.

Por parte de la asociación Down Huesca participan: Los participantes de "Miradas", son: David Vasco, David Pérez, Eva Tamargo, Gonzalo Lavilla, Noel Esteban, Lidia Arrasanz, Sandra Cazcarro, Sandra Azin, Beatriz Cabello, Azucena Aisa, Daniel García, Laura Pérez, Marcos Rufat, Loreto Peirón, Raúl Ariza, José Borrell, Daniel Morín, Rubén García, Mónica Velado, Alberto Alastrue, Alfredo Villacampa, Javi López, Gonzalo Olivan, Nacho Paño.

El objetivo principal del Proyecto "Miradas" es aprender a utilizar la fotografía como medio de conocimiento y diálogo. Miradas pretende ser un intercambio, un diálogo a través de la imagen fotográfica, en el que podamos expresar desde nuestra propia identidad, hasta la manera en la que comprendemos nuestro entorno.

Las fotografías se realizaran en diferentes ámbitos de la vida cotidiana de los participantes, como son: taller de cocina, reuniones y charlas en la Facultad de 
Ciencias Humanas y de la Educación, visitas a pisos de "vida independiente", visita a sus trabajos, taller de artesanía y restauración, "cena y baile", etc.

El proyecto "Miradas" estará focalizado en tres líneas fotográficas, que son el retrato, las relaciones y el espacio:

- El retrato, como forma de reconocimiento personal y social. Para ello, se buscará en el retrato la identidad en la que nos reconocemos, a través de la mirada, el gesto, etc.

- Las relaciones interpersonales abordará el tema de cómo nos comprendemos y comprendemos el entorno próximo a partir de la interactuación con las personas.

- Los espacios en los que nos movemos definen nuestro acercamiento al entorno así como nuestra configuración de la realidad, definiendo en parte nuestra identidad personal (espacios personales) y nuestra identidad social (espacios públi$\cos )$.

Mostramos algunas de las fotografías expuestas.

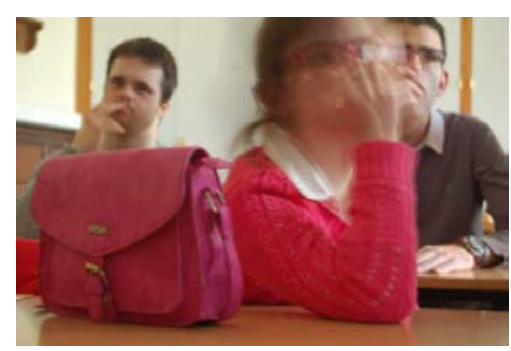

Ilustración 1. Fotografía de la serie Miradas, realizada en la Sala Roja del Casino de Huesca.

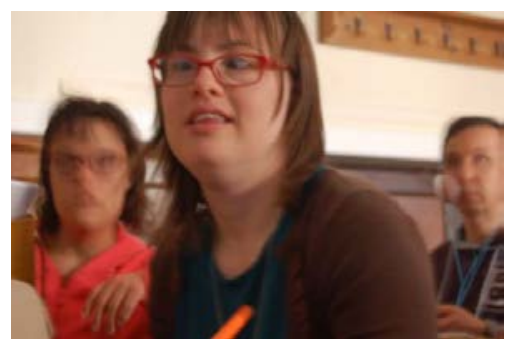

Ilustración 2. Fotografía de la serie Miradas, realizada en la Sala Roja del Casino de Huesca. 


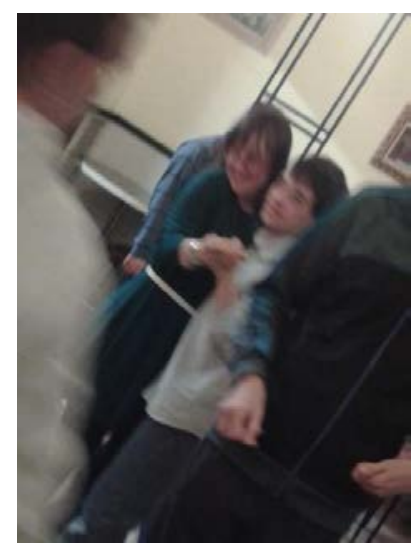

Ilustración 3. Fotografía de la serie Miradas, realizada en la Sala Roja del Casino de Huesca.

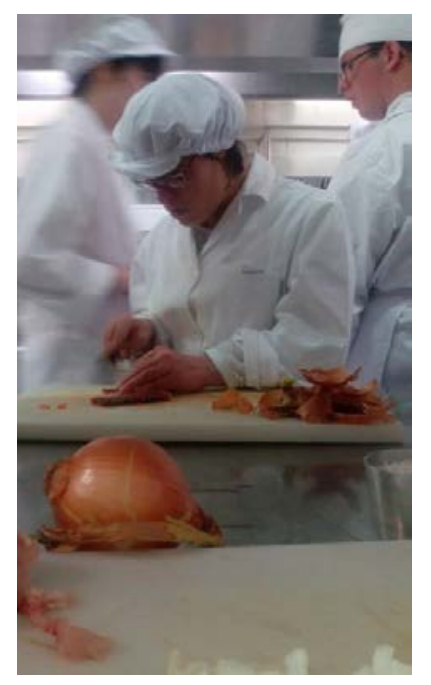

Ilustración 4. Fotografía de la serie Miradas, realizada en la Sala Roja del Casino de Huesca. 


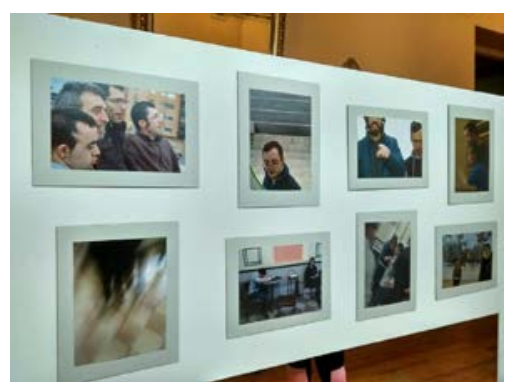

Ilustración 5. Montaje de la exposición de la serie Miradas, realizada en la Sala Roja del Casino de Huesca.

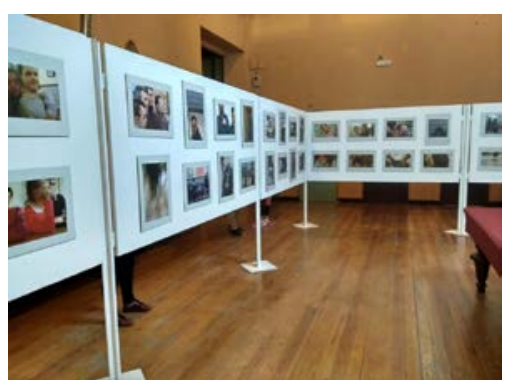

Ilustración 6. Montaje de la exposición de la serie Miradas, realizada en la Sala Roja del Casino de Huesca.

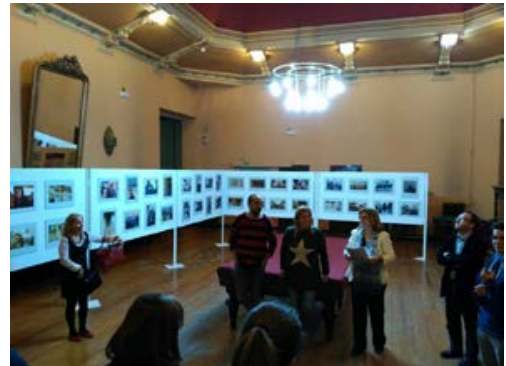

Ilustración 7. Montaje de la exposición de la serie Miradas, realizada en la Sala Roja del Casino de Huesca. 


\title{
15 \\ Música y diversidad: la música coral al servicio de la sociedad
}

\author{
Sara Escuer Salcedo \\ Proyecto 'Sinestesia' - Coro de Atades Huesca \\ sara@sinestesia.org
}

El desarrollo de una actividad musical contribuye al bienestar de las personas, mejorando su autoestima, su capacidad de escucha y concentración, y ofreciendo múltiples herramientas extrapolables a diferentes ámbitos de la vida cotidiana. Estos beneficios incuestionables que la música aporta al individuo se multiplican cuando la práctica musical se realiza en grupo. Ya sea en una agrupación instrumental o vocal, el hecho de compartir la creación artística con otras personas facilita los procesos de socialización y contribuye al establecimiento de vínculos entre miembros de un mismo colectivo que unen sus esfuerzos por un objetivo común.

Dentro de la gran variedad de agrupaciones musicales amateur existentes en nuestra sociedad, el coro permite un acercamiento a la música casi inmediato, al no ser precisos conocimientos musicales previos (indispensables para acceder a una agrupación orquestal $\mathrm{o}$, aunque sea en menor medida, a un conjunto instrumental de carácter popular o folklórico), ni la adquisición de un instrumento musical, por estar ya este -la voz-incorporado en nuestro propio cuerpo. Por todo ello, se puede considerar a la música coral (dentro del amateurismo) la más accesible de las disciplinas artístico-musicales.

La proliferación de agrupaciones corales de diferentes características (en cuanto a la edad de los integrantes -coros infantiles, juveniles, adultos-, el tipo de repertorio que se interpreta, o la estructura interna del coro -homofónico, a dos o más voces, mixto o de voces iguales-) y su aperturismo a la diversidad, hacen de la música coral un punto de encuentro entre personas que comparten un mismo interés común, 
Capitulo 15. Música y diversidad: la música coral al servicio de la sociedad.

favoreciendo la inclusión y convirtiéndose así en un elemento vertebrador de la sociedad, donde las diferencias que en otros ámbitos generarían abismos y ruptura, aquí desaparecen o se transforman.

En una entrevista concedida por John Rutter, director de coro y compositor de reconocido prestigio internacional, a la editorial norteamericana de música J. W. Pepper, en 2015, decía:

"You express, when you sing, your soul in song. And when you get together with a group of other singers, it becomes more than the sum of the parts. All of those people are pouring out their hearts and souls in perfect harmony, which is kind of an emblem for what we need in this world, when so much of the world is at odds with itself...that just to express, in symbolic terms, what it's like when human beings are in harmony. That's a lesson for our times and for all time. I profoundly believe that".

["Tú expresas, cuando cantas, tu alma en el canto. Y cuando te unes en grupo a otros cantores se conforma más que la suma de las partes. Todas esas personas están abriendo sus corazones y sus almas en perfecta armonía, lo cual es un verdadero emblema de lo que necesitamos en este mundo, cuando gran parte del mundo está en conflicto consigo mismo... solo para expresar, en términos simbólicos, cómo es cuando los humanos están en armonía. Esta es una lección para nuestro tiempo y para todos los tiempos. Creo en esto profundamente"].

Gracias a los beneficios que la práctica coral aporta a la salud física, mental y social y a su implicación directa en el bienestar de las personas, a propuesta de la Comisión de Cultura del Senado de España ha sido aprobada un declaración institucional de reconocimiento de la actividad coral como bien cultural de nuestra sociedad con fecha 19 de febrero de 2018:

[...] El canto colectivo tiene la capacidad de reafirmar la autoconfianza, promover la autoestima, y conectar con las emociones de las personas facilitando la inclusión social, apoya el desarrollo de las habilidades sociales y permite a personas de diferentes edades y habilidades reunirse en torno a la experiencia de la creación en el arte. Además, la música coral tiene la capacidad de hermanar diferentes pueblos a través de la interpretación de repertorios comunes, así como facilitar el intercambio y enriquecimiento cultural al posibilitar el conocimiento de otras culturas a través de su música $[\ldots]^{1}$. 1 "Declaración institucional de reconocimiento de la actividad coral como bien cultural de nuestra
sociedad y de apoyo de las iniciativas que persigan su fomento, así como de reconocimiento de la 
figura del director de coro como elemento indispensable en dicha actividad" en Boletín Oficial de las Cortes Generales. Senado, 209 (02 marzo 2018), pp. 36-37.

La creación de proyectos musicales con intervención de coros de diferentes características ofrece un espacio de intercambio y relación entre agrupaciones e individuos aún mayor, incrementando la colaboración a nivel artístico y favoreciendo la inclusión. Ejemplo de ello fue el concierto ofrecido por el Coro de Atades Huesca y el coro del Hogar de Mayores del IASS de Sabiñánigo celebrado en Huesca el día 7 de noviembre de 2017, como broche final a las II Jornadas ApSy responsabilidad social. En palabras de la directora de coro y docente Nuria Fernández (2013) "La práctica coral tiene, además, un componente emocional muy marcado a través de la integración, favoreciendo los procesos de socialización y facilitando el desarrollo de la creatividad y la sensibilidad a través de los sentidos". Como seguramente pudieron experimentar los asistentes a ese acto, la acción que se desarrolla en un evento musical de esas características y las emociones que genera en los coralistas -en esa ocasión, integrantes de dos coros que ya habían cantado juntos en otros dos conciertos y, por tanto, establecido lazos de cooperación y compartido la satisfacción tras la realización en conjunto de un concierto-, se transmiten de tal forma al público que este pasa de ser un espectador pasivo a convertirse en parte del proceso artístico y emocional que se está produciendo e irradiando desde el escenario.

De este modo, la actividad musical/coral desarrollada por colectivos tan específicos como los citados (discapacidad y tercera edad) se convierte en una herramienta de transformación social, por los beneficios (a nivel individual y colectivo) que aporta no solo a los responsables principales de dicha creación artística, sino también, de forma directa, sobre las personas que asisten a un concierto en el que -a diferencia de lo que pudiera suceder generalmente en un concierto llevado a cabo por músicos y agrupaciones profesionales- la música no es el objetivo final, sino un medio sobre el que construir y generar bienestar y salud social. Es la música coral puesta al servicio de la sociedad. 
Capitulo 15. Música y diversidad: la música coral al servicio de la sociedad.

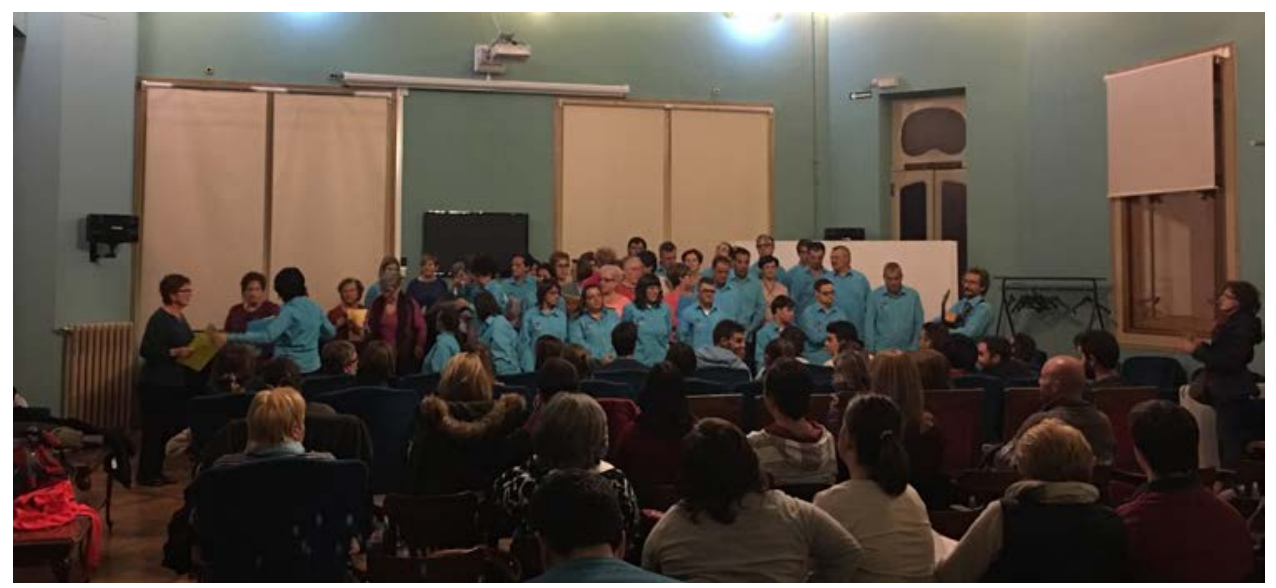

Coro de Atades Huesca y Coro del Hogar de Mayores del IASS de Sabiñánigo

\section{Bibliografía recomendada}

Fernández Herranz, N. (2013). Las agrupaciones corales y su contribución al bienestar de las personas (tesis doctoral inédita). Madrid: Universidad Carlos III.

Rutter, J. (2015). The importance of Choir (entrevista). Disponible en: http://blogs.jwpepper.com/index.php/john-rutter-the-importance-of-choir/

"Declaración institucional de reconocimiento de la actividad coral como bien cultural de nuestra sociedad y de apoyo de las iniciativas que persigan su fomento, así como de reconocimiento de la figura del director de coro como elemento indispensable en dicha actividad" en Boletín Oficial de las Cortes Generales. Senado, 209 (02 marzo 2018), pp. 36-37 